\title{
DISCURSOS FEMINISTAS SOBRE EL ABORTO Y LA ANTICONCEPCIÓN EN ITALIA (AÑOS SETENTA) Y POLONIA (AÑOS NOVENTA)
}

GEMMA: Máster Oficial Erasmus Mundus en Estudios de las Mujeres y de Género Erasmus Mundus Master's Degree in Women's and Gender Studies

\section{Agata Ignaciuk}

Directora: Teresa Ortiz Gómez

(Universidad de Granada)

Apoyo: Rita Monticelli (Universitá degli Studi di Bologna)
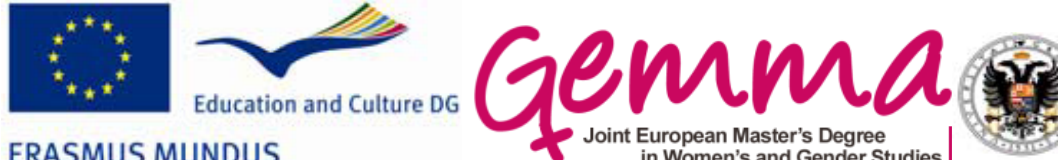
DISCURSOS FEMINISTAS SOBRE EL ABORTO Y LA ANTICONCEPCIÓN EN ITALIA (AÑOS SETENTA) Y POLONIA (AÑOS NOVENTA)

Quiero agradecer a la Profesora Teresa Ortiz su dedicación y ayuda en este proyecto y su inspiración como investigadora y feminista;

A Juan Francisco Castillo por apoyarme siempre y por el respeto a mi trabajo que me demuestra en todo momento. 


\section{Contenido}

Abstract .6

Resumen .8

Introducción .10

1.1 Introduciendo los conceptos: reproducción como discurso ....................................... 14

1.2 Unidad conceptual de la anticoncepción y el aborto................................................... 15

1.3 Separación discursiva de la anticoncepción y el aborto y los factores implicados en este proceso.

1.4 Crítica feminista al control de la reproducción ......................................................... 19

1.4.1 El caso de la anticoncepción hormonal: implicaciones de raza y clase en las prácticas de su uso

1.4.2 El caso del aborto: de la expresión de la voluntad propia de la mujer a la expresión de intereses culturales y políticos del Estado

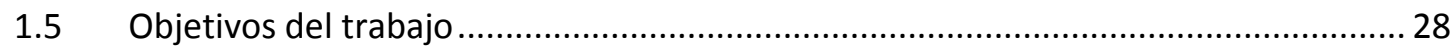

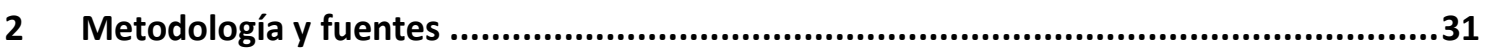

2.1 Definiciones de aborto y anticoncepción y su aspecto relacional ................................ 31

2.2 Género, biopoder y reproducción ......................................................................... 37

2.2.1 Niveles de análisis relacionados con la categoría de género de Joan Scott (1986) 39

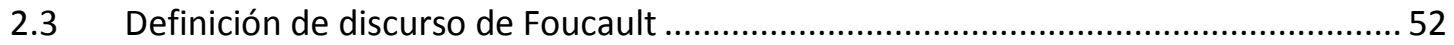

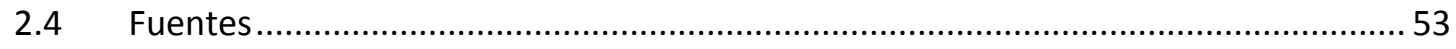

2.5 Método de análisis de los debates y discursos acerca del aborto y la anticoncepción

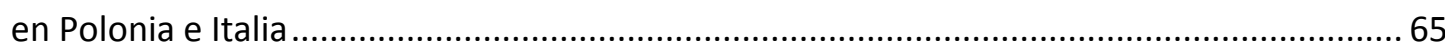

3 Debates y discursos sobre aborto y anticoncepción en Italia (década de 1970) ............67

3.1 Los debates acerca de la reproducción en Italia en el siglo XX ................................67

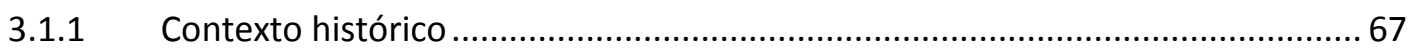

3.1.2 Leyes sobre el aborto y la anticoncepción en Italia .............................................68

3.2 Agentes implicados en la formulación de los debates................................................. 71 
3.2.1 Los roles de género y los símbolos de feminidad en relación con el sistema político 71

3.2.2 La implicación de la Iglesia Católica en las políticas de la reproducción

3.2.3 Las intervenciones de la profesión médica en los debates sobre la anticoncepción y el aborto.

3.3 El movimiento de mujeres y el movimiento feminista en Italia en la década de 1970 en relación con las políticas del control de la reproducción.

3.4 Análisis del discurso feminista italiano: por la autonomía de las mujeres en una sociedad patriarcal

4 Debates y discursos sobre aborto y anticoncepción en Polonia (1989-2004)

4.1 Las políticas acerca de la reproducción en Polonia en el siglo XX............................... 99

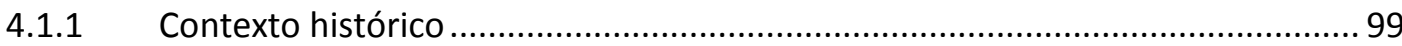

4.1.2 Leyes sobre el aborto y la anticoncepción en Polonia ...................................... 101

4.2 Agentes implicados en la formulación de los debates............................................ 103

4.2.1 Los roles de género y los símbolos de feminidad en relación con el sistema político 103

4.2.2 La implicación de la Iglesia Católica en las políticas de la reproducción 107

4.2.3 Las intervenciones de la profesión médica en los debates sobre la anticoncepción y el aborto.

4.3 El movimiento de mujeres y el movimiento feminista en Polonia en los años 1989-2004 en relación con las políticas de la reproducción

4.4 Discurso del feminismo polaco: sacando a la luz abusos y testimonios

5 Conclusiones

5.1 Propuestas de la futura investigación ....................................................................... 135

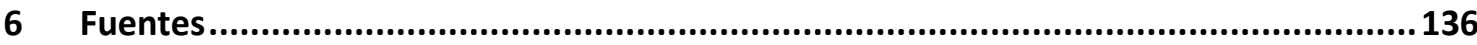

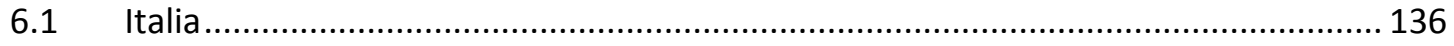

6.2 Polonia............................................................................................... 140

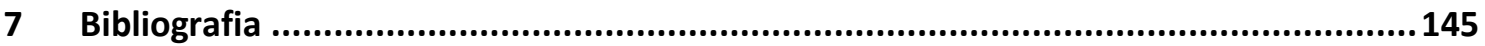

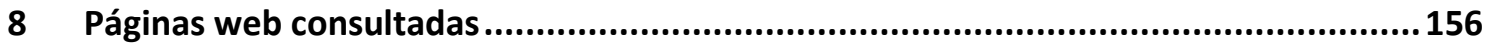


10 Traducciones de una selección de textos del feminismo italiano y polaco utilizados en el trabajo 161

10.1 Italia... 161

10.1.1 Rivolta Femminile. Sputiamo su Hegel [Escupimos sobre Hegel], 1970 161

10.1.2 Documento constitutivo del Comitato Romano per l'Aborto e la Contraccezione[La Comisión Romana por el Aborto y la Anticoncepción], noviembre de 1975176

10.1.3 Manifiesto del Movimento di Liberazione della Donna [Movimiento de la Liberación de la Mujer], septiembre de 1978.

10.2 Polonia

10.2.1 Dunin, Kinga. 2001. Dwa tysiące na skrobankę [Dos mil para la intervención]. Wysokie Obcasy (110). Accesible online en http://www.wysokieobcasy.pl/wysokieobcasy/1,96856,320252.html; último acceso 10/09/2009.

10.2.2 Graff, Agnieszka. 2001. Świat bez kobiet. Płeć w polskim życiu publicznym. [El mundo sin mujeres. El género en la vida pública polaca]. Varsovia: W. A. B.

10.2.3 Szczuka, Kazimiera. 2004. Milczenie owieczek. Rzecz o aborcji [El silencio de los corderos. Sobre el aborto]. Warszawa: W. A. B. 


\section{Abstract}

This thesis analyses two feminist discourses on abortion and contraception: the discourse produced in Italy in the 1970s and in Poland in the period of the democratic transition (1989-2004). In this thesis, I assume that reproduction can be read as a discourse, thus its components such as maternity, contraception or abortion are concepts which are formulated in specific manners in different geographical and historical contexts. When researching reproduction, it is necessary to take into consideration actors involved in giving it a specific meaning, such as: the religion, science and technology, political parties and State's institutions, the medical establishment and social movements, especially feminist and pro-life movements.

The starting point for my thesis is that the development and use of contraception intersects with the changes in gender roles accelerated in the second half of the $20^{\text {th }}$ century. The tolos used for the analysis of these processes are Joan Scott's definition of gender (1986) and the concept of biopower elaborated by Foucault (1987). I particularly wish to draw attention to the relational character of contraception and abortion, which may be used as a tool both for women's liberation and oppression. The possible uses of contraception are shaped by the interventions of the previously mentioned social actors.

This is why Polish and Italian feminist movements, based on different social and historical contexts, produced different discourses on contraception and abortion. While Italian feminists place the reproductive issues in the frame of a broader 
reflection on the patriarchy and the oppression of the female sexuality, Polish feminists concentrate on a particular law (the 1993's abortion ban) and intend to mobilize society to change it. The Italian feminist movement is a successful one: it influences the legalization of contraception and the adoption of a new, liberalized abortion law, whereas Polish feminism, at a different historical moment, is unable to obtain the same outcome. 


\section{Resumen}

Este trabajo examina el discurso y las prácticas feministas sobre el aborto y la anticoncepción en dos países y dos momentos muy diferentes: en Italia durante la década de 1970 y en Polonia en el periodo de la transición democrática (1989-2004). Mi punto de partida es que la reproducción se puede leer como un discurso y que sus componentes tales como maternidad, anticoncepción, y aborto son conceptos cuya formulación depende del contexto geográfico e histórico y de los actores sociales involucrados en el diseño de su significado social. La religión, la ciencia y tecnología, los partidos políticos y las instituciones del Estado, el sector sanitario y los movimientos sociales, como el movimiento feminista y el movimiento pro-vida, son agentes clave en este proceso.

En este trabajo menciono la interdependencia entre el desarrollo y el uso de los métodos y tecnologías anticonceptivas, y los cambios en los roles de género en la segunda mitad de siglo XX. El modelo de género de Joan Scott (1986) y el concepto de biopoder, elaborado por Foucault (1987) pueden servir como herramientas útiles para analizar estos procesos. En mi investigación quiero destacar en particular el aspecto relacional de la anticoncepción y el aborto, que pueden ser usados tanto como herramientas de liberación como de opresión de las mujeres. Los posibles usos de la anticoncepción se ven influenciados principalmente por los actores sociales arriba mencionados. 
Por ello los movimientos feministas polaco e italiano, creados en distintos contextos sociales e históricos, han producido diferentes discursos acerca de la anticoncepción y el aborto. Mientras las feministas italianas situaban las cuestiones reproductivas en el centro de una reflexión más amplia sobre el patriarcado y la opresión de la sexualidad femenina, las feministas polacas se han concentrado en una ley particular (Ley Anti-aborto del 1993) y han intentando movilizar a la sociedad para cambiarla. El movimiento feminista italiano logró la legalización de la anticoncepción y la liberalización de la ley del aborto, mientras que el feminismo polaco no ha podido conseguir el mismo objetivo. 
DISCURSOS FEMINISTAS SOBRE EL ABORTO Y LA ANTICONCEPCIÓN EN ITALIA

(AÑOS SETENTA) Y POLONIA (AÑOS NOVENTA)

\section{Introducción}

Para comenzar mi reflexión sobre las mujeres, el feminismo y el control sobre la reproducción quiero utilizar algunas imágenes producidas por la artista feminista estadounidense Barbara Kruger y las Guerilla Girls, un colectivo activista feminista estadounidense comprometido con denunciar los estereotipos de género en la producción artística.

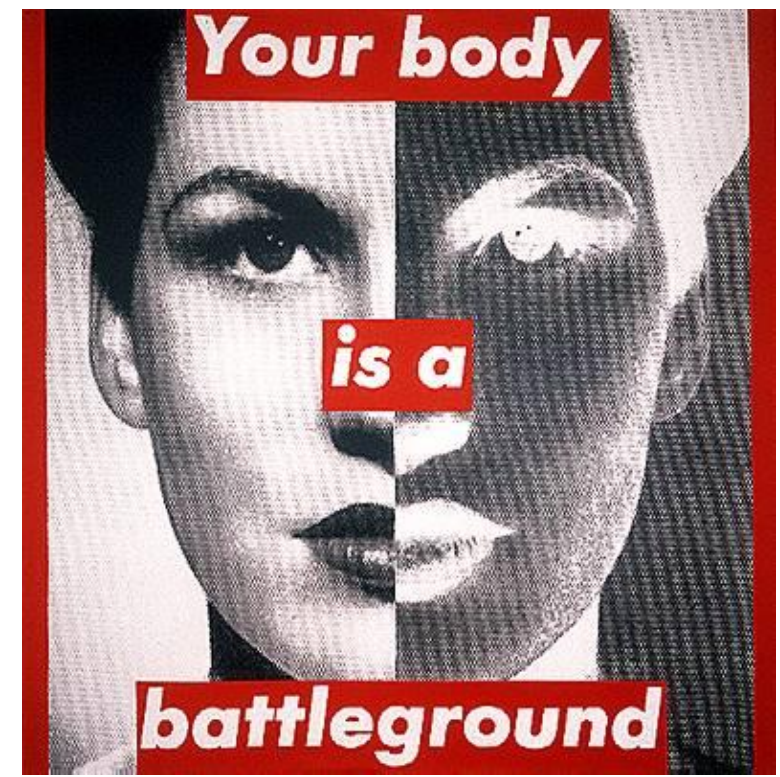

Figura 1 Kruger, Barbara. 1989. Your body is a battleground [Tu Cuerpo Es un Campo de Batalla], http://www.barbarakruger.com; último acceso 03/07/2009.

Your body is a battleground [Tu cuerpo es un campo de batalla] de Kruger (figura 1), diseñado para defender el derecho al aborto en la época del backlash ${ }^{1}$ en Estados Unidos lleva un mensaje muy interesante desde el punto de vista de los roles

\footnotetext{
${ }^{1}$ El termino backlash, que se refiere a los discursos y políticas de resistencia a la liberación de las mujeres a partir de la década de 1980 (bajo la presidencia de Ronald Reagan y George Bush padre) en Estados Unidos fue elaborado por Susan Faludi en 1991.
} 
de género y del control sobre la reproducción. El campo de batalla es un territorio tradicionalmente asociado con guerras y conflictos armados. Si lo interpretamos de acuerdo con los roles tradicionales de género, sería un territorio típicamente masculino. Paradójicamente, aquel campo de batalla es el cuerpo femenino. ¿A qué batalla se refiere Kruger? ¿Quién lucha contra quién y por qué? ¿Acaso es el sexo masculino quien ejerce el poder sobre el cuerpo femenino, controlando los tiempos y maneras en las que cumple con su función reproductiva? En mi opinión, la que intento sostener con este trabajo, la batalla sobre y en el cuerpo femenino llega mucho más allá de los conflictos de género, aunque los incorpore en cierto modo. Mi punto de partida para este trabajo es que en la batalla sobre el cuerpo femenino, concretamente en la definición y el control de la reproducción humana durante la historia, actúan numerosas fuerzas, reales y discursivas.

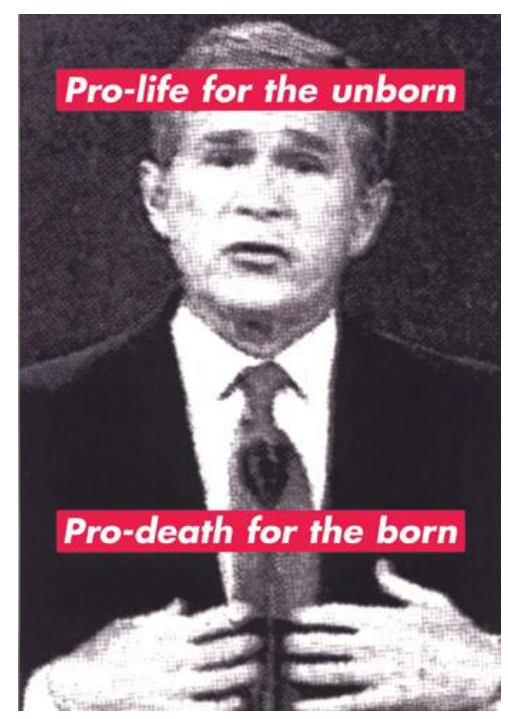

Figura 2 Kruger, Barbara. 2002/2004. Sin título (Pro-life for the unborn, pro-death for the born [Pro vida para los no nacidos, pro muerte para los nacidos]), http://www.barbarakruger.com; último acceso 03/07/2009. 
Entre ellas se encuentran los políticos concretos y las posiciones generales de los partidos politicos. Algunos de ellos, como George W. Bush a quien señala la segunda obra de Kruger que he elegido (figura 2), ejercen un tipo de poder muy concreto sobre las elecciones reproductivas de las mujeres en el mundo entero. En este contexto, recordemos, por ejemplo, que Estados Unidos financia numerosos programas de asistencia a la planificación familiar en los países en vía de desarrollo (Feldt 2004, 199223). No cabe duda de que en este campo de batalla están también los médicos, que se mueven dentro de los discursos de la medicina y la ciencia en general, y que controlan real y simbólicamente el acceso a los métodos anticonceptivos, el aborto, las técnicas de la reproducción asistida, etc. Otra parte del campo de batalla es la religión, que se empeña a menudo en regular los patrones de la reproducción humana.

En este trabajo me interesa especialmente la Iglesia Católica, teniendo en cuenta su rígida posición sobre el aborto y la anticoncepción, que, como hacen saber Guerilla Girls en su postal de 1992 (figura 3) no es inamovible ni inmutable, aunque se presente de este modo en el discurso oficial y actual del Vaticano. 


\section{GUERRILLA GIRLS DEMAND A RETURN TO TRADITIONAL VALUES ON ABORTION.}

Before the mid-19th century, abortion in the first fow months of pregnancy was legal. Even the Catholic Church did not forbid it until 1869.

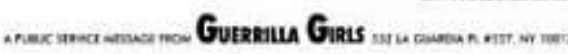

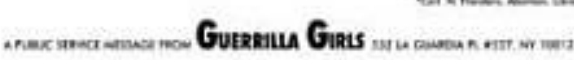

Figura 3 Guerilla Girls. 1992. Sin título (Guerilla Girls demand a return to traditional values on abortion ...) [Guerilla Girls demandan que vuelvan los valores tradicionales relacionados con el aborto. Descubre la verdad chocante sobre la posición de la Iglesia Católica sobre el aborto. Hasta mediados del siglo XIX el aborto fue legal durante los primeros meses del embarazo. La Iglesia Católica no lo prohibió hasta 1869], http://www.guerrillagirls.com; último acceso 03/08/2009.

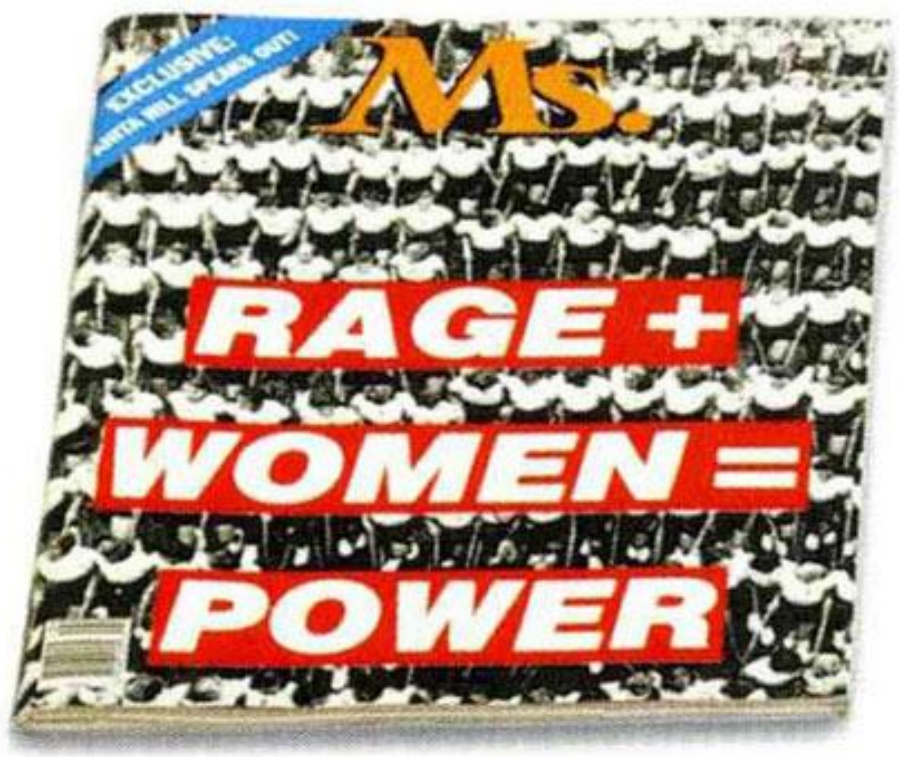

Figura 4 Kruger, Barbara. 1992. Rage + women $=$ power [Rabia + mujeres $=$ poder]. Portada de la revista Ms. Magazine (1-2/2002), http://www.barbarakruger.com; último acceso 03/07/2009. 
Finalmente, en el campo de batalla sobre el cuerpo femenino está presente el movimiento feminista, que desde hace más de cien años sitúa esta batalla en el centro de su interés. En países como Italia en la década de 1970, el “movimiento de mujeres cabreadas" (Bassnett 1986, 110) consigue, como sugiere Kruger en la portada de Ms. Magazine de 1992 (figura 4) convertirse en el agente más poderoso de la batalla sobre el cuerpo femenino, mientras que en Polonia en el periodo de la transición democrática iniciado en 1989 , las feministas "han perdido la batalla sobre el lenguaje" (Graff 2001, 121), cuando se han establecido en el lenguaje cotidiano las palabras para describir el embarazo provenientes del discurso de la Iglesia Católica y el movimiento pro-vida.

\subsection{Introduciendo los conceptos: reproducción como discurso}

Una de las principales aportaciones de la epistemología feminista es el énfasis en la historización, contextualización y ubicación geográfica de los conceptos. Autoras como Sandra Harding (1991) se inscriben en una tradición de crítica postmoderna, que siguiendo a Derrida (en Culler 1982) y Foucault (1997) opta por la deconstrucción de los discursos, tratándolos como textos llenos de contradicciones, marcados por las relaciones de poder. Para este trabajo voy a tratar la reproducción como un discurso, cuyo aspecto fundamental es su relación con el poder. En este marco, las nociones que de él se desprenden, como la maternidad, la fertilidad, el embarazo, el aborto, la anticoncepción, o el feto, son conceptos, es decir, construcciones históricas y sociales, cuyo significado muda dependiendo de un contexto particular para el que sirven y en el que se mantienen. 


\subsection{Unidad conceptual de la anticoncepción y el aborto}

Durante siglos, anticoncepción y aborto fueron conceptos equivalentes y, de hecho su separación semántica no se produce hasta finales del siglo XIX, como ha señalado Angus McLaren, historiador canadiense especializado en la historia de la sexualidad y la anticoncepción (McLaren 1991, 178-214). Robert Jütte, historiador alemán de la medicina también subraya que el término anticoncepción está en uso desde hace 150 años (Jütte 2008, 2). Linda Gordon, historiadora estadounidense y autora de varios textos sobre mujeres, género y planificación familiar, marca como fecha de esta separación el año 1870 (Gordon 2006, 70). La unidad discursiva de los dos conceptos hasta mediados del siglo XIX se puede interpretar de diversos modos. Uno de ellos es el hecho de la relativamente escasa intervención de la ciencia en el embarazo antes del siglo XIX. En el contexto occidental, es decir, en Europa y Estados Unidos, el embarazo se consideraba un proceso corporal femenino que en la mayoría de los casos era gestionado dentro del universo femenino. Antes del desarrollo de los conocimientos científicos sobre el desarrollo fetal, el momento clave para la determinación del embarazo era cuando la mujer embarazada afirmaba haber sentido los movimientos del feto. En cuanto a la prevención del embarazo, se hablaba más bien de limitación del número de hijos/as, con un conjunto de remedios herbales, mecánicos u otros para provocar la menstruación, según John Riddle, historiador estadounidense de la medicina y la farmacología (Riddle 1997, 10-34). Estos remedios desempeñaban una función entonces única, que hoy se divide en dos: prevenir el embarazo y, si ya ha ocurrido, terminarlo. En este sentido, Jütte $(2008,52)$ categoriza relaciones no 
vaginales o masturbación como técnicas preventivas; Riddle $(1997,207)$ señala que el aborto tenía como único significado terminar un embarazo muy avanzado. Gordon $(2002,31)$ habla de la continuidad del aborto y la anticoncepción en la experiencia de las mujeres, es decir, el hecho de que cuando fallaran los métodos preventivos, el aborto era considerado un recurso para limitar el tamaño de la familia.

Este tipo de discurso único sobre la anticoncepción y el aborto estaba codificado en forma de leyes. Giuglia Galeotti, historiadora del derecho italiana explica que en las sociedades pre-cristianas griega y romana el aborto funcionaba como un delito contra el cabeza de familia, al que de este modo se privaba de un potencial heredero (Galeotti 2003, 26). Riddle (1999, 95-97) describe varios ejemplos de leyes populares inglesas del siglo XV, que demuestran que el aborto no se consideraba delito al no ser el feto una persona legal a la que se causaban los supuestos daños. También la posición de la Iglesia Católica ha contribuido al mantenimiento de esta unidad igualando, en su discurso sobre la reproducción, la anticoncepción y el aborto como pecados contra la vida humana y la voluntad de Dios, que persisten en la doctrina oficial de la Iglesia en el siglo $\mathrm{XX}^{2}$.

\footnotetext{
${ }^{2}$ Como ejemplo del discurso de la Iglesia Católica en el que se mantiene la unidad entre el aborto y la anticoncepción se puede tomar la Encíclica Casti Connubii de Pío XI lanzada en 1930, en la que se condenó el empleo de la anticoncepción como una práctica ilícita, igual que el aborto. Esa Encíclica, según Reuther $(2008,186)$ fue la respuesta de la Iglesia Católica a la Conferencia de Lambeth de la Iglesia Anglicana que liberalizó su oposición hacia la anticoncepción.
} 


\subsection{Separación discursiva de la anticoncepción y el aborto y los factores implicados en este proceso}

Como ya he señalado, la separación discursiva entre la anticoncepción y el aborto se hizo realidad entre los siglos XIX y XX, cuando la ciencia empezó a determinar y controlar la reproducción humana, impulsada por el desarrollo del capitalismo que, proponiendo nuevos modelos de producción, exigía también mayor control sobre los cuerpos humanos.

Con la difusión de saberes científicos sobre el embarazo y la fertilidad en Europa y Estados Unidos, la anticoncepción se separa del aborto, tomando su significado actual, es decir el de prevención del embarazo en el sentido estricto. Así fue también incluida en el discurso público y masivo gracias al movimiento neomaltusiano, que nació en el ámbito anglosajón impulsado por la publicación de la obra An essay on the principle of population [Ensayo sobre el principio de la población] por Thomas Malthus en 1798 en Inglaterra. Malthus argumentaba que mientras la población aumentaba de manera geométrica, los recursos lo hacían de modo aritmético, lo cual implicaba su progresivo agotamiento. En este sentido, las guerras, las epidemias, las catástrofes naturales, etc., eran útiles para mantener el equilibrio entre la población y los recursos. El movimiento neo-maltusiano radicalizó esta teoría, insistiendo en que el control de la población era fundamental para una sociedad "sana". Mientras en Reino Unido los neo-maltusianos optaban por la anticoncepción, expresando un fuerte anticlericalismo, en Estados Unidos el neo-maltusianismo hacía referencia a la perfección de la raza humana, prefiriendo como remedio para la 
sobrepoblación la abstinencia sexual antes que la anticoncepción (Gordon 2002, 4046). En Estados Unidos, las ideas neo-maltusianas estaban íntimamente conectadas con el concepto de la maternidad voluntaria, una maternidad entendida como actividad "sagrada" que constituía una prueba de superioridad moral de las mujeres sobre los hombres, y voluntaria en cuanto se contemplaba la posibilidad de que la mujer se negara a cumplir con sus "deberes" en el lecho matrimonial por motivos de salud (Gordon 2002, 61-62).

Posteriormente, en el marco del neo-maltusianismo, bajo cuya influencia se movían las pioneras feministas de la planificación familiar como Margaret Sanger y Marie Stopes ${ }^{3}$, el concepto de maternidad voluntaria se transformó en la planificación familiar, que implicaba el empleo intencional de técnicas anticonceptivas. La legitimización social de la anticoncepción al principio del siglo XX impulsada por este movimiento en el ámbito anglosajón, fue a la vez la causa y el efecto del cambio más profundo de todo un sistema de valores victorianos, porque llevaba consigo la legitimización de la separación entre la reproducción y el sexo (Gordon 2002, 55-71).

En el siglo XX, los discursos sobre el aborto y la anticoncepción se siguen reformulando influidos por la ciencia y tecnología, economía, leyes y movimientos sociales, y sobre todo por el movimiento feminista y (a finales del siglo $X X$ ) el movimiento pro-vida.

\footnotetext{
${ }^{3}$ Para obtener más información sobre Margaret Sanger, véase Kennedy 1970; Gray 1979; Moore y Moore 1986; Chesler 1992; Franks 2005; o Sanger et. al. 2007. Para Marie Stopes véase Geppert 1998; Peel 2002; Peppis 2002; Rose 2007; Stopes editada por McKIbbin 2008.
} 


\subsection{Crítica feminista al control de la reproducción}

El aborto y la anticoncepción han sido objetos de interés para la academia feminista, cuya investigación crítica sobre estas prácticas en diferentes contextos históricos y geográficos lleva a la conclusión de que pueden servir tanto para ayudar a las mujeres a tomar el control sobre sus cuerpos, como para contribuir a la pérdida de este control. Por lo tanto, el empleo de métodos anticonceptivos o la existencia del derecho al aborto voluntario no se pueden interpretar únicamente como factores que contribuyen al aumento de la libertad de las mujeres, precisamente porque la anticoncepción y el aborto también pueden servir como herramientas de control por parte del Estado o la sociedad sobre las decisiones reproductivas femeninas.

Para demostrar esta ambigüedad retomaré aquí dos ejemplos elaborados por la academia feminista: el caso de la anticoncepción hormonal (la píldora y el implante) y el caso del feticidio femenino.

\subsubsection{El caso de la anticoncepción hormonal: implicaciones de raza y clase en las prácticas de su uso}

Aunque la implementación de la anticoncepción hormonal se suele relacionar con la liberación sexual y laboral de las mujeres, las autoras feministas como Germaine Greer (1984, 302-347) o Maria Mies $(1998,27-58)$ destacan su potencialidad como herramientas de control sobre las mujeres, utilizadas principalmente por los movimientos eugenésicos y de control de la población. Desde este punto de vista, cabe notar que los derechos reproductivos se han planteado desde la posición de las mujeres blancas de clase media, pero pueden tomar significados radicalmente 
diferentes en contextos distintos a este. Conviene señalar, por tanto, que el uso de la anticoncepción hormonal como una herramienta de liberación u opresión está fuertemente marcado por las categorías de raza, clase y localización.

La primera píldora anticonceptiva, Enovid, fue lanzada al mercado estadounidense en 1957 por la compañía farmacéutica Searle (Marks 2000, 79). En 1960 se empezó a prescribir por su valor anticonceptivo, además de como tratamiento para desarreglos ginecológicos y menstruales. Como apunta Lara Marks, historiadora inglesa de la medicina y autora de la monografía Sexual chemistry [La química sexual] fue entonces cuando las investigaciones de mercado sobre las actitudes sociales hechas por la compañía Searle comprobaron que la sociedad estadounidense estaba preparada para la recepción del nuevo método de planificación familiar, que eliminaba casi completamente el riesgo del embarazo no deseado de una manera muy cómoda (Marks 2001, 1-10). El impacto de la píldora fue enorme: no solamente separó la contracepción del acto sexual (permitiendo a las mujeres controlar su fertilidad sin la colaboración de los hombres) ${ }^{4}$, sino que con su casi plena eficacia en prevenir el embarazo cambió los estándares de la anticoncepción en general. Simultáneamente, siendo el "primer medicamento que marcaba un estilo de vida" (Marks 2001, 2) la píldora contribuyó al desarrollo de nuevas formas de medicina preventiva, dado que su

\footnotetext{
${ }^{4}$ Claramente, la píldora anticonceptiva influye sobre los patrones anticonceptivos tanto masculinos como femeninos (Marks 2001, 9). Sin embargo, la cuestión de responsabilidad de uso de la anticoncepción permanece abierta: por un lado la píldora libera los hombres de su rol tradicional en emplear las técnicas anticonceptivas como coitus interruptus (Fisher y Szreter 2003, 282), por otro lado, autoras como Seatnan $(2000,10)$ critican el hecho de que la píldora delega el peso de las responsabilidades reproductivas (embarazo o posibles efectos secundarios de la anticoncepción) a las mujeres.
} 
uso demandaba visitas médicas regulares. McLaren apunta que precisamente esta necesidad de seguimiento médico fue el factor decisivo para la incorporación de la planificación familiar a la medicina institucional, en contraste con el anterior escepticismo de las jerarquías médicas frente a ella (Marks 2001).

La implicación primaria de la píldora para las mujeres, el hecho de poder decidir realmente y con certeza sobre prevenir el embarazo, puso en movimiento toda una serie de cambios sociales que permitieron a las mujeres decidir más libremente sobre su participación en el mercado laboral, matrimonio, o la experiencia materna en caso de atender a un número limitado de hija/os. No parece exagerado relacionar el lanzamiento de la píldora con el nacimiento de la segunda ola del feminismo como un movimiento masivo. La parte de este movimiento entusiasmada por las tecnologías anticonceptivas (y más tarde con la reproducción asistida) subraya que la anticoncepción hormonal-con su eficacia-contribuye al éxito del proyecto feminista de desestabilizar la asociación histórica y discursiva de las mujeres con la naturaleza y reproducción (Stanworth 1990, 288).

La píldora, presentada como un remedio mágico tuvo un enorme éxito en los años $1960^{5}$. Su uso masivo produjo el conocimiento sobre los posibles riesgos para la salud proporcionados por la píldora. Aunque el movimiento feminista denunciaba la

\footnotetext{
${ }^{5}$ En Gran Bretaña, la píldora fue introducida en 1961; en 1969 casi el 50\% de las mujeres británicas de 33 años la estaba tomando (Cook 2005, 115).
} 
píldora como un medicamento lanzado al mercado sin pruebas suficientes ${ }^{6}$, es preciso decir que las pruebas clínicas de la píldora fueron unas de las primeras pruebas de medicamentos que se realizaron en Estados Unidos, quizás porque la píldora fue uno de los primeros remedios que se administraba a las mujeres sanas para interferir con las funciones naturales de sus cuerpos y no, de acuerdo con la definición de fármaco de la mitad del siglo XX, como un remedio para una enfermedad o trastorno. La píldora creó un precedente para un procedimiento estándar de control de medicamentos previo a su comercialización. A base de estudios de efectos secundarios y posibles interacciones con otros fármacos o hábitos, como fumar, la píldora fue el primer medicamento que se vendió con un folleto informativo (a partir de 1980). Aunque la FDA (Food and Drug Administration [Oficina de Administración de Alimentos y Medicinas estadounidense]) empezó a investigar ya en 1962 los posibles riesgos para la salud relacionados con la píldora, la opinión pública estadounidense e internacional fue directamente informada de sus potenciales riesgos en 1969, con el libro de Barbara Seaman, The doctor's case against the pill [El caso del médico contra la píldora]. Esta publicación llamo la atención de los políticos y dió lugar a las "Audiencias de Nelson" en el Senado de Estados Unidos en 1970, dedicadas a la seguridad de la píldora (Marks 2001, 89-115).

\footnotetext{
${ }^{6}$ La primera prueba de gran escala de Enovid tuvo lugar en Puerto Rico (urbanización de Rio Piedras y pueblo de Humacao). Por lo tanto, se podría decir que se practicó sobre las mujeres de "Tercer Mundo". En Estados Unidos, las primeras pruebas se conducían sobre las mujeres-pacientes de hospitales psiquiátricos y mujeres de origen puertorricense, mexicana o haitiana (Marks 2001, 101-105). Sin embargo, mientras en el caso de las pacientes de hospitales psiquiátricos podemos especular que no tuvieron poder para negarse a participar en las pruebas, Marks subraya que las mujeres de Rio Piedras no fueron "victimas" de las pruebas. Al contrario, estaban muy interesadas en poder participar en ellas a pesar de alto nivel de interferencia de esta participación con la vida cotidiana y desagradables efectos secundarios (Marks 2000, 146-176).
} 
En el año 1990 en el mercado estadounidense apareció un nuevo anticonceptivo hormonal bajo el nombre comercial de Norplant. Fue desarrollado por la organización Population Council [Consejo de la Población], como afirma Dorothy Roberts, autora feminista estadounidense especializada en estudios de derecho, género y raza, con el objetivo de regular la fertilidad en los países no occidentales con problemas de "sobrepoblación" (Roberts 1997, 104). Es uno de los pocos métodos anticonceptivos nuevos desarrollados y comercializados en Estados Unidos después de la píldora (Fried 2006, 240).

Norplant es un implante hormonal que se coloca a la mujer debajo de la piel del brazo. Una vez colocado, el implante permanece activo por un máximo de cinco años, lanzando continuamente una dosis de hormonas que evitan el embarazo. En el momento de su comercialización, Norplant se presentaba como un método anticonceptivo perfecto: limitaba la fertilidad a largo plazo, sin interferir con el acto sexual, y de manera completamente reversible (Roberts 1997, 107). Al principio, los inventores imaginaban que Norplant iba a ser utilizado sobre todo por las mujeres de clase media, teniendo en cuenta el elevado coste de su colocación y eliminación. En cambio, el gobierno federal estadounidense decidió financiar Norplant a través de Medicaid, el fondo público que cubre las necesidades básicas de salud de las personas más pobres. La colocación de Norplant, subvencionada por el Estado, fue en muchos casos una condición para obtener beneficios o ayuda social para las mujeres pobres, mientras su eliminación antes de los cinco años previstos (independientemente de ser justificada por efectos secundarios como hemorragias, dolores etc.) tenía que ser 
pagada por la mujer misma. Un problema de salud añadido consiste en el hecho de que las mujeres que lo usan dejan de utilizar los preservativos, y por tanto dejan de protegerse de las enfermedades de la transmisión sexual (Wall 1999, 69). En Estados Unidos, donde la clase social está estrechamente relacionada con la raza, las mujeres que utilizaban Norplant eran principalmente mujeres negras que, además, están fuertemente estereotipadas, ya que en el imaginario público la figura de la mujer negra se caracteriza por hiperfertilidad y dependencia de la asistencia social (Roberts 1997, 104-149). Angela Wall, que también ha estudiado este método anticonceptivo en relación con el género expresa la opinión de que Norplant se ha inscrito en el discurso más amplio sobre la maternidad, convirtiéndose en una herramienta de prevenir la maternidad "ilegítima" de las mujeres de clase baja, y aplazar la maternidad "legítima" de las mujeres de clase media (Wall 1999, 60).

\subsubsection{El caso del aborto: de la expresión de la voluntad propia de la mujer a la expresión de intereses culturales y políticos del Estado}

La toma del control por parte de mujeres sobre sus cuerpos fue uno de los postulados principales del activismo feminista de la segunda ola del movimiento en Estados Unidos y Europa ${ }^{7}$. Una de las articulaciones más emblemáticas de este postulado fue la lucha feminista por la legalización del aborto voluntario, que se inscribía dentro de la lucha por los "derechos reproductivos", una denominación que se empezó a utilizar en Estados Unidos en la década de 1970 como una alternativa feminista para el control de natalidad o de la población (marcada por rasgos clasistas y racistas arriba

\footnotetext{
${ }^{7}$ Véase también Thomson 1971; Tronto 1993; Reagan 1997; Solinger 1998.
} 
mencionados) (Gordon 2006, 67). En Estados Unidos, la sentencia de la Corte Suprema en el caso Roe v. Wade en 1973 legalizó abortos voluntarios en el primer trimestre inscribiéndolos dentro del derecho constitucional a la privacidad (Szczuka 2004, 127) ${ }^{8}$. En otras palabras, el interés legítimo del Estado en el embarazo durante los primeros tres meses era mínimo, pero aumentaba en cuanto avanzaba la gestación (Boyle 1997, $20)^{9}$. En Europa, siguiendo la liberalización de la ley del aborto británica (David Steel's Act de 1967), en la década de 1970 se renovaron las legislaciones de la mayoría de los países occidentales, para garantizar la posibilidad de interrumpir el embarazo en las primeras semanas de gestación a petición de la mujer embarazada. La involucración del movimiento de mujeres y del movimiento feminista en estos procesos fue particularmente fuerte en Alemania Occidental, Francia e Italia (Naciones Unidas, 1999). Por otro lado, en los países bajo influencia soviética (excluyendo Rumanía gobernada por Ceauşescu), los abortos voluntarios eran fácilmente accesibles ya que la legalización del aborto fue en muchos casos una de las decisiones prioritarias de los gobiernos comunistas, con el objetivo de promocionar la entrada masiva de las mujeres en el mercado de trabajo remunerado ${ }^{10}$.

\footnotetext{
${ }^{8}$ Esta decisión fue substancialmente debilitada por la Enmienda Hyde (1976) que prohíbe la financiación de abortos voluntarios con fondos federales (a través de Medicaid), asimismo limitando el acceso al aborto a las mujeres más pobres (Planned Parenthood 2009, http://www.plannedparenthood.org; último acceso 20/05/2009). Véase también Shrage 2003.

${ }^{9}$ Contemporáneamente, el interés del Estado estadounidense sobre el feto se traduce en intervenciones directas para proteger el feto durante los últimos meses del embarazo, por ejemplo, penalizando a mujeres embarazadas que fuman, toman drogas o alcohol (Oaks 2000, 64).

${ }^{10}$ Aunque en realidad las mujeres realizaban trabajos peor remunerados y no tenían el acceso real a las posiciones directivas, reservadas a los hombres (Hausner, Heynes y Mansbridge 1993, 257-273; Titkow 1993, 253-266)
} 
El derecho al aborto voluntario, entendido como una expresión del control por parte de las mujeres sobre sus cuerpos, fue uno de los postulados más importantes de la segunda ola del feminismo occidental y no cabe duda de que el acceso a la interrupción voluntaria del embarazo es un componente, dentro del mundo occidental, de la liberación de las mujeres, a pesar de que dependiendo de la legislación de un país dado, puede verse afectado por obstáculos económicos. Esto, junto con la proliferación de la anticoncepción, constituye una agenda de derechos en el campo de la reproducción, que empoderan a las mujeres en muchos contextos occidentales.

En contextos no occidentales, sin embargo, el acceso al aborto se puede convertir en un arma contra las mujeres. Como ejemplo pueden servir las preferencias de abortar los fetos femeninos en China y en la India. Aunque en ambos países estas prácticas están relacionadas con la inferioridad cultural de las mujeres, se organizan de manera distinta ya que en la India la práctica "viene de abajo" y el Estado está intentando contenerla, mientras en China es un resultado de la intersección de la cultura favorecedora para los hijos varones con política de "un hijo solo" impuesta por el Estado.

En la India la práctica de abortar los fetos femeninos está causada por varios factores, aunque existen importantes diferencias según castas y regiones. Por un lado, los factores culturales determinan la posición privilegiada de las mujeres que son madres de hijos varones, aumentando también la posición social de toda la familia de 
estas mujeres. Otro factor cultural es la práctica de dotes muy elevadas para las mujeres $^{11}$, que aumentan sustancialmente el coste de la educación de las niñas (Sinha 2008; Patel 2007, 21-23). Por otro lado, la causa directa del aumento del feticidio femenino, abortos intencionados de fetos femeninos motivados exclusivamente por el sexo del feto, es la proliferación de aparatos de radiografía fetal, incluso móviles, y los médicos que revelan el sexo del feto y practican abortos aprovechándose de la preferencia por hijos varones (Bose 2007, 80-87). La desproporción numérica entre los sexos llamó la atención del gobierno después del censo de 2001, provocando un esfuerzo por parte del Estado para cambiar la situación, adoptando medidas como el control de aparatos de radiografía (Patel 2007, 27-60).

En cambio, en China el feticidio femenino es un efecto indirecto de la política oficial de Estado de "un hijo solo", que empezó en China a finales de la década de 1970, se relajó en la mitad de los 1980 y se ha vuelto a reforzar en los 1990. Dicha política, diseñada según Greenhalagh (2008, 1-44) para acelerar la transformación de China en un poder global moderno, tiene un efecto discriminador sobre niñas y fetos femeninos donde la norma son las familias con dos o más criaturas, especialmente en las áreas rurales. En China los hijos varones, de manera parecida a la de la India, representan la buena suerte y el bienestar de la familia. Las familias son tradicionalmente patrilocales y los hijos varones son los que trasmiten el apellido de la familia, y son responsables del cuidado de los padres ancianos. Entonces, las familias

\footnotetext{
${ }^{11}$ A pesar de los esfuerzos del Estado en la India para disminuir su importancia, la institución de la dote sigue siendo practicada con frecuencia. Véase Dalmia y Lawrence 2005.
} 
forzadas por el Estado a tener un solo hijo son generalmente más interesadas en tener un hijo varón. La política del Estado refleja esta preferencia al permitir a las familias rurales un segundo embarazo si del primero resulta el nacimiento de una niña o un niño discapacitado. La transgresión de las prohibiciones reproductivas en China lleva consigo castigos como la penalización fiscal, negación de beneficios laborales etc.

Resumiendo, en esta introducción he querido señalar brevemente, por un lado, el desarrollo histórico de las prácticas del control de la reproducción como la anticoncepción y el aborto. Por otro lado, he mostrado el interés de feminismo por estudiar estos procesos, y su crítica a la universalización de los efectos positivos de la anticoncepción hormonal y el acceso al aborto voluntario, que han puesto de manifiesto que en contextos distintos al referente de la mujer blanca, occidental, heterosexual y de clase media, tanto la anticoncepción hormonal como el aborto pueden ser utilizados como una forma de control sobre las mujeres y no resultado de sus decisiones libremente tomadas.

\subsection{Objetivos del trabajo}

La primera inspiración para esta investigación nació con la investigación que hice para el trabajo de fin de carrera en Relaciones Internacionales y Estudios de Género en la Universidad de Łódź, Polonia, en 2007. El trabajo Abortion debate in Poland and its representation in the press [EI debate sobre el aborto en Polonia y su representación en la prensa] fue mi primer acercamiento a la problemática del aborto en mi contexto nativo polaco. En cambio, este trabajo está alimentado tanto de conocimientos 
adquiridos en el Máster GEMMA realizado en la Universidad de Granada, como en la movilidad del Máster en la Universidad de Bolonia, Italia.

A diferencia de mi primera aproximación a estos temas, que tuvo un carácter descriptivo y local, con este trabajo pretendo incluir una reflexión más amplia de carácter teórico, que es el resultado de un proceso de lecturas de producción científica, general y feminista, sobre varios de los aspectos de la reproducción, enriquecido gracias a una estancia de investigación en Florida International University, Miami.

El punto de partida para mi investigación es reconocer que la reproducción tiene carácter discursivo. En este marco, el significado de la anticoncepción y el aborto como prácticas, pero también conceptos, se transforma tanto en la historia como en contextos culturales diferentes.

El objetivo principal de este trabajo es estudiar los debates sobre la reproducción en Polonia durante la transición democrática en los años noventa y en Italia durante la transición social en los años sesenta y setenta, y en concreto analizar los discursos de los agentes sociales involucrados en la formulación de estos debates. Mi objetivo particular será conocer el papel y la posición del movimiento feminista en Polonia e Italia como uno de estos agentes, y analizar su discurso sobre el aborto y la anticoncepción a partir de las fuentes primarias (manifiestos, libros, artículos de revistas feministas, y de la prensa general) de los periodos mencionados. 
Para realizar este trabajo, aplicaré el modelo de género de Joan Scott (1986) y me apoyaré en los conceptos de biopoder y de discurso definidos por Foucault (1987; 1997).

He elegido estos contextos teniendo en cuenta, por un lado, el hecho de que son realidades locales para un proceso más general de proliferación de la anticoncepción hormonal y de la medicalización del control de la reproducción. Por otro lado, ambos países cuentan con una posición privilegiada de la religión católica, aunque luego esta toma una forma particular en una red concreta de relaciones simbólicas, institucionales y normativas en Polonia e Italia.

La innovación que supone este trabajo será comparar el discurso feminista polaco e italiano acerca de la anticoncepción y el aborto en el contexto de grandes cambios políticos y sociales, e identificar diferencias y similitudes que se producen entre las elaboraciones feministas occidentales y el feminismo postcomunista en el campo del control de la reproducción. 


\section{Metodología y fuentes}

En la parte introductora de este trabajo he señalado que la reproducción se puede analizar como un discurso. En este capítulo quiero definir los conceptos de anticoncepción y aborto utilizando la perspectiva de género, e incorporar los conceptos de biopoder y discurso de Foucault (1987; 1997). Como punto de partida para mi análisis sobre el aborto y la anticoncepción en Polonia y en Italia, voy a recurrir al modelo de género de Scott y utilizar los niveles de análisis (simbólico, normativo, institucional e individual) propuestos por ella. En este capítulo hablaré también de las fuentes sobre los países analizados que he empleado y la breve descripción de las mismas.

\subsection{Definiciones de aborto y anticoncepción y su aspecto relacional}

Como he ya señalado, la separación discursiva entre el aborto y la anticoncepción es, históricamente, un fenómeno bastante reciente. El aborto se entiende como una terminación prematura del embarazo por causas naturales o artificiales. En castellano e italiano, si se trata de aborto artificial, se pueden utilizar términos como interrupción voluntaria del embarazo (italiano: interruzione volontaria della gravidanza) para diferenciarlo del aborto natural que ocurre de manera no provocada. En otras lenguas, como inglés y polaco, las palabras abortion y aborcja se refieren solamente al aborto provocado, existiendo palabras de raíz diferente para describir un aborto natural: miscarriage/poronienie. Luc Boltanski, sociólogo francés, resalta el carácter universal de las prácticas del aborto que ha sido presente en la mayoría de las sociedades 
humanas. Sin embargo, a pesar de su universalización, el aborto permanece como una actividad practicada en secreto, que se tolera, pero se habla de ella con vergüenza y repugnancia. Por ello existen pocas representaciones del aborto, que se situa, según Boltanski (2007, 18-27), en la frontera entre lo prohibido y lo permitido, lo público y lo privado.

La definición de la anticoncepción es un ejercicio más complejo. Jütte $(1999,2)$ apunta, que el término científico de anticoncepción apareció por la primera vez (en inglés) en 1919 en el texto de Max Marcuse The sexual meaning of procreation and contraception [El significado sexual de la procreación y anticoncepción]. Entonces, la noción de anticoncepción sustituía otras como esterilidad voluntaria o artificial. Anteriormente, se popularizó también el término planificación familiar, utilizado por el movimiento neo-maltusiano (Riddle 1997, 226) o control de la natalidad acuñado en 1915 por Margaret Sanger (Roberts 1997, 56-60).

Para este trabajo, utilizaré la definición de anticoncepción de Russell y Thompson, basada en las propuestas del Family Planning Council [Consejo por la Planificación Familiar]. Según estos autores, la anticoncepción implica

Planificación familiar o control de la fertilidad tienen en la actualidad un sentido más amplio: abarcan tanto la anticoncepción (su práctica y tecnología), como las 
instituciones y políticas empleadas para promover un uso específico de los anticonceptivos.

Los estudios históricos sobre la anticoncepción (McLaren 1991; Riddle 1997; Gordon 2002; Jütte 2008) ${ }^{12}$ destacan el hecho de que en las sociedades humanas siempre se ha empleado alguna clase de métodos anticonceptivos con el objetivo de limitar la reproducción. Jütte $(2008,4)$ subraya que el uso de la anticoncepcion ha sido un fenomeno de carácter general, pero la conciencia de la universalidad de las prácticas anticonceptivas no aparece hasta el siglo XX. Riddle $(1997,12)$ expresa la posición de que los métodos anticonceptivos han sido empleados tanto por las clases educadas, como por las clases bajas.

Es cierto que la percepción actual de la anticoncepción, tanto en el nivel de conocimientos comunes, como en el nivel científico, está profundamente influenciada por la comercialización de la píldora anticonceptiva (en 1960 en Estados Unidos y posteriormente en Europa) y otros métodos hormonales. En otras palabras, los comportamientos en el pasado relacionados con el control de la fertilidad, como abstinencia, aborto, lactancia prolongada o, a partir de siglo XVIII, el coitus interruptus $^{13}$ (McLaren 1991, 1-11), se sustituyen por métodos muy efectivos de

\footnotetext{
${ }^{12}$ Véanse también otras publicaciones sobre la historia de la anticoncepción: Djerassi 1980; Pfeffer 1993; Brodie 1994; Asbell 1995; Dickens 2000; Tone 2001; Cook 2004; Fisher 2006.

${ }^{13} \mathrm{Si}$ hablamos de coitus interruptus, su empleo por parte de los hombres de clase medio-alta en Inglaterra, Francia y Estados Unidos a partir de siglo XVIII (Segalen citado por McLaren 1991, 2) implicó un cambio importante en materia de anticoncepción. Sin embargo, contemporáneamente el coitus interruptus está excluido de muchos discursos como un método anticonceptivo debido al alto nivel de riesgo que supone en relación con las enfermedades de transmisión sexual, pero en otros ámbitos sigue
} 
carácter médico (anticoncepción hormonal, DIU) o mecánico (preservativos). En el caso del aborto, como ya he dicho, hasta finales del siglo XIX, el aborto y la planificación familiar estaban íntimamente conectados, ya que el aborto constituía (en Estados Unidos) uno de los métodos principales de limitación del tamaño de la familia (Gordon 2006, 67-90).

Dickson (1997 citada por Baker 2008, 67) habla de tres revoluciones en el campo de la anticoncepción en los países industrializados. La primera de ellas se había iniciado con el empleo de los métodos de barrera por las parejas conyugales a finales del siglo XIX. El siguente paso estuvo marcado por la comercialización de la píldora anticonceptiva en los Estados Unidos en los años sesenta, fecha a partir de la cual se empezó a romper el vínculo exclusivo del uso de la anticoncepción por las parejas casadas. La tercera revolución, en los años setenta, está relacionada con el protagonismo de la esterilización masculina como método anticonceptivo. Jütte (2008, 1-10) habla, por su parte, de dos revoluciones: de la introduccion de preservativo de goma fina en la segunda mitad del siglo XIX y la comercialización de la píldora anticonceptiva un siglo después.

Como podemos observar, las divisiones propuestas por los historiadores y las historiadoras se basan en el aumento de la eficacia del método anticonceptivo más utilizado. Para resumir, la definición contemporánea del método anticonceptivo, da 
por hecho su alta eficacia, comodidad de empleo y reversibilidad de sus efectos, pero tambien el carácter tecnológico o médico del mismo (Marks 2001, 5).

En este contexto, es fundamental subrayar el aspecto relacional de la anticoncepción, entendido como el hecho de que las prácticas de uso de los métodos anticonceptivos y la percepción de este funcionamiento están mediadas por una variedad de relaciones, instituciones, conocimientos y creencias. Como ejemplo nos puede servir la observación de Baker $(2008,67)$ de que los primeros preservativos fueron empleados a finales del siglo XIX-sobre todo por las parejas casadas. En cambio, a finales del siglo XX, los preservativos se convirtieron en uno de los métodos principales en las relaciones inestables o esporádicas. El abandono del uso del preservativo en la pareja significa, en muchos casos, el paso hacia una relación estable (Boyle 1997, 86-88).

Otro ejemplo es el uso de la píldora anticonceptiva en Estados Unidos, que en los años setenta triunfaba entre las mujeres casadas que ya tenían el número de hijos deseado. Con el tiempo, la píldora pasó a ser el método principal en las relaciones prematrimoniales estables, que solían acabar en matrimonio, para convertirse más recientemente en un método empleado por las mujeres adolescentes independientemente de la presencia de una relación estable (Marks 2001, 8). Está claro que los cambios en los patrones de uso de la anticoncepción están relacionados con cambios sociales de carácter general. Así, los métodos anticonceptivos se convierten en algo más que tecnologías y comportamientos, operan y representan un 
universo cultural, moral y emocional ubicado en un contexto social e histórico determinado (Russell y Thompson 2000, 6). Las decisiones reproductivas (que abarcan la anticoncepción, posible aborto y el tamaño de la familia ideal) se posicionan en la frontera entre lo público (el Estado, sus normas e instituciones) y lo privado (los cuerpos de las mujeres), transgrediendo de este modo la división binaria establecida en las sociedades occidentales.

De esta manera, para los estudios de género, la anticoncepción constituye un tema de gran interés, ya que en el caso de los países occidentales, está íntimamente relacionada con la superación de la oposición discursiva entre las funciones reproductivas asociadas con las mujeres y las funciones productivas, tradicionalmente delegadas a los hombres. El cambio profundo en los patrones anticonceptivos durante los últimos cincuenta años ha llevado consigo una reformulación radical de las relaciones de género, pues con la anticoncepción hormonal, las mujeres han obtenido una herramienta de control sobre su reproducción sin precedentes históricos. En Europa (con la excepción de Irlanda, Polonia, y Malta) el acceso a los métodos de la planificación familiar y la legalización de carácter casi general de aborto voluntario durante las primeras semanas de embarazo ha contribuido al aumento del dicho control. Por otro lado, los cambios en el tamaño familiar y la masiva participación de 
las mujeres en la esfera pública (mercado laboral, instituciones políticas) influye de manera relacional en la construcción de los roles de género ${ }^{14}$.

\subsection{Género, biopoder y reproducción}

Una parte importante de la producción teórica del feminismo se ha centrado en la desnaturalización de la categoría Mujer como referente simbólico universal, fuera de contextualizar e historizar la situación de las mujeres en una época y cultura dadas. De esta producción teórica emerge género como una categoría de análisis nueva que llama la atención sobre los aspectos de la construcción de papeles socialmente aceptables de las mujeres y los hombres en un cierto momento histórico. Como he señalado, las prácticas anticonceptivas juegan un papel fundamental en el desarrollo de dichos papeles y en la relación entre ellos. De esta manera, se podría analizar la relación entre el género y el control de la reproducción (entendida aquí como las prácticas del uso de la anticoncepción o el aborto) a través de las categorías establecidas para el análisis de género en general.

Una de las definiciones operativas más completas de la categoría género fue elaborada por Joan W. Scott y publicada por la primera vez en su ensayo "Gender: A Useful Category of Historical Analysis" según la cual el género es:

el elemento constitutivo de las relaciones sociales basado en las diferencias percibidas entre los sexos y el modo primario de dar significado a las relaciones del poder $^{15}$ (Scott 1986, 1067-1068).

\footnotetext{
${ }^{14}$ Para más información sobre los varones y la anticoncepción véase Becker 2000; Darroch 2000; Oudshoorn 2000; 2003 y 2004.
} 
En el caso de un estudio sobre la anticoncepción y género, el poder del que habla Scott se puede traducir como biopoder, un término elaborado por Michel Foucault en su Historia de la sexualidad (1987, 169-176). El biopoder, o control discursivo y disperso sobre los cuerpos, auxiliar a las prácticas oficiales de los Estados, se forma paralelamente al capitalismo, siendo el control físico sobre los cuerpos una necesidad en un sistema económico que se mueve gracias a los trabajadores y las trabajadoras. En este marco, se distingue entre el poder en el sentido tradicional (centralizado, individualizado y represivo) y las formas de poder no centralizadas, ejercitadas sobre los cuerpos. El biopoder está compuesto por biopolíticas (que componen las políticas de control sobre la población, relevantes en cuanto a natalidad, muerte, matrimonio, salud y reproducción), y el poder disciplinar (que se establece para que los individuos sean más productivos, útiles y manejables). El biopoder interviene en las actuaciones de un cuerpo singular, influyendo en sus prácticas diarias: actuaciones, deseos, motivaciones. Opera también al nivel social, a través de un conjunto de instituciones y tecnologías (clínicas, hospitales, estadística, discurso médico, medios de comunicación, la escuela etc.) para supervisar, regular e intervenir en la vida de una población (Georges 2008, 4). Las prácticas conformes con las indicaciones de biopoder están socialmente premiadas y son una fuente del placer para los individuos; las personas que insisten en las prácticas contrarias pueden ser castigadas de alguna forma. Sin embargo, el biopoder también es un poder blando, es decir, permite márgenes de resistencia y deja ámbitos de travesura. Foucault (1987) mencionaba el manicomio o el

\footnotetext{
${ }^{15}$ Todas las traducciones de citas textuales de inglés, italiano y polaco son mías.
} 
burdel como ejemplos de espacios en los que están permitidos los comportamientos subversivos.

Resumiendo, el concepto de biopoder se convierte en una herramienta útil para analizar la anticoncepción y género, porque la reproducción, o producción de personas, constituye el núcleo de interés del biopoder. Según Foucault, el biopoder se ejerce a partir de innumerables puntos y está implicito en todo tipo de relaciones. En otras palabras, es un poder que viene de abajo: actúa dentro de los aparatos de producción, la familia y las instituciones (Foucault 1987, 170) ${ }^{16}$.

Si el objetivo del biopoder se centra en la producción de personas, debemos tener presentes las implicaciones de género en esta producción, que recae en gran medida y en todas las culturas en manos de las mujeres.

\subsubsection{Niveles de análisis relacionados con la categoría de género de Joan Scott (1986)}

Volviendo al concepto de género, Scott en su definición del mismo hace una especificación de niveles que interactúan para producir el sistema de relaciones de género en una sociedad dada:

1. el nivel simbólico, que contiene múltiples $y$, a veces, contradictorias representaciones culturales de la feminidad y la masculinidad, que se convierten en un referente para la formulación de los roles de género,

\footnotetext{
${ }^{16}$ Biopoder se contrasta con el poder que viene "de arriba" o poder institucional, ejercitado por el Estado en forma de leyes.
} 
2. el nivel normativo, dentro del que se establecen reglas de interpretación de dichas representaciones, con el fin de indicar las posibilidades metafóricas más adecuadas. Aquí actúan varias doctrinas (religiosas, políticas, científicas, legales), que categórica e inequívocamente designan el significado de lo femenino en oposición a lo masculino,

3. el nivel institucional, en el que la identidad de género se va construyendo a través y dentro de las instituciones como parentesco, economía, política, ciencia, familia, mercado, religión etc.,

4. el nivel individual, en el que se establece la identidad subjetiva de las personas (Scott 1986, 1067-1069).

La propuesta de análisis de género basada en estos cuatro niveles se convierte en una herramienta útil también para el análisis de la relación entre el género y el control de la reproducción, en un contexto más amplio de la construcción social y simbólica de los procesos de la reproducción.

\subsubsection{Símbolos. La reproducción como un recurso simbólico para la construcción de la nación}

Cuando Scott se refiere a símbolos, habla de los referentes de la feminidad y la masculinidad existentes en una sociedad dada. Estos símbolos están íntimamente relacionados con la construcción simbólica de la nación y actúan dentro del aparato del Estado. Las interacciones de las categorías de nación/Estado y género/sexualidad han llamado la atención de varias teóricas feministas, porque hacen referencia a la categoría simbólica del otro (Mayer 1999, 2). Es decir, la identidad nacional que une a 
los miembros de la misma nación se construye en oposición a la construcción exclusiva del otro. De forma similar, la categoría del otro aparece con frecuencia en el pensamiento feminista (por ejemplo de Beauvoir 1982) que observa que lo femenino se ha ido construyendo históricamente a base de ser otro opuesto a lo masculino. Además, tanto nación vista como una comunidad imaginaria (Anderson 1991 citado por Mayer 1999, 1) como género, definido por Judith Butler (1999) como una categoría performativa, se basan en una constante repetición y actuación de normas, símbolos y formas (Sharp 1996, 98-99).

La nación se puede definir como una colectividad que comparte un pasado común y cree que también comparte un futuro (Enloe 2000, 45), cuyos miembros residen o desean residir en un particular territorio. El Estado, que es la organización política de la nación, se crea en base de la autoridad, mientras la nación en sí se forma a base de una identidad compartida. Todos los Estados modernos se basan en la identidad, porque la soberanía del Estado no se justifica solamente con el poder de una dinastía gobernante, y recae sobre la misma nación. Es necesario, pues, que las instituciones, la población y el territorio se conecten bajo una construcción cultural de la nación (Gehmacher 2006, 207-217), aunque estas relaciones pueden complicarse debido a la presencia de las minorías étnicas o religiosas. En esta construcción, los roles establecidos de género juegan un papel muy importante. Generalizando, las mujeres dentro de este tipo de discursos tienen un rol prevalentemente pasivo. Es decir, en cuanto los hombres se presentan como defensores de la nación, el rol de las mujeres es aquel de las posesiones valiosas de la nación, que necesitan ser protegidas 
y defendidas, pero no participan activamente del proceso de definición de la identidad nacional. Por otro lado, las mujeres reproducen la nación, tanto física como simbólicamente (Mayer 1999, 6). A través de los cuerpos de las mujeres se reproduce la prole de la nación, y también son las mujeres quienes principalmente educan y trasmiten la cultura. Por este motivo, los cuerpos de las mujeres constituyen la frontera simbólica de la nación. Por tanto, el control sobre la reproducción (en forma de anticoncepción o aborto) se inscribe en este marco simbólico.

Es interesante, también, observar cómo se radicalizan las dinámicas entre el control sobre la reproducción en los Estados fascistas y comunistas. En toda forma de organización social represiva, el control ejercido por el Estado sobre las ciudadanas y los ciudadanos es mucho más alto que en los países democráticos. Gisela Bock (1996, 235-236) afirma que en Alemania durante el periodo nazi, el Estado penalizaba severamente los abortos en las mujeres de "raza" aria, llevando a cabo a la vez esterilizaciones y abortos masivos practicados sobre las mujeres de entornos sociales o "razas" inferiores ${ }^{17}$. Las prácticas de severas limitaciones en cuanto al acceso a la anticoncepción y el aborto se pudieron observar en la Italia fascista y la España franquista, donde la prohibición del uso de la anticoncepción o la práctica de abortos se inscribía en los discursos pro-natalistas que acompañaban a los discursos de fuerza y vitalidad nacional en estos países ${ }^{18}$

\footnotetext{
${ }^{17}$ Véase también David, Fleischhacker y Hohn 1988.

${ }^{18}$ Véase Ruíz Salguero 2005 y Whitaker 2000.
} 
En el caso de los Estados comunistas el fuerte control que el Estado ejerce sobre las vidas reproductivas de las ciudadanas tiene su raíz en el protagonismo económico del Estado que transforma las relaciones sociales para incorporar a las mujeres al mercado laboral. Eso conlleva, por lo menos en teoría, la mayor posibilidad de empleo de la planificación familiar para reducir las tareas de las mujeres en la esfera privada. Procediendo a la destrucción parcial de la familia, y a su sustitución por los servicios estatales de cuidado de carácter limitado, los Estados comunistas apuestan por la figura de la madre-trabajadora (Moore 1999, 173). En cambio Funk $(1993,2)$ apunta que los Estados comunistas optaban por una deconstrucción de la división entre los ámbitos privados y públicos, porque el Estado entraba en las prerrogativas tradicionales de la familia para educar a las nuevas generaciones en ideología comunista. Un ejemplo de esta práctica puede ser el discurso estatal que presentaba a Stalin como padre de todos los hijos y todas las hijas de la Unión Soviética (Kulagina 2006, 145-155). En la práctica, las opciones de control de la fertilidad se limitaban al aborto en la mayoría de los Estados socialistas de la Europa del Este (excluyendo Rumanía, con fuertes políticas pro-natalistas bajo la presidencia de Nicolae Ceauşescu (Githens 1996, 55). Este fue el caso de Polonia en los años 1956-1989 donde la escasa accesibilidad a los métodos anticonceptivos, convertía la interrupción del embarazo en el principal método de planificación familiar (Hadley 1996, 39). 


\subsubsection{Normas. La religión católica y la planificación familiar}

El control sobre la reproducción en el nivel simbólico se realiza en forma de normas, tanto generales, en la esfera del sentido común en una sociedad determinada, como concretadas en leyes. Pero, como he señalado en la parte introductoria del capítulo, las normas relacionadas con el biopoder no siempre están institucionalizadas y provienen de numerosos centros de poder. Aquí abordaré una categoría de normas religiosas no provenientes del Estado, porque en los casos de Polonia e Italia constituyen una parte fundamental en cuanto al tejido de los comportamientos legítimos sobre el control de la reproducción.

En primer lugar, es imprescindible reconocer, que tanto dentro del cristianismo como de la Iglesia Católica, se pueden nombrar múltiples y a veces contradictorias posturas relacionadas con el papel de las mujeres y el empleo de la anticoncepción. En este estudio, me centro en la posición oficial de la Iglesia Católica, teniendo en cuenta que su interpretación o aplicación a la vida cotidiana de los católicos puede producir efectos distintos ${ }^{19}$

Para analizar la relación entre el género y el control de la reproducción en las líneas oficiales de la Iglesia Católica cabe observar que la aceptación o rechazo de prácticas anticonceptivas por parte de la teología católica tiene un carácter

\footnotetext{
${ }^{19}$ Como ejemplo de las prácticas católicas alternativas en cuanto al empleo de la anticoncepción se puede apuntar la organización estadounidense Catholics for Choice [Católicos por la Libre Elección], formada en 1973. Catholics for Choice populariza la opinión de que las mujeres tienen el derecho moral y legal de actuar de acuerdo con su conciencia personal en las materias de sexualidad y salud reproductiva. Véase www.catholicsforchoice.com, último acceso 12/07/2009.
} 
profundamente histórico, es decir, ha ido mudándose y reformulándose durante siglos $^{20}$. Por ejemplo, el aborto no se consideraba homicidio, tal como lo considera la Iglesia Católica contemporánea, hasta los finales del siglo XVII. Este cambio de postura fue debido, por un lado al desarrollo de la obstetricia, por otro lado se relacionaba con el dogma de la Inmaculada Concepción de la Virgen María, que reforzaba la teoría de la animación inmediata del feto, es decir en el momento de la concepción (Galeotti 2003, 97). De todas formas, las normas lanzadas por la Iglesia Católica que permanecen más o menos estables en cuanto a las políticas de género, se basan principalmente en la condición de la inferioridad de las mujeres y el carácter pecaminoso de las relaciones sexuales, derivadas de las obras de Santo Tomás de Aquino y San Agustín. Esta visión cambió ligeramente a principios del siglo $\mathrm{XX}$, motivada por la aparición de movimientos sociales relacionados con el socialismo y sufragismo que reformulaban el papel de las mujeres en la sociedad. La nueva postura de la Iglesia Católica apuesta por la celebración de la feminidad como complementaria a la masculinidad. Desde esta posición, las mujeres son por naturaleza diferentes a los hombres, y se pueden realizar plenamente sólo como madres y cuidadoras (Curran 2006, 133-135). Por otro lado, en cuanto a las relaciones sexuales, según la doctrina de la Iglesia Católica, su principal objetivo es la concepción de la prole, y por ello son legítimas exclusivamente dentro del matrimonio. Este enfoque se traduce en la oposición estable de la Iglesia Católica a la anticoncepción. Mientras muchas iglesias protestantes se han posicionado desde principios del siglo $\mathrm{XX}$ a favor de las prácticas anticonceptivas en las relaciones de

\footnotetext{
${ }^{20}$ Véase Hurst 1989.
} 
matrimonio ${ }^{21}$, dentro de la doctrina católica los únicos métodos aceptados para los cónyuges son los métodos "naturales", es decir aquellos métodos que se basan en la observación del ciclo de fertilidad de la mujer y la restricción de las relaciones sexuales durante la fecha prevista para la ovulación (Ruether 2008, 186), una "naturalidad", tal como la entendemos ahora, que es también una construcción social e histórica.

Una posibilidad de reformulación de la posición de la Iglesia Católica acerca de la anticoncepción ocurrió después de la comercialización de la píldora anticonceptiva en Estados Unidos en 1960. El papa Pablo VI creó en 1963 una Comisión del Control de Natalidad, compuesta por la jerarquía de la Iglesia, médicos y católicos seculares, para que generara opiniones sobre la posibilidad de empleo de la píldora anticonceptiva en las familias católicas. El informe oficial de la Comisión apoyaba la aceptación para la píldora; se la consideraba un método de carácter "natural", dado que "mantenía" el ciclo menstrual femenino (Marks 2001, 219). Claramente, esta cualidad de la píldora actualmente no la clasifica como un método "natural".

A pesar de esta opinión, Pablo VI, basándose en un informe alternativo de algunos obispos, lanzó en 1968 la encíclica Humanae Vitae en la que reafirmó la posición conservadora de la Iglesia Católica en contra de la anticoncepción (Ruether $2008,187)$.

\footnotetext{
${ }^{21}$ La progresiva aceptación de la anticoncepción está en un cierto modo de acuerdo con la "mentalidad" protestante, es decir, la responsabilidad de las personas por sus condiciones materiales. En este sentido el número de hijos e hijas tiene que adaptarse a las posibilidades económicas de mantenerlos. Del mismo modo, la atención protestante al contacto individual e interpretación personal de la Biblia refuerza la dimensión de la conciencia personal, también en cuanto a la sexualidad y reproducción.
} 
En Europa Occidental y Estados Unidos en la década de cambios fuertes hacia la emancipación política y económica de las mujeres impulsada por la segunda ola del feminismo, la norma que marcaba la prohibición de la anticoncepción fue rechazada por los católicos laicos, produciendo una fuerte ruptura entre la doctrina oficial de la Iglesia Católica y la práctica de sus miembros (Marks 2001, 220). Frente a esta ruptura en cuanto al uso de los métodos anticonceptivos, la Iglesia reafirmó su posición sobre el aborto, cuya prohibición total e identificación con homicidio constituye una de las posiciones más emblemáticas y reconocibles de la Iglesia Católica contemporánea ${ }^{22}$.

Resumiendo, la producción de normas en el campo de género y anticoncepción proviene de múltiples centros del poder, entre ellos la Iglesia Católica. Las normas de la Iglesia cambian dependiendo del contexto histórico y geográfico. Históricamente, la Iglesia Católica tomó posiciones variadas acerca de la anticoncepción y el aborto, y la condena especifica del aborto como homicidio es un concepto bastante reciente en la doctrina católica. Es preciso recordar, que en la formulación de dichas posiciones influyen factores como los discursos científicos o los roles de género establecidos en un momento histórico dado.

\footnotetext{
${ }^{22}$ Para más información sobre los católicos y la historia de la anticoncepción en Estados Unidos, véase Woodcock 2005.
} 


\subsubsection{Instituciones. Medicalización del control sobre la reproducción y sus consecuencias para la relación entre el control de la reproducción y el género}

No cabe duda que el sector sanitario desempeña una función central en cuanto a las prácticas del control de la reproducción. Es la profesión médica la que controla el acceso al aborto y la anticoncepción hormonal. Además, el sector sanitario, implicado en la atención a la salud reproductiva, produce y reproduce su propio discurso sobre la reproducción. Dicha implicación, que en la actualidad se da por sentada, es el resultado de un largo proceso de medicalización de las prácticas y los métodos del control de la reproducción que tuvo lugar desde mediados del siglo XIX en Europa y Estados Unidos. Por medicalización se entiende:

\footnotetext{
el proceso de carácter cada vez más global, en el cual la biomedicina ha conseguido la autoridad para redefinir y tratar un panorama de eventos de la vida personal y de carácter social como problemas médicos para, en definitiva, usurpar el dominio sobre el cuerpo (Georges 2008, 4).
}

La medicalización es una parte fundamental de la modernidad y una de las formas de la actuación del biopoder influida por matices de género. Estos rasgos se ven de manera muy clara en los procesos de la reproducción, en particular en el fuerte vínculo ideológico entre las mujeres y la maternidad, la ciudadanía de las mujeres y la reproducción como una contribución al cuerpo de la nación.

La medicalización de la reproducción y de las prácticas de su control se puede analizar a niveles diferentes. A un nivel de más general es preciso ver el proceso de institucionalización de saberes sobre el cuerpo femenino y su incorporación en la medicina oficial, que según Galeotti $(2003,79)$ significaba en gran parte la trasferencia 
de poder de las matronas o "mujeres sabias" hacia los cirujanos y médicos varones, practicantes de la medicina oficial. En relativamente poco tiempo las matronas dejaron de tener el privilegio de asistir al parto y atender a las mujeres en el embarazo y el post-parto de manera autónoma, y se convirtieron en asistentes a disposición de los cirujanos varones, cuya ventaja técnica sobre ellas era el hecho de poseer un titulo y una formación de base teórica. Este giro se produce en los distintos países de Europa a lo largo de los siglos XVIII y XIX (Grabes 2001; Marland 1993 y 1997).

A un nivel más particular hay que tener en cuenta varios procesos de la medicalización del control de la reproducción. Según Riddle (1997, 206-227), la institucionalización de saberes sobre la anticoncepción se inscribe en la tendencia general de tecnologización y dominio del discurso científico en sociedades postmodernas, pero los primeros discursos de carácter público y masivo sobre la anticoncepción provenían mayoritariamente de centros no relacionados con la medicina en sentido estricto, como el movimiento neo-maltusiano, o personas que se acercaban a la planificación familiar desde la práctica, con o sin vocación feminista. El movimiento neo-maltusiano, según Jütte $(2008,3)$, dio a finales de siglo XIX y principios de siglo XX el impulso para el desarrollo del discurso científico sobre la planificación familiar como práctica universal. Entonces la ciencia del control de la reproducción se producía alrededor de eugenesia. Esta práctica, cuya prioridad era mejorar la raza humana, propagaba el aumento de la reproducción de individuos más aptos (eugenesia positiva) y limitación de la misma en individuos socialmente 
desventajados (los pobres, las personas con "insuficiente" inteligencia, de razas diferentes a la blanca etc.: eugenesia negativa) ${ }^{23}$.

La percepción contemporánea de la eugenesia está afectada por las atrocidades de la experiencia práctica y extrema de la eugenesia estatal en la Alemania nazi, pero es preciso recordar que algunas de las pioneras de la planificación familiar combinaban sus creencias eugenésicas con un profundo feminismo. Este fue el caso de Margaret Sanger, la precursora de la planificación familiar en Estados Unidos y la fundadora de la primera consulta anticonceptiva en este país en 1916. Sanger veía la anticoncepción como remedio para la sobrecarga reproductiva de las mujeres pobres y postulaba la emancipación de las mujeres a través de la planificación familiar (Ortiz 2009 , 3). Marie Stopes, fundadora de la primera clínica de planificación familiar en Inglaterra (1921) fue miembra de la Sociedad Eugenésica inglesa (McKibbin 2008, 14). En su primera obra, Married love [Amor conyugal] de 1918 Stopes destacaba el derecho de las mujeres a la satisfacción sexual en el matrimonio ${ }^{24}$.

Para los historiadores y las historiadoras de la anticoncepción el ambiente médico a principios de siglo XX generalmente no mostraba el interés por las prácticas anticonceptivas. Las primeras iniciativas de la planificación familiar provenían de varios ámbitos no necesariamente relacionados con la medicina. Mientras Aletta Jacobs,

\footnotetext{
${ }^{23}$ Para más información sobre la historia de la eugenesia en Estados Unidos, véase Broberg y RodHansen 1996; Kline 2001; Black 2003.

${ }^{24}$ Para una presentación completa de las pioneras de la planificación familiar, véase Huston 1992 u Ortiz 2009.
} 
fundadora de la primera clínica anticonceptiva en Holanda en 1882 era médica, y Margaret Sanger era de profesión enfermera, Mary Stopes era científica (paleontóloga y geóloga) sin educación médica (Ortiz 2009, 3). Solinger $(2001,38)$ cuando habla de la participación activa de los médicos estadounidenses en el siglo XIX en el proceso de la criminalización del aborto y la anticoncepción, la denomina como una estrategia para excluir las matronas y practicantes de medicina no institucionalizada de la atención a la reproducción.

Marks $(2001,117)$ señala que la incorporación de la anticoncepción en la práctica médica tuvo lugar con la píldora anticonceptiva, siendo un método que necesitaba atención medica previa a su empleo y durante el mismo. En la actualidad, los métodos que exigen una supervisión médica (métodos hormonales, DIU) compiten con los métodos accesibles sin la misma (preservativos).

\subsubsection{Subjetividad individual}

Habiendo señalado varias influencias que resultan útiles para el análisis de la anticoncepción y el aborto desde el punto de vista de género, pasaré a plantear la cuestión de la anticoncepción dentro del contexto de la subjetividad de las mujeres. Scott, cuando define este nivel de análisis, hace referencia a las biografías como fuentes de historias personales que permiten a los historiadores y a las historiadoras 
Esta subjetividad, como apuntan las teorías feministas de interseccionalidad (intersectionality) no se crea en un vacio social ${ }^{25}$. Al contrario, la subjetividad individual se forma en un contexto histórico, geográfico y social concreto, teniendo en cuenta categorías de diferenciación como raza, clase, edad, o sexualidad, factores que pueden constituir fuentes de discriminación o privilegio.

Como se verá en los siguientes capítulos, tanto el discurso feminista italiano como polaco hacen referencia a las difíciles experiencias personales de las mujeres que se encuentran en la situación del acceso limitado a los métodos anticonceptivos y el aborto voluntario. Estos testimonios ocupan una posición central sobre todo en el discurso feminista polaco, que hace pública la experiencia de mujeres como Alicja Tysiąc, que perdió la vista tras negársela un aborto por motivos de salud o el matrimonio Wojnarowscy, que no pudieron realizar los análisis prenatales durante el segundo embarazo y en consecuencia son padres de dos hijos con graves malformaciones genéticas.

\subsection{Definición de discurso de Foucault}

Como último elemento del marco teórico de este trabajo, quiero volver a la definición foucaultiana del discurso como:

conjunto institucionalizado de ideas, actitudes, acciones, creencias y prácticas que delimitan las maneras plausibles de pensar y hablar sobre un campo de saber específico (Foucault 1997, 33-64).

\footnotetext{
${ }^{25}$ Para más información sobre la teoría de la interseccionalidad, véase Yuval-Davis, 2006.
} 
Un discurso feminista sobre el aborto y la anticoncepción engloba por tanto ideas feministas acerca del aborto, la anticoncepción y la reproducción en general; actitudes de las feministas acerca de la misma y acerca de las formas en las que se la regula en una sociedad dada; creencias relacionadas con el aborto, la anticoncepción pero también el embarazo, la maternidad y el feto; y acciones que el movimiento feminista toma para intervenir en la forma del debate sobre el aborto y la anticoncepción. Todos estos elementos se reflejan en el lenguaje utilizado, cuya importancia en cuanto a las opciones pro-choice y pro-vida ${ }^{26}$. Además, el conjunto de los elementos del discurso, expresados en el lenguaje, para poder construir sujetos tienen que tener una dimensión comunicativa, es decir, el feminismo comunica su posición sobre el aborto y la anticoncepción con la esperanza de producir efectos sociales y políticos.

\subsection{Fuentes}

Para realizar este trabajo, empecé por una búsqueda sistemática y lectura de bibliografía científica para estudiar los debates sobre el control de la reproducción en Polonia e Italia y conocer los agentes involucrados en ellos. Para ello, he utilizado las fuentes (monografías y libros editados) de la Biblioteca del Instituto de Estudios de la Mujer de la Universidad de Granada y otras bibliotecas de esta universidad, además de las fuentes de la Biblioteca de Women's Studies Center de la Universidad de Łódź, de la Biblioteca Italiana delle Donne de Bolonia y Biblioteca de la Florida International

\footnotetext{
${ }^{26}$ Comentado brevemente, la opción pro-choice apoya el derecho de la mujer a tener una posibilidad de terminar un embarazo no deseado, mientras el movimiento pro-vida resalta al feto que tiene que disfrutar, a su juicio, de la plenitud de derechos considerándolo un ser humano desde el momento de la concepción.
} 
University, Miami. Al mismo tiempo, he realizado una búsqueda en las bases de datos online de artículos de revistas académicas accesibles a través de la Universidad de Granada: MUSE y JSTOR.

Después de la lectura de la bibliografía, que me permitió analizar directamente los debates sobre el aborto y la anticoncepción en Polonia e Italia, di comienzo a una búsqueda sistemática de fuentes primarias. Localicé las fuentes italianas principalmente en los archivos de la ya mencionada Biblioteca Italiana delle Donne de Bolonia, donde he trabajado durante mi periodo de movilidad en la Universidad de Bolonia durante el curso académico 2008/2009. Los materiales que he utilizado están parcialmente digitalizados y se encuentran en la sección electrónica de la página web de la biblioteca. Las fuentes polacas proceden de la Biblioteca de la Universidad de Łódź, Polonia, de mi archivo personal, y de la páginas web de la Fundación Feminista Efka (Revistas Pełnym Głosem y Zadra) y Federación Polaca por las Mujeres y la Planificación Familiar (Revista Mam Prawo).

\subsubsection{Italia}

He utilizado dos tipos de fuentes: revistas feministas y manifiestos feministas. El discurso feminista de la época se formula dentro de la prensa especializada, es decir, prensa con clara vocación feminista que muchas veces es auto-gestionada por el colectivo de redactoras y se mantiene independiente. Otra forma de comunicación utilizada por las feministas son los manifiestos, muchos de los cuales se publican también en la prensa feminista, aunque otros son panfletos o comunicados que 
acompañan a las manifestaciones u ocupaciones feministas. Como se verá, las fuentes que he utilizado reflejan el carácter independiente del movimiento feminista italiano de la época, es decir su práctica del activismo autónomo, alejado en esta fase de cualquiera de las fuerzas políticas.

He utilizado diez manifiestos del periodo 1970-1979, que representan a varias organizaciones feministas de la década de 1970 y su activismo dirigido a garantizar a las mujeres italianas lo que hoy llamaríamos derechos reproductivos. Todos los manifiestos que he utilizado excepto los manifiestos de Rivolta Femminile proceden de la recopilación de los textos del feminismo italiano sobre aborto y anticoncepción editada por Cristina Damiani et. al 1981. Los manifiestos analizados son los siguientes:

Rivolta Femminile y Carla Lonzi. 1974 [1970]. Sputiamo su Hegel. En Sputiamo su Hegel. La donna clitoridea e la donna vaginale. Milano: Rivolta Femminile, 13-22.

Manifiesto Sputiamo su Hegel [Escupimos sobre Hegel] fue el primer manifiesto feminista publicado en Italia $(06 / 1970)^{27}$.

Rivolta Femminile. 1991 [1972]. Sessualità femminile e l'aborto. En Italian feminist thought: A reader, ed. Sandra Kemp, Paola Bono, 37-40. Oxford: Basil Blackwell.

Este manifiesto fue, que como señala Calloni $(2001,187)$ el primer manifiesto feminista italiano que se centraba en los temas de la reproducción.

\footnotetext{
${ }^{27}$ Aquí utilizo una edición de los textos de Rivolta Femmile de Lonzi de 1972. El manifiesto está publicado online en castellano por la organización fem-e-libros (2004), véase http://www.nodo50.org/herstory/textos/Escupamos\%20sobre\%20Hegel.pdf, último acceso 01/09/2009.
} 
Comitato Romano per l'Aborto e la Contraccezione. 1981 [1975]. Documento constitutivo. En Oltre l'aborto. Posizioni e documenti del movimento delle donne. Metodi di controllo della fecondità. Chiesa e "dissenso". La legge e le proposte di modifica, ed. Cristina Damiani, et al, 19-20. Roma: Cooperativa Editoriale Ottanta.

CRAC fue fundado en Roma (09/1975) con el objetivo de promocionar la práctica de autogestión del aborto, implementación del aborto terapéutico en las estructuras de la sanidad pública y la promoción de la anticoncepción.

Comitato Romano per l'Aborto e la Contraccezione. 1981 [1976]. Piattaforma per i consultori. En Oltre l'aborto..., 21-24.

Es un documento de la CRAC en el que la organización presenta sus recomendaciones sobre los consultorios feministas.

Unione Donne Italiane. 1981 [1976]. Aborto come violenza. En Oltre l'aborto..., 24-34.

Es un documento en el que UDI, una de las organizaciones feministas italianas más destacadas de la época, expone su postura acerca del aborto.

Cristiani per il Socialismo. 1981 [1976]. Dal documento uscito dal seminario nazionale. En Oltre l'aborto..., 34-43.

Es el sumario del documento final del Seminario Nazionale dei Cristiani per il Socialismo organizado por las mujeres.

Dal opuscolo "Roma Policlinico": un reparto occupato dalle donne. 1981 [1978]. En Oltre l'aborto..., 46-52.

Es un folleto informativo sobre una ocupación de un departamento de ginecología en un hospital romano. 
Movimiento di Liberazione della Donna. 1981 [1978]. Manifesto (A tutte le donne...). En Oltre l'aborto..., 53.

Es el manifiesto de la organización feminista de carácter separatista MDL.

Movimiento di Liberazione della Donna. 1981 [1979]. Documento (Aborto libero e gratuito...). En Oltre l'aborto..., 54-57.

Es un manifiesto elaborado por MDL pocos meses después de la legalización del aborto voluntario en Italia.

Coordinamento Consultori Governo Vecchio. (1981 [1979]). Lettera aperta alle Reggione Lazio. En Oltre l'aborto..., 57-59).

Es una carta abierta de la coordinación de los consultorios de Governo Vecchio a las autoridades de la región de Lazio.

Además, he utilizado artículos y noticias de tres revistas feministas de la década de 1970: Effe, Noi Donne y Quotidiano Donna. La enumeración completa de los artículos que he utilizado se encuentra en el apartado de fuentes.

Effe (de la primera letra de la palabra feminismo) es una revista feminista que se publicó en Italia durante casi diez años, de 1973 a 1982. A partir de 1975 fue autogestionada por la cooperación de las redactoras y mantenida gracias a las subscriciones y contribuciones de las lectoras. Effe se posicionaba como una revista que abarcaba todos los aspectos de la vida femenina y participaba activamente en los grandes debates de la década de 1970: sobre el aborto y la violencia sexual (Biblioteca Digitale delle Donne, http://www.bibliotecadigitaledelledonne.it; último acceso 
14/08/2009). Para este trabajo, he revisado once números de la revista Effe, siguiendo el criterio de elegir los números en los que los temas del aborto y la anticoncepción fueron más representados: tres números de 1973, tres números de 1974 y cinco números de 1975.

Noi Donne, la revista feminista más antigua en Italia, nació en Francia en 1937 como una expresión de las mujeres anti-fascistas emigrantes. En Italia la revista salió de la clandestinidad en 1944 y en 1945 se convirtió en la revista de la UDI. En la etapa inicial fue distribuida mensualmente, en los años 1970 fue semanal, para volver a ser mensual en 1981 (Noi Donne, http://www.noidonne.org; último acceso 10/09/2009). En la revista Noi Donne se publicó el ya mencionado artículo I figli che non nascono [Los hijos que no nacen] que en 1973 (Flamigni 2008, 53) contribuyó a la apertura del debate social sobre el aborto. Para este trabajo he revisado dos números de la revista: el número especial dedicado a la maternidad (35/1974) y el número especial dedicado al aborto (16/1979).

Quotidiano Donna fue establecido en 1978 como un diario del MDL, organización de feminismo radical y autónomo italiano. Fue auto gestionada por la redacción y financiada por las lectoras. Luego se convirtió en un semanal y finalmente cerró en 1982. Para este trabajo, he revisado las portadas del diario de los años 1978 y 1979, facilitadas en forma digital por la Biblioteca Italiana de las Mujeres (http://www.bibliotecadigitaledelledonne.it; último acceso 14/08/2009). Considero estas portadas una fuente de información relevante, ya que en las portadas de este 
diario se destacaban los temas más importantes para cada número. En la figura 5 reproduzco una de estas portadas (número 11/1978).

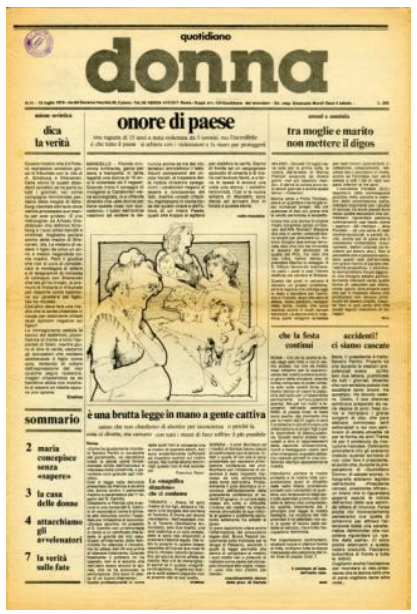

Figura 5 La portada de Quotidiano Donna, número 11/1878, http://www.bibliotecadigitaledelledonne.it; último acceso 14/08/2009.

\subsubsection{Polonia}

El discurso feminista polaco, en general, es el resultado de la producción de un grupo de mujeres con nombres conocidos y no de colectivos u organizaciones. A diferencia del feminismo italiano, el feminismo polaco no se expresa por medio de los manifiestos. Para analizar su discurso, he utilizado una selección de fuentes heterogéneas, provenientes tanto del feminismo académico como del feminismo activista, y publicadas entre 1989 y 2004 . He utilizado por un lado libros, capítulos de libros, artículos feministas de la prensa general, e informes sobre el aborto y la educación sexual editados, en su mayor parte, por la Federación Polaca por las Mujeres y la Planificación Familiar, la principal organización que se dedica a promocionar los derechos reproductivos en Polonia. Por otro lado, he revisado la 
prensa feminista y la revista electrónica de divulgación de la Federación Polaca por las Mujeres y la Planificación Familiar.

Las publicaciones del primer grupo fueron producidas por las feministas más destacadas en Polonia, como Agnieszka Graff, Kinga Dunin, Kazimiera Szczuka, Małgorzata Fuszara, Wanda Nowicka, y por las autoras relacionadas con la Federación Polaca por las Mujeres y la Planificación Familiar. Son las siguientes:

Fuszara, Małgorzata. 1991. Will the abortion issue give birth to feminism in Poland? En Women's Issues in Social Policy, eds. Mavis Maclean y Dulcie Groove, 205-228. London: Routledge.

Małgorzata Fuszara es una teórica de derecho, autora de varias elaboraciones, publicadas en inglés, sobre el aborto en Polonia. Este artículo es uno de los primeros publicados sobre la cuestión del aborto en Polonia en una edición feminista europea.

Nowicka, Wanda. 1993. Ban on abortion in Poland. Women's Global Network for Reproductive Rights Newsletter (43): 49.

Wanda Nowicka es presidenta de la Federación y una de las figuras más destacadas del movimiento feminista y de los derechos reproductivos polaco. Con este artículo, posterior a la aprobación de la Ley Anti-aborto, comunica este hecho a la comunidad internacional.

Nowicka, Wanda. 1996. Skutki ustawy antyaborcyjnej z 1993 [Las consecuencias de la Ley Anti-aborto de 1993]. Federación Polaca por las Mujeres y la Planificación Familiar. Accesible online en http://www.federa.org.pl/publikacje/raporty/rapab96.htm; último acceso 12/09/2009 
Es el segundo informe de la Federación sobre las consecuencias de la Ley Anti-aborto, sobre todo los abortos clandestinos y negación por parte de los médicos de practicar abortos terapéuticos legales en los hospitales públicos.

Godlewska, Barbara, y Solik, Aleksandra, eds. 2001. Piekło kobiet. Historie współczesne [El infierno de mujeres. Las historias contemporáneas]. Warszawa: Federación Polaca por las Mujeres y la Planificación Familiar. Accesible online en http://www.federa.org.pl/publikacje/podrecznik/pieklo_kobiet/index.htm; último acceso 12/09/2009.

Es un libro que recoge las historias contadas por las mujeres en el Primer Tribunal Sobre el Derecho de las Mujeres al Aborto, organizado en 2001 por la Federación Polaca por las Mujeres y la Planificación Familiar.

Dunin, Kinga. 2001. Dwa tysiące na skrobankę [Dos mil para la intervención]. Wysokie Obcasy [Tacones Altos] (110). Accesible online en http://www.wysokieobcasy.pl/wysokie-obcasy/1,96856,320252.html; último acceso 10/09/2009).

Es un artículo de una de las feministas más reconocidas en Polonia sobre la facilidad de conseguir un aborto ilegal, publicado en el suplemento para las mujeres del mayor diario liberal polaco.

Koral, Jolanta. 2001. Tutaj lekarz jest Bogiem [Aqui el médico es Dios]. Wysokie Obcasy (145). Accesible online en http://www.wysokieobcasy.pl/wysokieobcasy/1,53662,553147.html; último acceso 10/09/2009).

Es un artículo de una periodista feminista sobre las barreras para el acceso al aborto legal y los análisis prenatales en Polonia.

Graff, Agnieszka. 2001. Znikająca kobieta. Polskie rozmowy o prawie do aborcji [La mujer desaparece. Las conversaciones polacas sobre el derecho al 
aborto]. En Świat bez kobiet. Płeć w polskim życiu publicznym [El mundo sin mujeres. El género en la vida pública polaca] Warszawa: W. A. B, 115-151.

Agnieszka Graff es una de las feministas académicas más reconocidas en Polonia, su libro Świat bez kobiet fue la primera publicación feminista que logro un éxito importante en ventas.

Nowicka, Wanda. 2003. Wychowanie seksualne po polsku [Educación sexual en Polonia]. Federación Polaca por las Mujeres y la Planificación Familiar. Accesible online en http://www.federa.org.pl/publikacje/mat_info/zeszyt3.pdf; último acceso 12/09/2009.

Es el primer informe de la Federación en el que se analiza detalladamente el carácter de la educación sexual en Polonia en relación con la Ley Anti-aborto y el acceso a la anticoncepción.

Federacja na Rzecz Kobiet i Planowania Rodziny 2004. [Federación Polaca por las Mujeres y la Planificación Familiar]. Piekło kobiet trwa [El Infierno de mujeres continua]. Accesible online en http://www.federa.org.pl/publikacje/pieklo2.pdf; último acceso 12/09/2009.

Es la segunda edición del libro de testimonios relacionados con el aborto y la anticoncepción recogidos en el Segundo Tribunal por el Derecho de las Mujeres a la Autonomía Sexual, organizado por la Federación Polaca por las Mujeres y la Planificación Familiar.

Szczuka, Kazimiera. 2004. Milczenie owieczek. Rzecz o aborcji [El silencio de los corderos. Sobre el aborto]. Warszawa: W. A. B.

Es una reflexión de una de las feministas intelectuales más reconocidas en Polonia sobre el aborto. 
En el segundo grupo de fuentes he incluido los artículos relacionados con el aborto y la anticoncepción de tres revistas feministas y de planificación familiar feminista polacas:

Pełnym Głosem [En Voz Alta] fue la primera revista feminista polaca. Se publicaron cinco números entre 1993 y 1997. Gestionada por el colectivo feminista Efka de Cracovia, fue una revista en que se juntaban reflexiones de carácter teórico, político y práctico sobre el feminismo y la situación de las mujeres en Polonia.

Para este trabajo, he revisado los cinco números de la revista, accesibles en la página del colectivo Efka http://efka.org.pl/index.php?action=p spt (último acceso 20/08/2009), donde se encuentran parcialmente digitalizados. La figura 6 presenta una de las portadas de la revista Pełnym Głosem (número 2/1994).

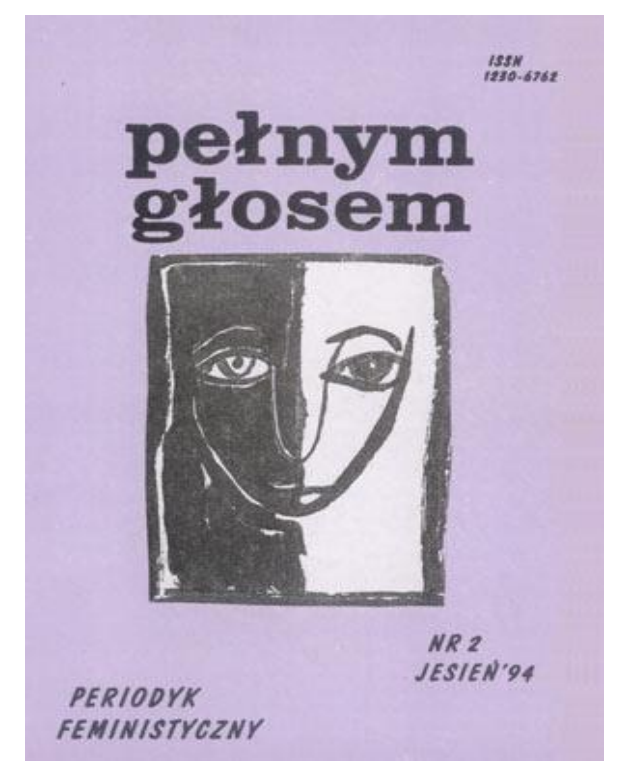

Figura 6 Portada de la primera revista feminista polaca, Pełnym Głosem 2/1994. El número dedicado al aborto. Imagen tomada de la página de la Fundación Efka, http://efka.org.pl/index.php?action=p spt; último acceso $13 / 09 / 2009$. 
Zadra [Astilla] es la continuación de Pełnym Głosem, cuyo primer número salió en 1999. Es la única revista feminista que se puede encontrar ahora en el mercado de prensa en Polonia, dirigida por Beata Kozak. No es una revista académica, pero contiene tanto elaboraciones teóricas de las cuestiones de interés feminista como relaciones políticas.

Para este trabajo he revisado dieciocho números de Zadra que se han publicado entre 1999 y 2004, accesibles en la página del colectivo Efka http://efka.org.pl/?action=z spt (último acceso 20/08/2009), donde se encuentran parcialmente digitalizados.

Mam Prawo [Mi Derecho] de la Federación Polaca por las Mujeres y la Planificación Familiar es una revista de carácter divulgativo de la mayor organización polaca de planificación familiar feminista. Su primer número se público en papel en 1995, luego desde 1998 hasta 2007 la revista fue publicada paralelamente en papel y online en la página de la Federación. Desde 2007, Mam Prawo se publica solamente online. La revista trata los temas del ámbito de los derechos reproductivos en Polonia y en el mundo.

Para este trabajo he revisado veinte portadas (o páginas principales) de la revista Mam Prawo, publicadas entre 1998 y 2004. Las he consultado en su versión online en la página web de la Federación. Igual que en el caso de Quotidiano Donna italiano, considero estas portadas una fuente de información relevante, ya que proporcionan 
los temas más destacados para cada número de la revista. En la figura 7 presento una de las portadas de la versión online de la revista Mam Prawo (número 2/1998).
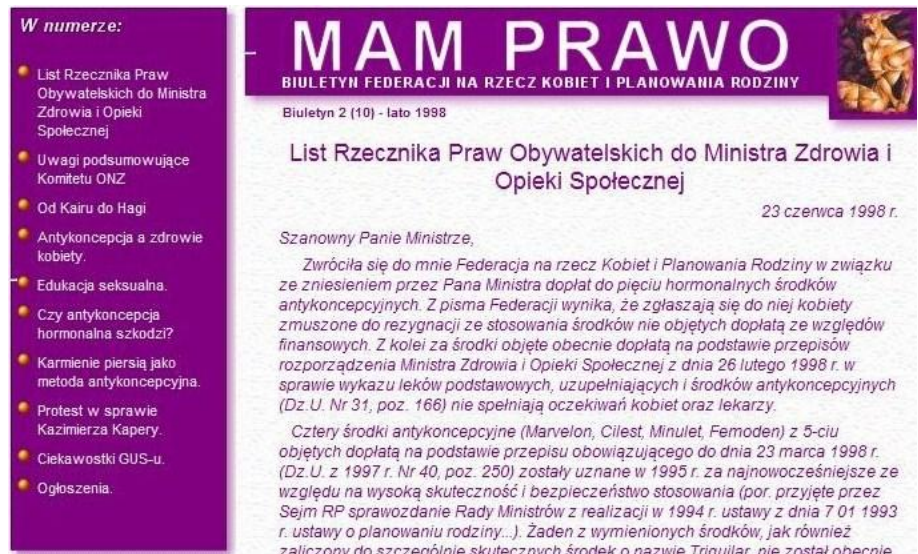

List Rzecznika Praw Obywatelskich do Ministra Zdrowia i Opieki Społecznej

Szanowny Panie Ministrze,

Zwrócita siẹ do mnie Federacja na rzecz Kobiet i Planowania Rodziny w związku ze zniesieniem przez Pana Ministra doplat do pięciu hormonalinych srodków antykoncepcyjnych z pisma Federacj wynika, ze z głaszają się do niej kobiely

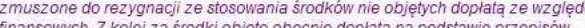
rozporzadzenia linistra Zdrowia i Opiki Spolecznei z dnia 26 lutego 1998 s sorawie wykazu leków podstawowych uzupetniających iśrodków antykoncepcying h (Dz.U. Nr 31, poz. 166) nie spelniają oczekivań kobiet oraz lekarzy.

Cztery środki antykoncepcyine (Marvelon, Cilest, Minulet, Femoden) z 5-ciu objętych doptata na podstawie przepisu obowiazujacego do dnia 23 marca 1998 r. (Dz.U. z 1997 r. .Nr 40, poz. 250) zostaly uznane w 1995 r. za najnowocześniejsze ze wzglẹdu na wysoką skutecznosci bezpleczenistwo stosowania (por, przyjęte przez Sejm RP sprawozdanie Rady Ministrow z realizacji W 1994 r. ustawy z dnia 7011993 r. ustawy o planowaniu rodziny...j, zaden z wymienionych srodkow, jak rowniez

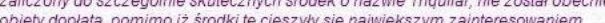
objęty doplat.
kobiet.

Figura 7 Publicación online de la revista Mam Prawo 2/1998 en la página web de la Federación Polaca por las Mujeres y la Planificación Familiar, http://www.federa.org.pl/mamprawo.php?catid=163\&lang=1; último acceso $12 / 09 / 2009$.

\subsection{Método de análisis de los debates y discursos acerca del aborto y la anticoncepción en Polonia e Italia}

Para cumplir el objetivo de conocer los debates sobre la reproducción y el aborto en Polonia e Italia en los periodos planteados y, específicamente, conocer el papel y el discurso del movimiento feminista producido en estos contextos, he realizado dos tareas.

En primer lugar, a partir de la bibliografía he reconstruido los debates sobre el control de la reproducción en ambos países, ubicándolos en sus contextos históricos. Consecuentemente, he aplicado el modelo de Joan Scott para describir los agentes que participan en la creación de estos debates, y he relacionado los modelos de feminidad dominantes con la construcción simbólica de la nación (nivel simbólico), el papel de la 
Iglesia Católica (nivel normativo), y el rol desempeñado por la profesión médica (nivel institucional).

En segundo lugar, una vez reconstruidos los debates sobre el aborto y la anticoncepción, he utilizado las fuentes primarias para conocer el papel del movimiento feminista en ellos, y el discurso que este movimiento ha producido acerca de la anticoncepción y el aborto, entendiendo discurso según lo ha definido Foucault (1987).

Por último, he comparado los debates y discursos feministas acerca del control de la reproducción en Polonia e Italia, buscando las posibles semejanzas y diferencias, y teniendo en cuenta los distintos contextos históricos y geográficos. 


\section{Debates y discursos sobre aborto y anticoncepción en Italia (década de 1970)}

\subsection{Los debates acerca de la reproducción en Italia en el siglo XX}

\subsubsection{Contexto histórico}

Hasta la segunda mitad del siglo XIX en la Península Italiana existían repúblicas, principados y reinados locales que se sometían a la regla extranjera (española y austrohúngara). En 1861 Italia se unificó como país bajo el sistema político de monarquía constitucional, aunque se mantuvieron importantes diferencias culturales, lingüísticas y económicas. Durante la primera guerra mundial Italia se unió a la oposición contra Alemania y Austro-Hungría, apoyando el Triple Entente en 1915. Después de la guerra entre 1919 y 1921 se formó en Italia un partido fascista dirigido por Benito Mussolini, que tomó el poder en 1922. Mussolini, o el Duce (su título oficial) progresivamente se convirtió en la cabeza del Estado nacionalista, militarista y pronatalista, que contaba desde 1929 con el apoyo de la Iglesia Católica. Hacia finales de la década de 1930, Italia se acercó a la Alemania Nazi y en 1940 se sumó a la segunda guerra mundial a su lado, donde permaneció hasta 1943, cuando el rey mandó el encarcelamiento de Mussolini y empezó las negociaciones con los países aliados. Después de la liberación de Italia en 1945, el país se convirtió en república en 1946 y en 1948 adoptó una nueva constitución (Davis 1997). En la década de 1950 y 1960 Italia se transformó en un país industrializado y urbano, que dio lugar a un boom económico. Durante la mayor parte de la segunda mitad de siglo XX Italia estuvo gobernada por la Democracia Cristiana (DC) con la agenda política del centro, que incluyó a Italia en el grupo de los países fundadores de Comunidad Europea del Carbón 
y del Acero, una organización económica que constituyó el pilar para la creación de la Unión Europea. El periodo crucial para la modernización italiana fue la década de 1970 (Gaiotti de Biase 2004), que es el periodo de la máxima importancia de movimientos sociales, sobre todo el movimiento feminista, y la deconstrucción de algunas leyes fascistas que permanecían en vigor hasta entonces. En la década de 1980, el primado de la democracia cristiana fue sustituido por un sistema de pentapartito o amplia coalición gobernante. En los 1990, la Democracia Cristiana desapareció como resultado de intensos escándalos de corrupción.

\subsubsection{Leyes sobre el aborto y la anticoncepción en Italia}

En el código penal fascista de 1930 (Codice Rocco) el aborto fue definido como delito en todos los casos excepto para proteger la vida de la mujer embarazada. El aborto fue definido como un crimen contra "la continuidad, integridad y salud de la raza" (Calloni, 2001, p. 182). El mismo código prohibía la difusión de la información sobre los métodos anticonceptivos, que podrían ser prescritos exclusivamente por razones médicas (Perez Delgado y Livi-Bacci 1993, 165) y desconsideraba la violación como delito si el violador proponía el matrimonio a su víctima.

Después de la segunda guerra mundial Italia adoptó una constitución nueva, pero precisamente las leyes fascistas que regulaban las cuestiones relacionadas con la reproducción se mantuvieron en vigor. Sin embargo, el incumplimiento de estas leyes no fue perseguido, sobre todo en el caso del uso de la anticoncepción. 
La reforma de dichas leyes empezó en la década de 1970 y fue impulsada sobre todo por el movimiento feminista. En 1971 la Corte Constitucional eliminó del código penal la prohibición de la publicidad y difusión de los anticonceptivos. En el mismo año se presentó la primera propuesta de la ley que decriminalizaba el aborto terapéutico (Ley Fortuna). El movimiento feminista durante los primeros años de la década de 1970 se empeñaba en denunciar los riesgos relacionados con los abortos clandestinos y el hecho de que el aborto más que una cuestión ética, fue una expresión de desigualdades de clase, ya que las mujeres mejor situadas económicamente acudían a abortar en Suiza, mientras que las mujeres obreras arriesgaban su salud utilizando servicios ilegales (mammane).

En 1975 la Corte Constitucional legalizó los abortos terapéuticos, sancionando que el derecho de la mujer a la salud (incluyendo salud psicológica) prevaleciera sobre los derechos del feto (Calloni 2001, 186). En el mismo año se estableció una institución de consultorios, o centros de planificación familiar, para proporcionar a las mujeres servicios de salud reproductiva, incluyendo la anticoncepción. Después de una intensa movilización feminista en torno a la legalización del aborto voluntario, apoyada por algunos médicos que practicaban abortos y la Asociación Italiana de Educación Demográfica, la ley del aborto cambió en 1978, cuando se aprobó la Ley 194 sobre las normas de la tutela social de la maternidad, que no quitó el delito del aborto del código penal, pero legalizó el aborto voluntario durante los primeros noventa días del embarazo (Calloni 2001, 188). Durante este plazo, al ser la mujer la única para determinar la continuación o interrupción del embarazo, el personal médico no puede 
interferir con esta decisión. Tampoco el padre del feto tiene este derecho y su opinión puede ser escuchada solamente si la mujer así lo decide. Después de los primeros noventa días del embarazo, el aborto se puede practicar exclusivamente por razones médicas, es decir cuando entra en juego la salud de la mujer o se han detectado malformaciones en el feto (Gruppo Donne... 1978, 25). Desde entonces el aborto legal puede ser practicado exclusivamente en la sanidad pública, los abortos practicados en las consultas privadas siguen siendo ilegales (Flamigni 2008, 62).

Las fuerzas políticas opuestas a esta legislación, compuestas por la jerarquía de la Iglesia Católica y por católicos seculares, impulsaron a someter la Ley 194 a un referéndum, que tuvo lugar en 1981. En el referéndum, con una participación del 80\% de la sociedad italiana, el 68\% de los votantes decidió mantener la Ley 194 en vigor, como recuerda Rita Armeni, una periodista y escritora italiana y autora de una publicación sobre la ley del aborto y la ley sobre la fecundación asistida en Italia (Armeni 2006, 23).

La intervención legal más reciente en la materia de salud reproductiva en Italia tuvo lugar en 2004 y con la adopción de la Ley 40 que opta por una regularización de las nuevas tecnologías reproductivas de carácter restringido. ${ }^{28}$ Esta ley limita el número de los óvulos fecundados durante un ciclo del procedimiento in-vitro a tres y exige que todos los embriones fecundados, siendo portadores de derechos, sean implementados en el útero, independientemente de su cualidad. La ley bloquea

\footnotetext{
${ }^{28}$ La ley ha sido sobrepuesta al referéndum abrogativo en 2005 en el que, gracias a una vasta movilización de la Iglesia Católica y movimiento pro-vida laico se mantuvo en vigor.
} 
también la investigación sobre las células estaminales y el acceso al tratamiento invitro para las parejas no casadas (Armeni 2006, 28). Esta ley está en conflicto con la Ley 194, ya que los embriones una vez implementados, pueden ser libremente abortados durante los primeros noventa días del embarazo ${ }^{29}$.

\subsection{Agentes implicados en la formulación de los debates}

A continuación, describo los agentes y las fuerzas principales implicados en la formulación de los discursos y leyes sobre la anticoncepción en Polonia, siguiendo el modelo de Scott.

\subsubsection{Los roles de género y los símbolos de feminidad en relación con el sistema político}

En la Italia fascista el modelo de feminidad promocionado por el Estado se centraba en la maternidad y el matrimonio. Las imágenes de cuidado de los niños como el rol ideal para las mujeres se trasmitía a través de la propaganda estatal desde la infancia: en la imagen mostrada abajo (figura 8), que es una portada del manual para las niñas scouts del 1935, se destacan los elementos clave para una jefa de la escuadra de scouts italiana: el cuidado de los niños y el nacionalismo ${ }^{30}$.

\footnotetext{
${ }^{29}$ Para obtener más información sobre la Ley 40, véase Armeni 2006.

${ }^{30}$ Para más información sobre las mujeres en el fascismo italiano, véase Whitaker 2000.
} 


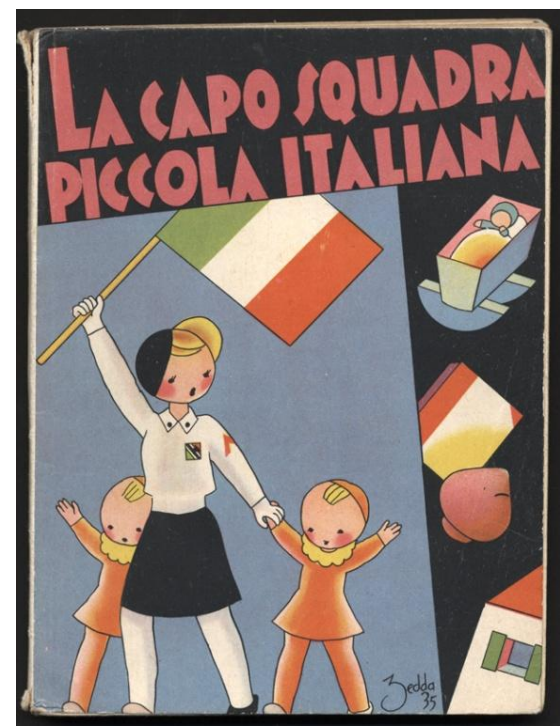

Figura 8 La portada del manual de las scouts italianas del periodo fascista. La Caposquadra Piccola Italiana. 1935. Roma; Milano: Arti Grafiche Pizzi y Pizio. Colección de Wolfsonian en Florida International University.

Después de la Segunda Guerra Mundial, en la décadas de 1950 y 1960, aumentó la estabilidad económica y nivel de vida de los italianos y las italianas. Especialmente en la década de 1960, se hizo fuerte la figura de ama de casa tradicional (casalinga), apoyada ideológicamente por la Iglesia. El aspecto particularmente represivo para las mujeres a principios de la segunda mitad del siglo XX en Italia fue la dominación del discurso sexista sobre la sexualidad, es decir, la exigencia de la virginidad femenina, en la que acumula el honor de toda la familia. Este tipo de discursos fueron particularmente corrientes en el Sur de Italia (Greer 1984, 111-114), pero sobre el plano general afectaban a todas las mujeres, en cuanto se les ofrecía un modelo cultural de la sexualidad basado en las necesidades y el placer masculino. Este modelo de relaciones de género desiguales constituye el objetivo del desafío feminista italiano de los años setenta, que describiré más adelante. 


\subsubsection{La implicación de la Iglesia Católica en las políticas de la reproducción}

En el periodo fascista, la Iglesia Católica tenía en Italia una posición privilegiada: los Pactos Lateranenses de 1929 ( el concordato firmado por el Mussolini y el Papa Pío XI), suponían el mutuo reconocimiento entre el Reino de Italia y la Ciudad del Vaticano, y constituían al catolicismo como la religión estatal en Italia. El catolicismo permaneció como la religión oficial del Estado italiano hasta 1985 (Calabrini y Vaccaro 1996, 140), representando una gran influencia en la política estatal, lo cual tiene que ver con la presencia de la Santa Sede en el territorio italiano (Calloni 2001, 182). El catolicismo es una religión casi unánime en Italia, pero también es practicada en versión light (Armeni 2006, 32), es decir, lo que se entiende en España o Polonia como catolicismo "creyente pero no practicante". En Italia, a diferencia de Polonia, la Iglesia no fue un referente intelectual de gran importancia. En la década de 1970, Italia abolió últimas leyes fascistas que prohibían la comercialización de la anticoncepción (1971), el divorcio (1974) y el aborto (1978). La oposición de la Iglesia italiana a estos procesos fue en este momento insuficiente para pararlos; Gaiotti de Biase $(2004,66)$ apunta que la Iglesia estaba "sorprendida" por la discrepancia entre la participación religiosa de sus creyentes y la falta de apoyo de los mismos a la doctrina social católica en los discursos políticos. En otras palabras, los cambios propiciados en la década de 1970 , con la invalidación de las leyes fascistas que reflejaban la moral católica, representaron un periodo de separación del Estado y la religión que la Iglesia católica no fue capaz de resistir. La demanda de dicha separación fue formulada también en gran parte por los mismos católicos laicos, que sentían que los postulados de la Iglesia en los asuntos 
como el aborto o el divorcio eran demasiado radicales (Damiani et al. 1981, 129). La movilización de la Iglesia contra la Ley 194, bajo el liderazgo de Juan Pablo II, elegido papa en 1978, se consolidó a finales de la década de 1970, e influyó en el hecho de sobreponer la ley al referéndum popular en 1981. El resultado del referéndum apoyaba a la Ley 194, siendo según el movimiento feminista el triunfo del país laico y secular italiano. Esta laicidad, según Armeni (2006, 7-26), fue expuesta a un desafío en el nuevo contexto político de los primeros años del siglo XXI, cuando la Iglesia influyó con éxito para la adopción de una ley sobre las tecnologías de reproducción asistida basada en valores cristianos.

\subsubsection{Las intervenciones de la profesión médica en los debates sobre la anticoncepción y el aborto}

Los médicos tienen un rol importante en la formulación de las políticas de la anticoncepción y aborto, debido a que por un lado son articuladores del discurso científico acerca la reproducción y, por otro lado, son ellos los que, en la mayoría de los casos en el contexto occidental, practican abortos y aconsejan sobre los métodos anticonceptivos.

En Italia la legalización de la anticoncepción (1971) fue la culminación de un proceso anterior de incumplimiento de la prohibición de la difusión de los métodos anticonceptivos por motivos diferentes a los relacionados con la salud. Algunos médicos se hacían visibles como practicadores de abortos ilegales en los años setenta, para denunciar los peligros relacionados con abortos ilegales ofrecidos por mammane, las personas fuera de la profesión médica. En este sentido, el discurso médico apoyaba 
al discurso feminista de legalización del aborto. Después de la introducción de la Ley 194, que tenía prevista la objeción de conciencia del personal médico en cuanto al procedimiento de la interrupción del embarazo, la mayoría de los médicos se declararon objetores. En la actualidad, según Armeni $(2006,109)$, más de la mitad de los ginecólogos, casi la mitad de los anestesiólogos y casi $40 \%$ del personal no médico es objetor de conciencia. Armeni expresa una opinión, que estas objeciones no están motivadas solamente por razones morales o religiosas, sino también por razones económicas, es decir los médicos no practican abortos en centros públicos, pero sí en sus consultas privadas. Como resultado, los pocos ginecólogos no objetores están sobrecargados con la demanda de servicio de abortos y en muchos casos también optan por la objeción (Armeni 2006, 113).

\subsection{El movimiento de mujeres y el movimiento feminista en Italia en la década de 1970 en relación con las políticas del control de la reproducción}

En mi análisis de los debates sobre el control de la reproducción mi particular interés descansa sobre el papel del movimiento feminista en estos procesos, y sobre el discurso que produce. Como ya he señalado, el feminismo activista desempeñó un papel fundamental articulando los postulados de la sociedad en la revisión de los residuos legales fascistas que prohibían la anticoncepción, el divorcio y el aborto. Bassnett $(1986,110)$ se refiere al movimiento feminista italiano de la década de 1970 como el previamente mencionado "movimiento de las mujeres cabreadas", ya que las feministas cuestionaban en voz alta las relaciones de poder en la sociedad italiana y se referían al hogar y la familia como sitios de explotación. Esta llamada de atención 
sobre las desigualdades de género en el hogar con la destacada figura de ama de casa en la década que sigue al boom económico de los años sesenta, remite al feminismo estadounidense de la segunda ola. En Estados Unidos, los principios del movimiento masivo de mujeres a finales de los sesenta se basaban en gran medida en la frustración de las amas de casa educadas pero subordinadas dentro del modelo patriarcal de familia de la década de 1950, analizadas en la obra de Betty Friedan The feminine mistique [La mística de la feminidad] (1963).

Las feministas italianas se apoyaban teóricamente en autoras como Adrienne Rich o Luce Irigaray, quienes visitaban a menudo la Libreria delle Donne, organización cultural feminista fundada en Milan en 1975. Uno de los temas de especial interés desde el punto de vista teórico fue el modelo de sexualidad dominante (masculino) en la sociedad italiana. El objetivo de las feministas era deconstruir este modelo, destacando las relaciones de poder y la violencia que suponía para las mujeres. Otra reivindicación destacada fue aquella de la violencia sexual (entendida como violación), que también se convirtió en un postulado legal del movimiento feminista (Kemp y Bono 1991, 12).

El movimiento italiano, según Kemp y Bono (1991, 1-29) tenía un carácter separatista y activista, es decir, no estaba, por lo menos en los años setenta, vinculado con ningún partido político. No obstante, Calloni $(2001,183)$ afirma que desde la apertura de los debates sobre el aborto y la anticoncepción, se crearon dos ramas del movimiento feminista: una, separatista respeto a la política y las estructuras del Estado 
(constituida por Movimento di Liberazione della Donna), y otra que optaba por trabajar con las mismas estructuras, promocionando la transversalidad de género dentro de ellas. A comienzos de los años ochenta una parte del movimiento feminista se acercó a la política, sobre todo al PC, mientras otras feministas preferían permanecer independientes. En esta época no existía un fuerte feminismo académico italiano; las mismas autoras comentan que el movimiento no confiaba en la academia y que la actividad feminista desde las universidades se consolidó más tarde en la década de los 1990.

Los primeros proyectos feministas relacionados con el aborto y la anticoncepción estuvieron relacionados con la fundación de centros de salud para mujeres (consultori), para ofrecer una alternativa al sistema sanitario público. El primer consultorio fue fundado en 1973 en Milán; en los años siguientes se abrieron establecimientos parecidos en Padua, Turín y Roma. Los consultorios se institucionalizaron en 1975 con una ley que los incluía en el sistema sanitario público. De forma similar al movimiento feminista por la salud de las mujeres de Estados Unidos $^{31}$, las feministas italianas se apoyaban en los grupos de auto conciencia y fundaban clínicas de salud femenina basadas en principios de autogestión, es decir, la reconquista del poder de las mujeres sobre sus cuerpos y funciones reproductivas a través del empleo de la anticoncepción y el aborto (Damiani et al. 1981, 11).

\footnotetext{
${ }^{31}$ Véase Morgen 2002.
} 
En el mismo año se constituyó el Centro Italiano Sterilizzazione e Aborto, que Ilamó la atención pública sobre la discrepancia entre la ley que prohibía el aborto y el número elevado de abortos clandestinos. El centro propuso la autogestión de abortos como un acto de desobediencia civil y como un método para combatir esta situación, y se empeño en divulgar la información sobre los métodos anticonceptivos y las maneras de obtener un aborto entonces ilegal. Otro grupo coordinado muy importante fue la Comitato Romano per il Aborto e la Contracezzione (CRAC), fundado en 1975, que denunciaba el aborto como violencia, y un fenómeno de masa ya que las mujeres se veían obligadas a someterse a arriesgados abortos ilegales sin tener plena información sobre cómo prevenir el embarazo no deseado. CRAC postulaba, entre otros, a través de su Piattaforma per i consultori (1976), por la sexualidad separada de la reproducción y la mayor difusión de los métodos anticonceptivos y auto-abortos, practicados por las mismas mujeres (Damiani et al. 1981) ${ }^{32}$.

EI CRAC organizó la primera manifestación masiva de mujeres por el derecho al aborto en 1975. Mientras el aborto por motivos médicos se legalizó en 1975, las manifestaciones feministas se repitieron en los años siguientes (1976 y 1977), con el postulado de una ley que pudiera incluir la autodeterminación de las mujeres en el campo reproductivo.

\footnotetext{
${ }^{32}$ Estas prácticas se parecen a las del colectivo Estadounidense JANE, que funcionaba en Chicago en los años sesenta, antes de la legalización del aborto en Estados Unidos en 1973. El colectivo aconsejaba a las mujeres que necesitaban abortar, donde podrían practicar abortos ilegales seguros. En algunas ocasiones, las mujeres asociadas en el colectivo practicaban abortos en persona. Para más información sobre el colectivo JANE véase Kaplan 1995; 1998.
} 
Otra organización feminista involucrada en el proceso fue Unione Donne Italiane (UDI), que denunció la doble moral detrás de la clandestinidad del aborto en el artículo I figli che no nascono, publicado en 1973 en la revista de la organización, Noi Donne. Este colectivo destacaba por hacer una consulta social de masa sobre las cuestiones relacionadas con la maternidad, la sexualidad y el aborto, otra vez denunciando el aborto clandestino como una forma de violencia contra las mujeres.

En 1978 se aprobó la Ley 194, que, como ya he dicho, permitía el aborto voluntario justificado solamente por la decisión de la mujer embarazada durante los primeros noventa días del embarazo, respondiendo casi plenamente a los postulados del movimiento feminista. El movimiento feminista frente a esta ley formuló postulados nuevos, como el establecimiento de consultorios en todo el país (en el Sur no se han constituido consultorios) o como la garantía del acceso universal al aborto y planificación familiar, necesaria para hacer funcionar la Ley 194. Las preocupaciones feministas se volvieron también hacia las menores de edad, que para abortar sin consentimiento de los padres necesitaban el permiso del la Corte de Menores, lo cual obstaculizaba su acceso a la interrupción del embarazo. Algunos grupos feministas separatistas, como MDL (figura 9), pedían la cancelación de la ley fascista que prohibía el aborto, pero a la vez rechazaban cualquier otra regulación del aborto como una forma de opresión del Estado sobre el cuerpo femenino.

Ante el referéndum del 1981, propuesto por el movimiento pro-vida encabezado por el papa Juan Pablo II, con el objetivo de limitar la Ley 194, el movimiento feminista 
se volvió a movilizar y consiguió mantener la ley intacta, gracias a la amplia participación en el referéndum ganado con la mayoría de $68 \%$ de votos válidos (Flamigni 2008, 59). La figura 10 reproduce uno de los pósteres de UDI para movilizar la sociedad contra la abrogación de la Ley 194 en el referéndum.

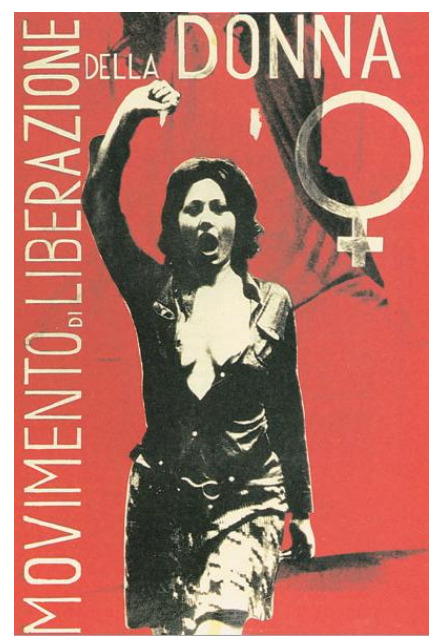

Figura 9 El poster del Movimento di Liberazione della Donna, Roma, años setenta (Biblioteca Nazionale di Napoli, http://www.bnnonline.it; último acceso 10/09/2009.

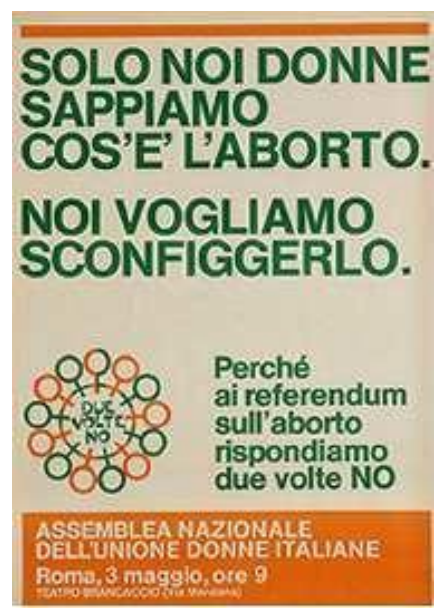

Figura 10 Poster de UDI para mantener en vigor la Ley 194 durante el referéndum en 1981 [Solo nosotras mujeres sabemos lo que es el aborto. Nosotras queremos combatirlo. Por ello, en los referéndums sobre el aborto contestamos dos veces NO]. Instituto Statale per la Istruzione Professionale e Technica [Instituto Estatal de la Educación Profesional y Técnica], http://www.racine.ra.it; último acceso 27/07/2009. 
Como ya he mencionado anteriormente, el movimiento feminista se movilizó en la década de 1970 con el objetivo principal de reivindicar la mayor libertad sexual femenina y promocionar el cambio en de las antiguas leyes fascista, que prohibían las prácticas de la anticoncepción y el aborto. Este movimiento se incorporó parcialmente en la siguiente década en las estructuras políticas mientras que otra parte de las activistas se mantuvo separada. Después de obtener su objetivo, la ley de aborto voluntario acompañada por el derecho al acceso real a la anticoncepción dentro de la sanidad pública, el conjunto llamado por Armeni $(2006,10)$ "Habeas corpus de las mujeres", el movimiento feminista progresivamente abandona la escena social italiana.

La nueva generación de mujeres italianas, que entraron en su edad reproductiva después de 1978, no se moviliza, según Armeni $(2006,61)$, por los derechos reproductivos, considerándolos algo inmutable y dado de una vez para siempre. Sin embargo, en el último debate sobre las cuestiones reproductivas en Italia, el debate sobre la reproducción asistida en 2004, fue la Iglesia Católica la que protagonizó la escena pública y hizo su discurso sobe la condición del embriones el discurso corriente, sin protestas feministas. Armeni expresa una opinión que a través de la ley sobre la reproducción asistida la Iglesia intenta meter in discusión la Ley 194, sin la resistencia por parte del movimiento de las mujeres. 


\subsection{Análisis del discurso feminista italiano: por la autonomía de las mujeres en una sociedad patriarcal}

El discurso feminista italiano sobre el control de la reproducción a través de la anticoncepción y el aborto se inscribe, según las fuentes estudiadas, en una amplia elaboración teórica de la opresión femenina. Los postulados de la extensión del acceso a la planificación familiar y la legalización del aborto voluntario en Italia se justifican dentro de un sistema patriarcal en el que los hombres oprimen a las mujeres en su sexualidad y les imponen el rol materno sin que ellas puedan realmente elegirlo. Todos los conceptos que veremos a continuación están estrechamente relacionados entre si; por lo tanto, la propuesta feminista respecto al aborto y la anticoncepción es una propuesta holística que quiere proporcionar profundos cambios sociales en cuanto al rol de las mujeres y su lugar en la sociedad. Las fuentes feministas que he revisado sitúan su lucha por la accesibilidad a la anticoncepción y la legalización del aborto en un contexto social y cultural más amplio que no es favorable hacia las mujeres. Consecuentemente, se trabaja la lucha por los derechos reproductivos como una parte de la transformación social de carácter más vasto, que pide la cooperación de las mujeres, los varones y la clase política.

En los primeros manifiestos del feminismo italiano, Rivolta Femmiline emplea el feminismo radical de la diferencia y se centra en la crítica del patriarcado, subrayando que los varones oprimen a las mujeres, imponiéndoles modelos de conducta y encerrándolas en lugares de opresión como la familia: 
La mujer como sujeto no rechaza al varón como sujeto, pero lo rechaza como un referente absoluto. En la vida social rechaza su papel autoritario ${ }^{33}$;

En el matrimonio la mujer pierde su nombre y su identidad, lo cual significa un paso de ser propiedad de su padre a ser propiedad de su marido ${ }^{34}$;

Reconocemos el matrimonio como institución que subordina a la mujer al destino masculino. Estamos contra el matrimonio ${ }^{35}$ (Rivolta Femminile y Carla Lonzi 1981 [1970], 13-22).

La portada de la revista Effe (número 11/1975, figura 11) representa esta opresión con una imagen: la mujer con el útero abierto bajo el control de las figuras masculinas que representan los médicos, los curas, los políticos, los militares, etc.

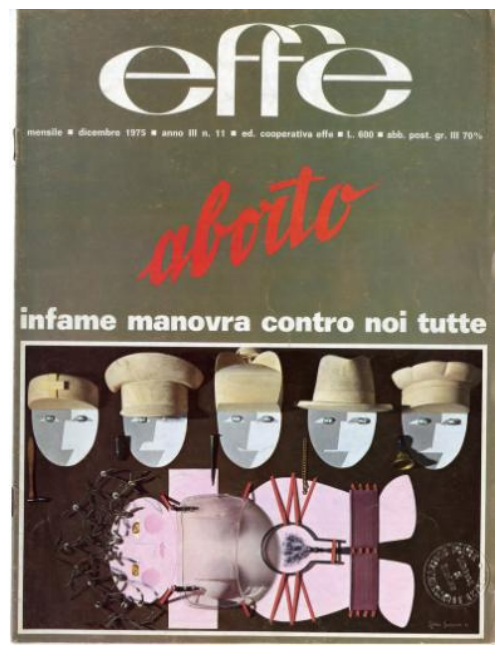

Figura 11 [Maniobras infames contra todas nosotras] Portada de la revista Effe 11/1975, http://www.bibliotecadigitaledelledonne.it; último acceso 14/08/2009.

\footnotetext{
${ }^{33}$ La donna come soggetto non rifiuta l'uomo come soggetto, ma lo rifiuta come ruolo assoluto. Nella vita sociale lo rifiuta come ruolo autoritario.

${ }^{34} \mathrm{Nel}$ matrimonio la donna, privata dal suo nome, perde la sua identità significando il passaggio di proprietà che è avvenuto tra il padre di lei e il marito.

${ }^{35}$ Riconosciamo nel matrimonio l'istituzione che ha subordinato la donna al destino maschile. Siamo contro il matrimonio.
} 
Para las feministas de Rivolta Femminile la familia es un lugar donde el patriarcado ejerce su control sobre las mujeres:

La virginidad, castidad, fidelidad no son virtudes. Son vínculos para construir y mantener la familia. La consecuencia de esto es el honor en su papel de codificador represivo $^{36}$ (Rivolta Femminile y Carla Lonzi 1981 [1970], 14).

Como vemos, las feministas rechazan conceptos como virginidad, fidelidad y pureza, que según su discurso han sido establecidos para vigilar y contener a las mujeres y su sexualidad dentro de la familia. En este sentido, el modelo de la familia tradicional es rechazado por las feministas y se proponen su politización, y revisión por las mismas mujeres en el marco de tratar las experiencias personales como experiencias políticas:

Queremos volver a abrir el discurso sobre la pareja y la familia. Conquistar espacios nuevos de autonomía, de crecimiento y a la vez luchar por los servicios sociales y por una sociedad en la que será posible dar una respuesta al problema del aborto ${ }^{37}$ (Cristiani per il Socialismo 1981 [1976] en Oltre l'aborto, 39).

Otro concepto básico que se relaciona con las peticiones de la liberalización de la anticoncepción y del aborto, es el de la sexualidad femenina. El tema de la represión de la sexualidad femenina está presente en muchas de las comunicaciones feministas que he revisado y parece ser central también en cuanto a la anticoncepción y el aborto. En primer lugar, las feministas denuncian el hecho de que la sexualidad femenina está subordinada al placer masculino: el placer femenino no es necesario para las relaciones sexuales tradicionales y el acto sexual es una manera en la que los

\footnotetext{
${ }^{36}$ Verginità, castità, fedeltà, non sono virtù; ma vincoli per costruire e mantenere la famiglia. L'onore ne è la conseguente codificazione repressiva.

${ }^{37}$ Vogliamo riaprire il discorso sulla coppia e sulla famiglia. Conquistare spazi nuovi di autonomia, di crescita, e nello stesso tempo lottare per ottenere servizi social e complessivamente per una società in cui sia possible dare una risposta in positivo al problema dell'aborto.
} 
hombres reafirman su virilidad. Por otro lado, los hombres no se responsabilizan de la reproducción, cediendo toda la responsabilidad por las consecuencias de las relaciones sexuales a las mujeres:

Cuando el marido dice que él no puede preocuparse, que necesita "disfrutar" y que se las arregle ella como las otras mujeres, practicándose un aborto casero, quiere decir que la mujer no es considerada siquiera un ser humano, sino un servicio doméstico $^{38}$ (Dal Pozzo 1974, 25-26).

Por otro lado, las feministas ironizan sobre qué pasaría si fueran los hombres quienes se tuvieran que preocupar por el embarazo. Una ilustración de esta ironía podría ser la portada de revista Effe 02/1974 (figura 12), en la aparece un hombre preocupado, esperando supuestamente la menstruación, la otra un dibujo de Patricia Smith (figura 13) publicado también en Effe, titulado Se sucedesse a lui, ci starebbe più attento [Si pasara a él, estaría más atento].

\footnotetext{
${ }^{38}$ Quando un marito dichiara che lui non può proccuparsi, che debe "scapricciarsi" e se la cavi lei come fanno le altre donne, ricorrendo agli aborti casalinghi, vuol dire che sua moglie non è considerata nemmeno un essere umano, ma un servicio domestico.
} 


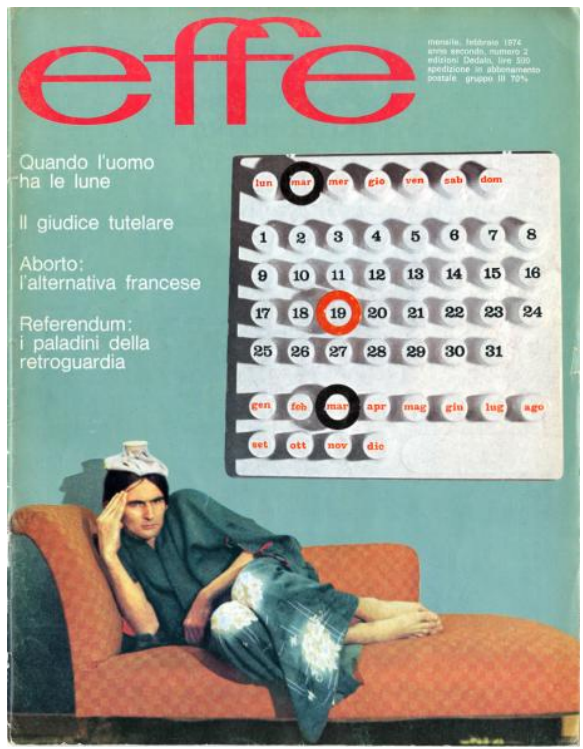

\section{antieoncezionali NON BASTA LA LEGGE}
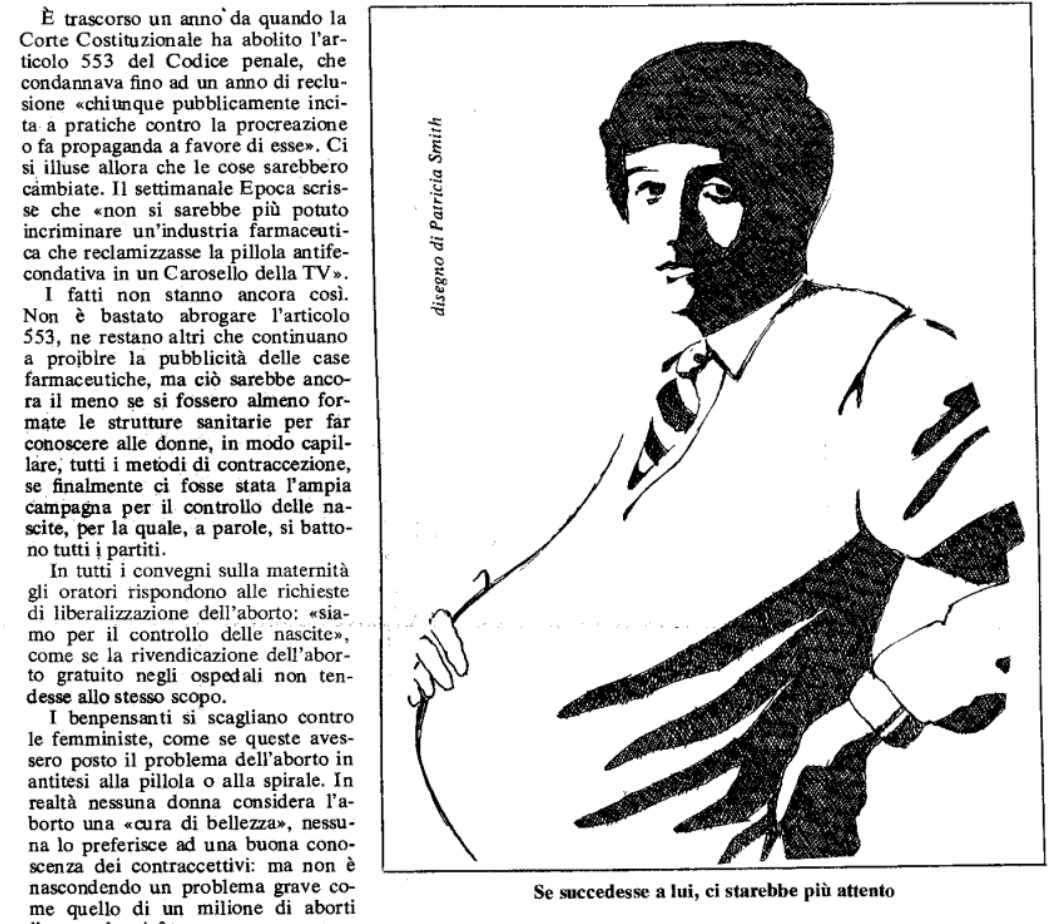

me quello

Se succedesse a lui, ci starebbe più attento

Figura 13 Smith, Patrizia. 1972. Se sucedesse a lui, ci starebbe più attento [Si pasara a él, estaría más atento] Publicado en revista Effe $(0 / 1972,38)$ para acompañar el artículo de D. T. Anticoncezionali. Non basta la legge 
Al mismo tiempo, algunas feministas rechazan la liberación sexual según el modelo masculino de la promiscuidad que, al fin y al cabo, lleva consigo la opresión para las mujeres:

Sabemos bien que la "liberación sexual" ha significado casi siempre el uso más fácil del cuerpo de la mujer por parte del varón, sacrificando las necesidades reales de la mujer ${ }^{39}$ (Cristiani per il Socialismo 1981 [1976] en Oltre l'aborto, 41).

Como ya he dicho, se subraya que la sexualidad femenina es legítima exclusivamente en la familia, pero ni siquiera allí es libre, ya que está limitada por los modelos culturales que obligan a la mujer a contenerse sexualmente. A la luz de las prácticas comunes de abusos y violencia por parte de los hombres, las mujeres viven su sexualidad con miedo y angustia por un embarazo no deseado, y se postula la mayor participación de los hombres en cuanto a la prevención del embarazo a través del empleo de la anticoncepción:

\footnotetext{
De hecho, en la historia, si la responsabilidad por la procreación no se ha convertido en una responsabilidad colectiva, es porque este problema descansaba plenamente sobre la mujer. (...) El ansia y miedo con el que vivimos las relaciones sexuales con los hombres; la angustiosa espera e la menstruación; la vergüenza y la dependencia con la que nos enfrentamos a las consultas con el ginecólogo; el temor y el sentimiento de impotencia cuando esperamos el resultado de una prueba del embarazo; todas estas son manifestaciones en las que se expresa nuestra alienación ${ }^{40}$ (Unione Donne Italiane 1981 [1976] en Oltre l'aborto, 27).
}

\footnotetext{
${ }^{39}$ Sappiamo bene che la cosidetta liberazione sessuale ha significato quasi sempre un uso più facile del corpo della donna da parte dell'uomo, sacrificando i reali bisogni della donna.

${ }^{40}$ Di fatto, nella storia, se finora la responsabilità della procreazione non è diventata un problema di responsibilità collettiva, è perchè questo problema è stato intieramente scaricato sulla donna. (...) L'ansia e la paura con cui viviamo il rapporto sessuale con l'uomo; l'angosciosa attesa delle menstruzazioni; la vergogna e la dipendenza disarmata con cui affrontiamo la visita del ginecologo o dell'ostetrica; il timore $e$ in senso di impotenza con cui attendiamo il risultato di un test di gravidanza; sono tutte manifestazioni in cui si esprime la nostra alienazione.
} 
En este marco, el hecho de que las mujeres recurran al aborto, se presenta como una mera expresión de la irresponsabilidad de los hombres. Las feministas preguntan retóricamente “¿Por el placer de quien me quedo embarazada? ¿Por el placer de quién tengo un aborto?" (Rivolta Femminile en Bono y Kemp, 1991 [1972], 37-40). El aborto desaparecería, a su juicio, si las mujeres pudieran retomar el control sobre sus órganos reproductivos y vivir su sexualidad libremente, plenamente separada de la reproducción:

Solamente cuando retomemos el control sobre nuestros órganos reproductivos, solamente cuando podamos controlar la medicina y a los médicos, solo cuando podamos vivir nuestra sexualidad plenamente y felizmente sin vergüenza, sin verla destinada a la reproducción, solamente cuando podamos decidir nosotras, el aborto dejará de existir ${ }^{41}$ (Sassaroli y Rossellini, 1975, 2, énfasis suya).

El último concepto central abordado por las feministas en las fuentes que he revisado es la maternidad, que las feministas desean replantear como de libre elección y no un rol impuesto por la sociedad patriarcal. Se critica que la sociedad italiana exige a las mujeres que sean madres, pero no adopta medidas para que la maternidad fuera realmente una elección, y no una obligación:

\footnotetext{
Las mujeres se rebelan contra una sociedad en la que, mientras se les imponen todas las responsabilidades relacionadas con la maternidad y el cuidado de los hijos, no se les garantiza medidas para que la maternidad sea una elección libre y consciente ${ }^{42}$ (Comitato Romano per l'Aborto e la Contraccezione 1981 [1975] en Oltre l'aborto, 20).
}

\footnotetext{
${ }^{41}$ Solo quando ci saremo riappropriate dei nostri organi di riproduzione, solo quando potremo controllare la medicina ed i medici, solo quando potremo vivere la nostra sessualità pienamente e felicemente senza vergogna senza più vederla finalizzata alla riproduzione solo quando potremo decidere noi, l'aborto non esisterà più.

${ }^{42}$ Le donne si ribellano contro una società che, mentre impone loro tutte la responsabilità della maternità e dell'allevamento dei figli, non garantisce nessuna condizione perchè la maternità sia una scelta libera e consapevole.
} 
En la sociedad patriarcal, dicen las feministas de UDI, neppure la maternità è nostra [ni siquiera la maternidad nos pertenece (a las mujeres)] (Unione Donne Italiane 1981 [1976] en Oltre l'aborto, 28) porque no es una elección libremente tomada, sino un rol que se espera que todas las mujeres desempeñen. En todo caso, en la conciencia feminista, la decisión de tener un hijo es a la vez una decisión personal y política:

Tener un hijo no debería ser considerado una decisión que pertenece exclusivamente a la esfera privada: es también un problema social y por lo tanto, "político", que solamente la educación y la toma de conciencia pueden resolver ${ }^{43}$ (D. T. 1973, 38).

El derecho al aborto se plantea en el discurso feminista como el primer paso para conseguir la verdadera libertad de elección de la maternidad lo cual permitirá vivirla como alegría y no como opresión:

\begin{abstract}
Queremos tener, por lo menos por ahora, una libertad para rechazar a un hijo que no deseamos. Sabemos bien que esto no es libertad, que el aborto en sí no resuelve todos nuestros problemas, pero es un punto de partida como primer paso hacia la verdadera libertad de elección. Y no será así hasta que tengamos la posibilidad de no aceptar a un hijo...No es justo que la maternidad tenga que ser siempre vivida de esta manera tan dramática. La maternidad debe ser una cosa alegre, y cuanto más alegre resulta para la madre, más alegre lo es para el hijo ${ }^{44}$ (Remiddi 1974, 44-46);
\end{abstract}

\footnotetext{
${ }^{43}$ Avere un figlio quando si vuole, non debe più essere considerato exclusivo della sfera privata: è anche un problema sociale e come tale "político", che solo l'istruzione e la presa di conscienza possono risolvere.

${ }^{44}$ Vogliamo avere, almeno per ora, la libertà di rifiutarlo il figlio che non desideriamo. Sappiamo benissimo che questa non è libertà, che l'aborto in sè non risolve tutti i nostri problemi, ma è un punto fermo, un primo passo verso la vera libertà di scelta. Che non è tale finchè non avremo la possibilità di non accettare il figlio... Non è giusto che la maternità debba essere quasi sempre vissuta in questa maniera drammatica. La maternità debe essere gioiosa e quanto più gioiosa è per la madre, tanto più lo è per il bambino...
} 
El aborto no es una fiesta: el aborto legal, o, mejor, el aborto libre y gratuito que queremos tiene sentido (...) porque se convierte en el primer paso para la revaluación de la alegría de ser madre ${ }^{45}$ (Cambira y Colombo 1973, 2).

En este sentido, la mujer, teniendo la posibilidad de utilizar los medios anticonceptivos $y$, en el caso de que estos fallen, recurrir al aborto, se convierte en la dueña de su maternidad (Del Pozo 1974, 25-26) de acuerdo con uno de los eslóganes más reconocibles del feminismo italiano de la década de 1970: l'utero è mio e me lo gestisco io (Effe 04/1975, p. 12-13, figura 14).

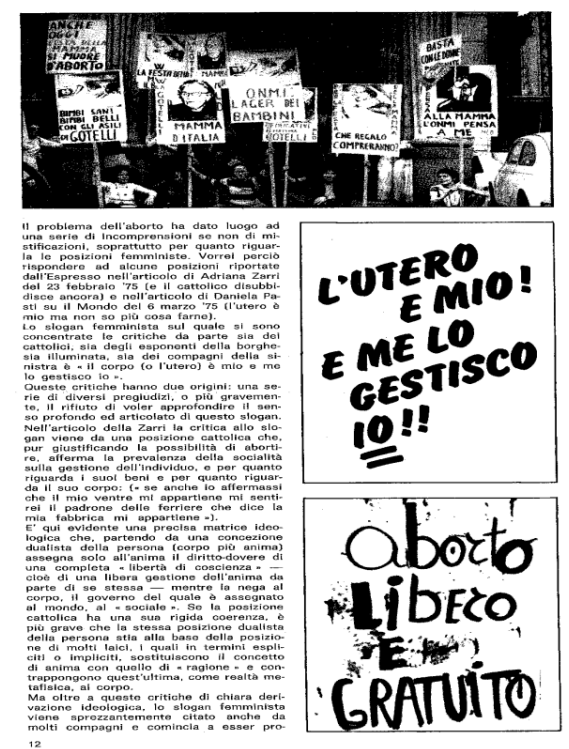

Figura 14 Fragmento de la página 12 de la revista Effe 4/1975 con el eslogan del movimiento feminista italiano l'utero è mio e me lo gestisco io [il útero es mío y lo gestiono yo]. Arriba las pancartas de una manifestación feminista, debajo otro eslogan: aborto libero e gratuito [aborto libre y gratuito].

Por último, un factor de opresión que se repite en las publicaciones feministas de la década de 1970 es la religión católica, que reproduce y legitima los modelos de

\footnotetext{
${ }^{45}$ L'aborto non è una festa: l'aborto legale, o, meglio ancora, libero e gratuito che vogliamo, ha un senso (...) perchè diventa il primo passo per la rivalutazione della gioia di essere madri (...).
} 
inferioridad de las mujeres y subordina su sexualidad a la reproducción dentro de la familia (Cristiani per il Socialismo 1981 [1976] en Oltre l'aborto, 40). Se atribuye a la educación católica el sentimiento de culpa en las mujeres que les impide disfrutar de su sexualidad (Cambria y Colombo 1973, 2), aunque se publican también opiniones favorables a la anticoncepción y el aborto de católicos seculares (Roscioni entrevistada por Cambria 1973, 42-43). Tras la aprobación de la Ley 194, las feministas separatistas relacionadas con MDL y Quotidiano Donna critican directamente a la Iglesia por alentar a los médicos a declararse objetores de conciencia (Grazia y Marina B. (Come smascherare i medici...) 1978). Más tarde lanzan una campaña directa de recopilación de firmas contra las amenazas de excomunión por parte de la Conferencia Episcopal Italiana para quienes se someten al aborto o lo practican (Cari vescovi, vi abbiamo denunciato 1979; Contro le minacce dei vescovi. La nostra denuncia 1979; Continuamo a pubblicare le firme di adesione alla denuncia fatta da Quotidiano Donna contro i vescovi della CEI e invitiamo le compagne a presentare denunce uguagli nelle loro città 1979).

En las comunicaciones feministas la reflexión de carácter teórico sobre la opresión de las mujeres en la sociedad italiana es seguida por propuestas de cambio de esta situación. Las herramientas que se muestran más repetidas potencian la autonomía femenina, algo que se puede conseguir a través del trabajo de autoconciencia, la autogestión del control de la reproducción, y la acción política. 
La autonomía femenina es el postulado central en el discurso feminista italiano de la década de 1970 y aparece en estrecha relación con la maternidad y el aborto voluntario: las feministas exigen la plena liberalización del aborto (y no solamente el aborto terapéutico), argumentando que la autonomia no si conquista a pezzi [la autonomía no se consigue a trozos] (Unione Donne Italiane 1981 [1976] en Oltre l'aborto, 31). El colectivo Rivolta Femminile argumenta:

La negación de la libertad del aborto se inscribe en un veto global acerca de la autonomía de la mujer $^{46}$ (Rivolta Femminile y Carla Lonzi 1974 [1970], 18).

Otra manifestación de la falta de autonomía de las mujeres es el hecho de que el Estado y la Iglesia se niegan a reconocer su derecho a tomar sus propias decisiones reproductivas, temiendo que el aborto libre pudiera convertirse en un método anticonceptivo (Carla (Stato e Chiesa dicono...) 1979).

La principal herramienta para conseguir la autonomía, que se inscribe en el marco general de la práctica feminista de la segunda ola en Europa y Estados Unidos, es la autoconciencia, que consiste en reuniones de mujeres en las que se discuten temas relacionados con la identidad femenina, sexualidad, reproducción, maternidad etc., para identificar en común las matices de la opresión como primer paso para deconstruirla. Se entiende que las mujeres tienen que vaciar y volver a llenar los discursos sobre la sexualidad, la pareja y la familia, que han sido históricamente elaborados sin ellas, y convertir lo personal en lo político (Cristiani per il Socialismo

\footnotetext{
${ }^{46}$ La negazione della libertà d'aborto rientra nel veto globale che viene fatto all'autonomia della donna.
} 
1981 [1976] en Oltre l'aborto, 38). Esta práctica está profundamente relacionada con la salud reproductiva de las mujeres, se propone que los consultorios se conviertan en centros en los que las mujeres puedan practicar la autoconciencia, trabajar su identidad y profundizar su relación con el propio cuerpo. En este sentido, los consultorios auto gestionados son:

(...) las estructuras del movimiento y de la lucha, donde las mujeres se encuentran, se reúnen, discuten y se conjuntan para una maduración sobre los problemas de la maternidad, la anticoncepción, del aborto, del control sobre su propio cuerpo y su sexualidad, y para organizarse para luchar contra todas las formas de opresión que ellas experimentan ${ }^{47}$ (Comitato Romano per l'Aborto e la Contraccezione 1981 [1976] en Oltre l'aborto, 22).

Otra herramienta práctica es la autogestión de la anticoncepción y el aborto. La práctica del aborto se presenta como una forma de resistencia política (Testimonianze. Dopo l'aborto... 1975, 4), militancia feminista, y solidaridad con las mujeres (Testimonianze. Perchè faccio aborti 1975, 18). Para algunos grupos es una actividad complementaria a la presión política para promocionar la práctica del aborto en las estructuras públicas (Comitato Romano per l'Aborto e la Contraccezione en Oltre l'aborto... 1981 [1975], 20), para otros, como MDL una práctica alternativa a estas estructuras, que se va dirigiendo, después de la Ley 194, a la militancia dentro de las estructuras sanitarias para asegurar que el aborto sea practicado:

La práctica de nuestra autoayuda es un punto de partida, es una práctica auto gestionada de nuestro cuerpo y de nuestra salud para llegar a exigir la plena autodeterminación también dentro de las instituciones y el control colectivo de

\footnotetext{
${ }^{47}$ (...) strutture di movimiento e di lotta sono i consultori autogestiti, dove le donne si incontrano, si riunisconio, discutono e si confrontano per una maturazione comune sui problemi della maternità, della contraccezione, dell'aborto, del controllo del proprio corpo e della sessualità e per un'organizzazione di lotta contro tutte le forme della loro oppressione.
} 
estas, es decir, su gestión conjunta ${ }^{48}$ (Movimiento di Liberazione della Donna 1981 [1979], en Oltre l'aborto, 54).

Frente a la escasa realización de este postulado, los colectivos más radicales de autogestión de abortos relacionados con MLD no se desmovilizaron hasta varios meses después de la aprobación de la Ley 194 (Mercoledì si runiranno a Roma i nuclei aborto 1978; Irene (I nuclei aborto no smobilitano) 1978).

A pesar de las prácticas radicales de autogestión del aborto y la anticoncepción, las feministas se afanan en formular postulados oficiales del movimiento para que sirvan de referencia a los partidos políticos. Antes de la aprobación de la Ley 194, se exige la legalización del aborto y la universalización del acceso a la anticoncepción en las estructuras de la sanidad pública, después el discurso se centra en los fallos de la ley y los obstáculos para su plena implementación, y la masiva objeción de conciencia por parte de los médicos (Movimiento di Liberazione della Donna 1981 [1979] en Oltre I'aborto, 54; Elena M. (Denunciamoli, si fa così) 1978; Coordinamiento Donne Università Scuola 1978) o las dificultades del acceso al aborto experimentadas por las jovenes menores de edad. La cuestión de las menores y el embarazo forma parte fundamental del discurso feminista. De hecho, la revista Effe hizo de ella el tema principal de uno de sus números de 1974, cuya portada se reproduce en la figura 15.

\footnotetext{
${ }^{48}$ La practica del nostro self-help è un punto di partenza, è practica autogestionaria del nostro corpo e della nostra salute per arrivare ad esigere la piena autodeterminazione anche all'interno delle instituzioni e il controllo colettivo di esse, cioè la cogestione.
} 


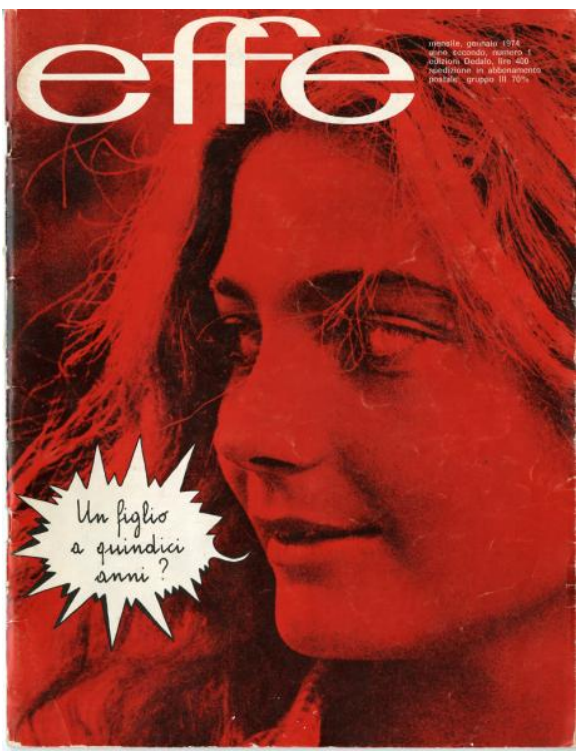

Figura 15 [¿̇Un hijo con quince años?]. Portada de la revista Effe 1/1974, http://www.bibliotecadigitaledelledonne.it; último acceso 14/08/2009.

Para complementar lo dicho sobre el aborto, en las fuentes previas a la Ley 194 que he analizado destaca la construcción discursiva del aborto como violencia. Las feministas se refieren aquí al aborto clandestino, que siendo una experiencia peligrosa y punitiva para las mujeres, las culpabiliza y las hace más vulnerables. El hecho de tener que terminar un embarazo no deseado en la clandestinidad se interpreta como una forma de violencia contra las mujeres (Unione Donne Italiane 1981 [1976] en Oltre l'aborto, 24). Las comunicaciones feministas intentan normalizar la experiencia del aborto, que es, según ellas, universal para las mujeres, y por tanto no debería ser ni demonizada ni idealizada. Para conseguirlo, en las revistas feministas se presenta selección de testimonios de las experiencias del aborto (Tiziana (Diario di un aborto) 1978; Un aborto si dovrebbe fare così, 1979, 18-25; Abortire a Washington 1973, 4-6; Testimonianze. Dopo l'aborto... 1975, 4), en las que se contrastan las experiencias 
negativas del aborto clandestino con las experiencias "positivas" del aborto practicado por los colectivos feministas en Estados Unidos.

El discurso sobre el aborto está íntimamente conectado con el discurso sobre la anticoncepción, que es reivindicada con igual insistencia. La anticoncepción es necesaria para limitar el número de abortos (D. T. 1973, 38), y es una herramienta imprescindible para que las mujeres puedan vivir su sexualidad de manera libre (Cristiani per il Socialismo 1981 [1976] en Oltre l'aborto, 34). Después de su legalización en 1971 las feministas exigen que se garantice un acceso real a los métodos anticonceptivos para todas las mujeres: solteras, casadas, adultas y menores de edad (D. T. 1973, 38). Sin embargo, la cuestión de la anticoncepción está muy problematizada: las feministas, estando a favor de la anticoncepción, son criticas acerca de la píldora (con sus posibles riesgos para la salud: Píldora masculina 1975, 22) o DIU (denuncia de los Dalkon Shield ${ }^{49}$ : Anticoncezionali. Tra due fuochi 1974, 49). También, se publican informaciones prácticas relacionadas con la anticoncepción, como direcciones de centros de salud en los que se prescribían los anticonceptivos: Indirizzi dei centri nei quali si ottengono consigli e visite sugli anticoncezionali 1973, 36; Anticoncezionali: indirizzi dei consultori 1975, 40; (Anticoncezionali) Dove, come, quando: ecco gli indirizzi 1974, 47).

\footnotetext{
${ }^{49}$ Dalkon Shield fue un dispositivo intrauterino producido en los años setenta en Estados Unidos que causó lesiones en un número muy alto de mujeres que lo usaban. Véase Hicks 1994 y Grant 1992.
} 
Resumiendo, en Italia en la década de 1970 se lleva a cabo una transformación de carácter general de las costumbres. En el contexto de este proceso de modernización social no se sostenían las antiguas leyes fascistas que prohibían la anticoncepción y el aborto. El esfuerzo feminista sirvió como catalizador de un cambio que estaba de acuerdo con los deseos de la mayoría de la sociedad italiana de la época. La Iglesia Católica, aunque tenía una posición fuerte, no jugó un papel central en determinar la dirección de los cambios sociales.

El movimiento feminista obtuvo un apoyo social vasto, ya que la mayoría de los italianos y las italianas en esta época tenía interés por disminuir el fenómeno del aborto clandestino. Los esfuerzos feministas se vieron reflejados en gran medida en el proceso legal, cuya culminación fue la legalización de la anticoncepción en 1971 y, siete años después, del aborto voluntario en el primer trimestre del embarazo.

La reflexión sobre la anticoncepción y el aborto generado por el feminismo italiano en la década de 1970 constituye el punto central del discurso feminista de la época. Estas prácticas se consideran herramientas para obtener una sexualidad y una maternidad libres. En general, la anticoncepción se discute de manera independiente del aborto, como una manera de limitar el número de los abortos y contribuir a la separación de la sexualidad y la reproducción en la experiencia femenina. Las 
feministas denuncian la falta del acceso a la anticoncepción y al aborto como una expresión de las relaciones desiguales de poder en la sociedad italiana. El discurso feminista habla tanto de las desigualdades de género, sobre todo en cuanto a la sexualidad y la doble moral relacionada con ella, como del poder de los médicos que bloquean, incluso después de su legalización, el acceso de las mujeres al aborto voluntario. Las técnicas que emplean las feministas italianas de la década de 1970 (trabajo en grupos de autoconciencia, manifestaciones, o autoayuda para el acceso a la anticoncepción y el aborto) hacen clara referencia a las prácticas feministas de la segunda ola en todo el mundo occidental democrático de la época. 


\section{Debates y discursos sobre aborto y anticoncepción en Polonia (1989-2004)}

\subsection{Las políticas acerca de la reproducción en Polonia en el siglo XX}

\subsubsection{Contexto histórico}

Polonia es un país que durante los últimos doscientos años ha experimentado una serie de ocupaciones extranjeras. El periodo de particiones, durante el que Polonia estaba dividida entre Prusia, Rusia y el Imperio Austrohúngaro acabó, después de 123 años, con la recuperación de la independencia en 1918. Durante las particiones, los países que gobernaban sobre lo que era previamente el territorio polaco se esforzaban en imponer su lengua y cultura sobre la nación polaca. Son de destacar, sobre todo, las políticas de germanización por parte de Prusia y rusificación por parte de Rusia. Después de la primera guerra mundial, de 1918 a 1939 Polonia fue una república democrática, en la que en 1926 se instaló un régimen semi-autoritario, asociado con el general Józef Pilsudski. Con el fin de la segunda guerra mundial, los acuerdos de Yalta (1945) posicionaron a Polonia bajo la esfera de influencias de la Unión Soviética. Polonia se reconstruyó como un país-satélite de la Unión Soviética, con un régimen totalitario comunista. En 1980 se construyó en Polonia el movimiento sindical democrático de Solidarność [Solidaridad], cuyas peticiones presionaron al gobierno comunista hasta introducir la ley marcial (1981-83). El movimiento sobrevivió en la clandestinidad y se recompuso para impulsar las primeras elecciones semidemocráticas en Polonia en 1989 y las primeras elecciones plenamente democráticas en 1990, empezando asimismo el proceso de la transformación democrática e integración con la Europa occidental (Davies 1997), que finalizó sobre el 
plano político con la entrada de Polonia en la Unión Europea en 2004. Asimismo, las fechas límite para mi análisis del discurso feminista polaco son las fechas de la transición democrática, comenzada en 1989 y terminada cuando Polonia se ha convertido en uno de los países-miembros de la Comunidad Europea.

Este periodo de transformación se caracterizó en Polonia por la sustitución de la economía comunista por el mercado capitalista liberal, lo cual tuvo consecuencias particularmente graves para las mujeres. La regularización del empleo para adaptarlo a la economía liberal llevó consigo altas tasas de paro femenino, porque en el sistema patriarcal que se conservó por debajo de la propaganda de la igualdad del Estado comunista, el empleo de los hombres como cabezas de familia merecía ser más protegido por el Estado que el empleo femenino, considerado tradicionalmente una fuente de dinero adicional para la renta de la familia. Funk $(1991,2)$ afirma que las transformaciones de los mercados en los países comunistas fueron posibles gracias a las masivas despedidas de las mujeres redirigidas de este modo a la esfera privada. Otro proceso que influyó de manera importante en la situación de las mujeres en Polonia durante la transición, y está directamente relacionado con el control de la reproducción, fue la descomposición de las políticas y estructuras del Estado de "bienestar" comunista para apoyar a las madres trabajadoras, como la baja maternal remunerada prolongada o la red estatal de guarderías (aunque muchas autoras denuncian estas políticas como superficiales e insuficientes). Durante la transformación el peso de las tareas del cuidado de los hijos, hijas y las personas mayores fue delegado del Estado a la familia (Heinen y Wator 2006, 207) sin proveer 
apoyo suficiente e ininterrumpido del Estado, que justificaba los cortes en los gastos públicos dedicados a las familias con el periodo de la crisis económica relacionada con la transición (Saxonberg y Szelwa 2007, 355-356) ${ }^{50}$.

\subsubsection{Leyes sobre el aborto y la anticoncepción en Polonia}

Durante las particiones en la segunda mitad del siglo XVIII, el aborto estaba penalizado en los territorios polacos bajo las leyes de los países ocupantes. La primera regularización del aborto en Polonia data en 1932, cuando se adoptó, por influencia de la profesión médica y con el apoyo de algunas revistas femeninas de la época Głos Kobiet [La Voz de las Mujeres] o Kobieta Współczesna [Mujer Contemporánea] la despenalización del aborto por motivos criminales (incesto, violación, relaciones con personas con limitadas capacidades mentales) y de salud (bajo directas indicaciones médicas).

En 1956, el régimen comunista liberalizó el aborto para las mujeres en "condiciones difíciles de vida", las cuales eran certificadas desde el 1959 por el mismo médico que practicaba el aborto (Mazur 1981, 195-198). La legalización del aborto está relacionada, como en otros países comunistas, con la demanda de trabajo femenino en el mercado del trabajo remunerado, controlado por el Estado (Jankowska 1993, 291296). La ley con la que el Estado facilitaba el acceso al aborto también incluía las subvenciones de los anticonceptivos, aunque su provisión fue insuficiente. La falta de producción e importación de productos anticonceptivos convirtió al aborto, junto a los

\footnotetext{
${ }^{50}$ Véase también Glass y Fodor 2007.
} 
métodos "naturales", en el método de planificación familiar más utilizado en la Polonia comunista (Okolski 1983, 196; Nowicka 2000; 2007). La legislación del aborto fue una de las primeras que se reformaron en la Polonia democrática en 1990, cuando se discutió la primera propuesta de una ley de protección de niño no nacido (Fuszara 1991, 117-128). Frente a esta propuesta legislativa se formaron las primeras organizaciones oficiales de mujeres en el periodo de la transición: Polska Organizacja Feministyczna [Organización Feminista Polaca], Pro Fémina y Demokratyczna Unia Kobiet [Unión Democrática de Mujeres].

En 1991, los profesionales de la medicina cambiaron el Código de Ética Médica, introduciendo principios de protección del feto e imponiendo la prohibición de practicar la profesión a los médicos que hubieran practicado un aborto por motivos que no fueran de salud. En 1993, la ley comunista del aborto fue sustituida por la Ley de planificación familiar, protección del feto humano y condiciones para terminar el embarazo (Ilamada popularmente Ley Anti-aborto), que permite el aborto por motivos de salud física de la mujer, malformaciones graves e irreversibles del feto y por motivos criminales dentro de las primeras doce semanas del embarazo. La ley incluye los derechos a la anticoncepción y la educación sexual como maneras de limitar el número de embarazos no deseados. Esta ley, que continúa en vigor en la actualidad fue brevemente liberalizada en 1996 por el gobierno socialista de Sojusz Lewicy Demokratycznej (SLD) [Alianza de la Izquierda Democrática], cuando se incluyeron las condiciones económicas como un motivo para terminar el embarazo, liberalización que 
fue considerada inconstitucional por el Tribunal Constitucional en 1997 (Holc 2004, 757).

La interpretación restrictiva de la Ley Anti-aborto de 1993 por los médicos empleados en hospitales públicos contribuyó a la creación de servicios de abortos clandestinos, ya que era difícil hacer abortos legales en los hospitales públicos. El Estado no implementó ninguna política ejecutiva que subvencionara la anticoncepción, mientras los programas de educación sexual públicos estaban basados en los modelos de abstinencia, de acuerdo con los principios de la Iglesia Católica.

\subsection{Agentes implicados en la formulación de los debates}

En esta breve introducción he dado ya algunas pistas sobre las fuerzas involucradas en el proceso de creación de leyes acerca de la reproducción en Polonia. A continuación, profundizo en estas fuerzas, siguiendo el modelo de Scott.

\subsubsection{Los roles de género y los símbolos de feminidad en relación con el sistema político}

Uno de los símbolos más fuertes en la cultura polaca es la figura de Matka Polka [Madre Polaca], que ha sido denominado por Oleksy $(2005,179)$ como su "narrativa maestra". Es un tópico elaborado durante el romanticismo del siglo XIX, que estuvo muy relacionado con el cristianismo y el mesianismo de Polonia. En la literatura del periodo del romanticismo fue muy corriente la metáfora de Polonia como el "Cristo de las naciones", que sufre inocentemente para que las otras naciones puedan ser salvadas. En este contexto tan marcado por la religión, Matka Polka es una exaltación 
de la figura materna que, siendo portadora de la cultura y la lengua polaca y educadora de sus hijos e hijas, no tiene necesidades propias más allá de cultivar la cultura y sacrificarse por la nación. Es un referente simbólico fuerte y destacado, a pesar de que las mujeres en la historia de Polonia han desempeñando muchas funciones y no necesariamente maternas: patriotas, escritoras, educadoras, trabajadoras sociales, sufragistas etc., como apunta Shana Penn, autora estadounidense que ha estudiado el papel de las mujeres durante la transición democrática en Polonia (Penn 2005, 243). Durante el comunismo la figura de Matka Polka contó con el apoyo de la Iglesia Católica, siendo su alternativa a la propaganda del Estado que ofrecía imágenes de mujeres fuertes y trabajadoras, sin énfasis en la familia. Eso no significaba necesariamente que estos modelos fueran siempre bienvenidos: muchas mujeres-activistas de Solidarność entrevistadas por Penn evaluaban el papel de las mujeres propuesto por el Estado comunista como una “emancipación forzada” (Penn 2005, 80).

En cambio, durante el comunismo, Matka Polka tuvo una misión nueva: cultivar "el alma polaca" en el ámbito doméstico, resistir a la propaganda y educar a sus hijos e hijas en el catolicismo y la libertad, que fueron en este momento histórico casi sinónimos. Oleksy $(2004,163)$ llama la atención sobre la íntima conexión entre la figura simbólica de Matka Polka y el tótem cultural de la Virgen María, cuyo culto es una parte distinguida del catolicismo polaco, especialmente intenso en el caso de la Madonna Negra de Częstochowa, que fue coronada como reina espiritual de Polonia. 
En muchas representaciones artísticas de la madre polaca podemos encontrar analogías entre la figura de Matka Polka y la Virgen dolorosa.

Para ilustrar este concepto, reproduzco algunas de las representaciones de mujeres y madres polacas del siglo XIX de Artur Grotter, uno de los pintores románticos polacos más importantes. La primera obra (1866), posterior a la fallada insurrección de enero de 1863 contra la ocupación rusa, presenta una mujer joven despidiéndose de un joven al que está adornando para el combate (figura 16).

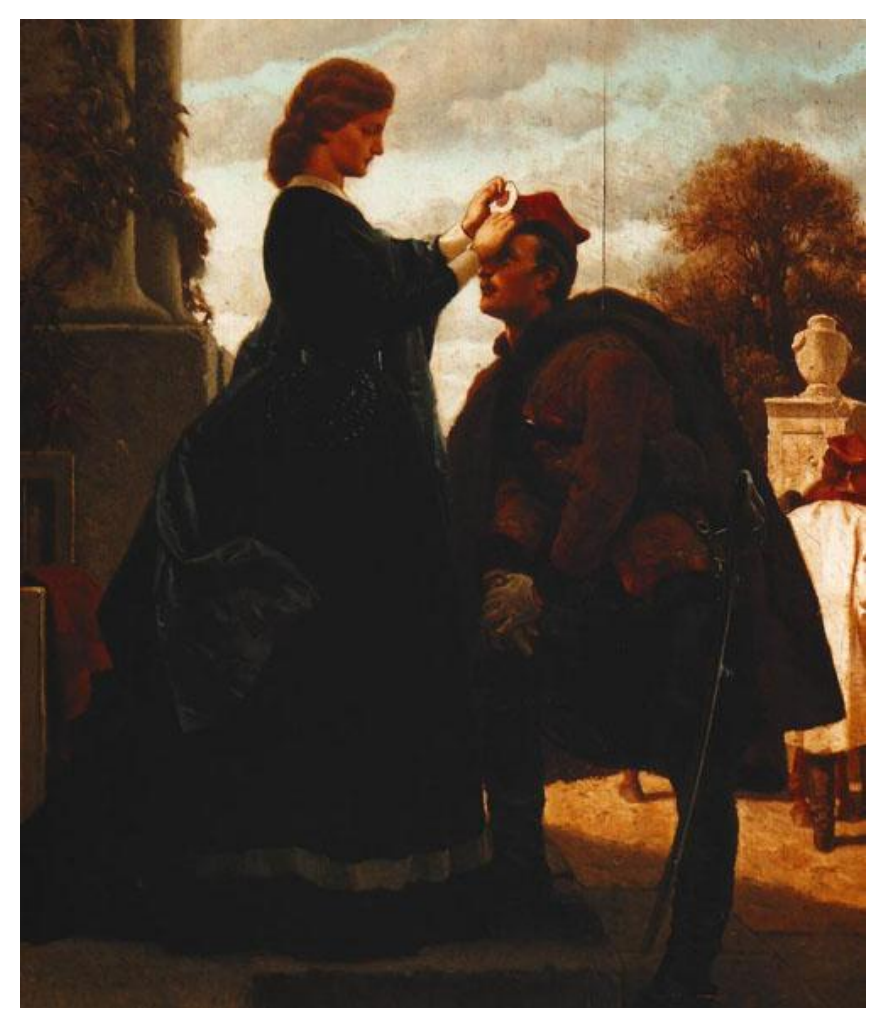

Figura 16 Grottger, Artur. 1866. Pożegnanie powstańca [La despedida del guerrillero]. Museo Nacional de Cracovia, http://www.malarze.pl; último acceso 03/08/2009. 
En cambio la figura 17, anterior en el tiempo (1863) pero también relacionada con la insurrección de 1863, representa el duelo de la madre y mujer/novia/hermana sobre el cuerpo de un guerrillero muerto. En la última obra (figura 18) (1866-67) Grotter vuelve a la escena de la despedida, pero esta vez la mujer lleva un bebé en brazos, que hace pensar en la representación habitual de la Virgen. Las figuras femeninas en estas obras son heroicas pero pasivas, en el sentido que despiden al hombre querido, esperan su vuelta y lloran después su muerte.

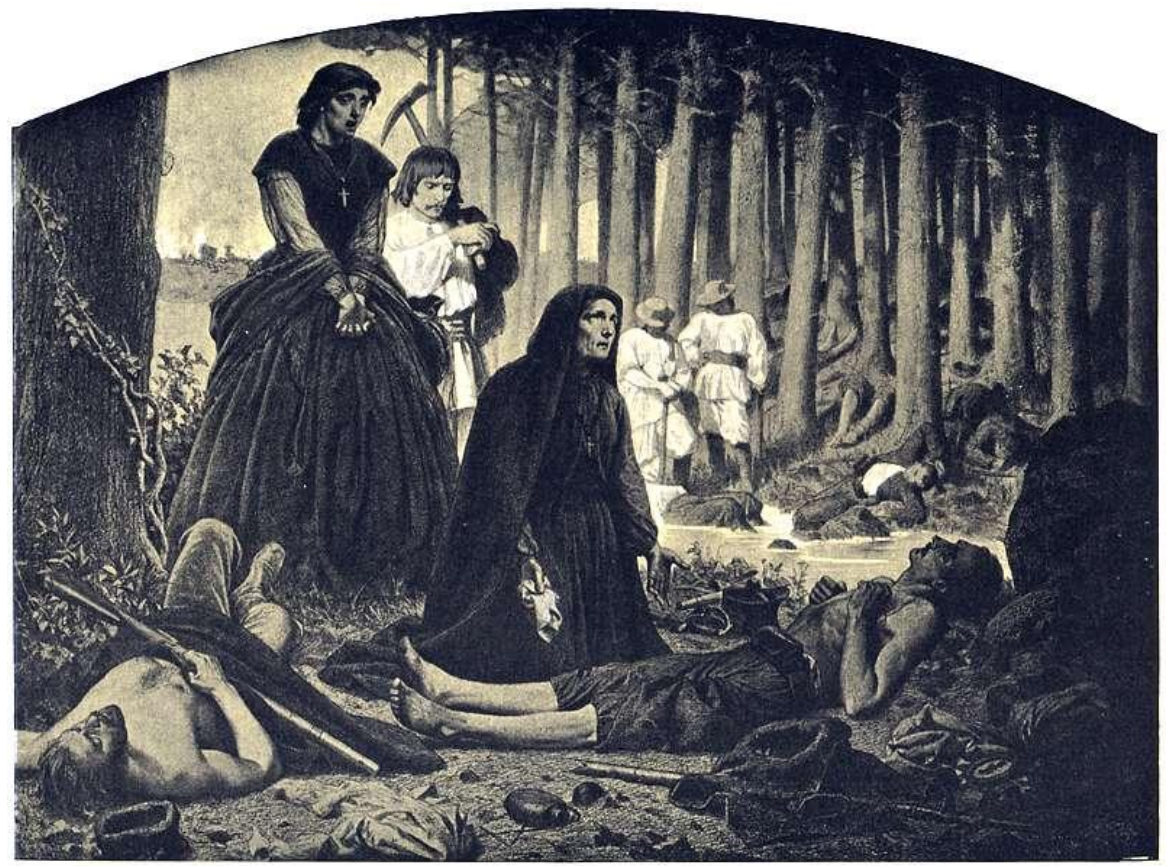

Figura 17 Grotter, Artur. 1863. Po bitwie [Después del combate]. Ciclo Polonia, http://www.pinakoteka.zascianek.pl; último acceso 03/08/2009. 


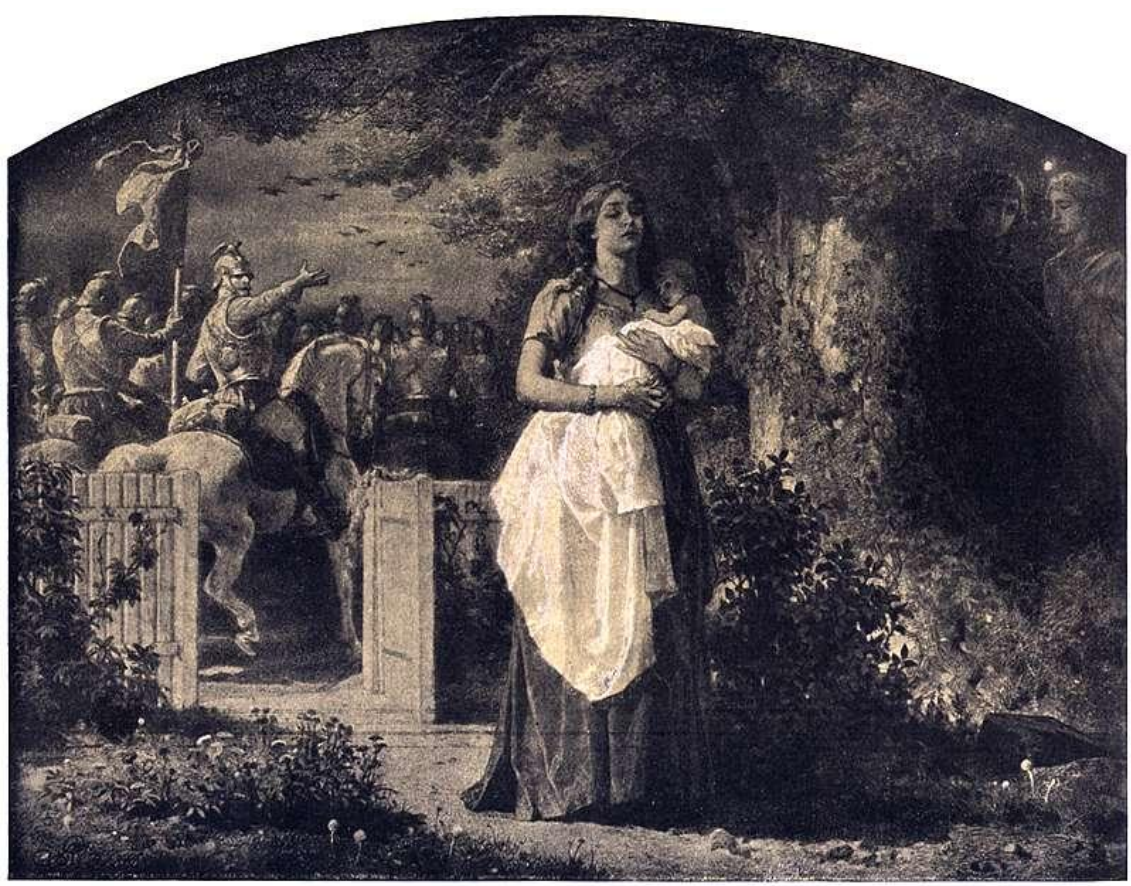

Figura 18 Grotter, Artur. 1866-7. Pożegnanie [Despedida]. Ciclo Wojna [Guerra], http://www.pinakoteka.zascianek.pl; último acceso 03/08/2009.

El ideal femenino de paciencia y auto negación permanece vivo durante el comunismo y en el periodo de la transición democrática, cuando se da un valor social alto a la figura genotípica de la mujer capaz de solucionar problemas relacionados con la perpetua falta de recursos, marcada por el sacrificio por la patria y la familia, por el que no esperaba más que gratitud (Titkow 1991, 253).

\subsubsection{La implicación de la Iglesia Católica en las políticas de la reproducción}

El carácter de los debates políticos y legales del aborto en Polonia está influido de manera destacada por las doctrinas de la Iglesia Católica acerca de la vida humana. La posición de la Iglesia en Polonia en el periodo de la transición democrática es particularmente fuerte por razones históricas, porque la Iglesia Católica polaca fue la 
única institución capaz de conservar su independencia frente a las particiones y el comunismo ateo. En el periodo de las particiones, el cristianismo, moldeado con mesianismo y romanticismo, formaba la raíz de la identidad nacional polaca en el contexto de los intentos de germanización y rusificación. En este contexto, la Iglesia Católica fue

el dispositivo amado de la historia, cultura y tradición de la nación y de la memoria colectiva del pueblo polaco (Casanova 1994, 137).

En el periodo de las particiones, la Iglesia estaba directamente involucrada en la resistencia y la preservación de la lengua y cultura polaca. Durante el periodo comunista, la Iglesia encarnaba la resistencia de la nación polaca contra el sistema político y social impuesto, creando una situación única en la escala europea, si tenemos en cuenta que de todos los países de Europa Occidental bajo el comunismo estatal solo Polonia conservó la institución religiosa independiente del Estado. La existencia de la Iglesia causó el fracaso de las estrategias comunistas de socialización, ya que ofrecía contra-socialización en las iglesias y en las familias, donde esta misión descansaba sobre las mujeres.

La posición de la Iglesia en la vida pública en Polonia se consolidó con la elección como papa de un cardenal polaco, Karol Wojtyła en 1978. Juan Pablo II fue durante todo su papado un declarado oponente a la anticoncepción y el aborto, trasmitiendo estos valores a la jerarquía y los católicos laicos de la Iglesia polaca ${ }^{51}$.

\footnotetext{
${ }^{51}$ Véase John Paul II 1995.
} 
En este contexto, la intervención directa de la Iglesia Católica en los debates acerca de la reproducción es un fenómeno que no sorprende. Ya durante el comunismo la jerarquía católica lanzaba peticiones a la profesión médica de no conformarse con la legalización del aborto. Durante la transición, la Iglesia expresaba su opinión contra el aborto de manera indirecta, a través de los activistas cristianos de Solidarność, y directamente, dirigiendo acciones de recogida de firmas con el apoyo de iniciativas de protección del feto. En cuanto a la anticoncepción, el discurso de la Iglesia Católica polaca acepta la posición de Vaticano que explícitamente condena tanto la anticoncepción como el aborto. A diferencia del aborto, la intervención de la Iglesia contra la anticoncepción no se ubica en la esfera política, siendo más bien transmitida durante las prácticas religiosas y las clases de religión en los colegios.

\subsubsection{Las intervenciones de la profesión médica en los debates sobre la anticoncepción y el aborto}

Otro actor social que influye en los discursos del aborto y anticoncepción es la profesión médica. La primera ley del aborto en Polonia de 1932 fue en gran medida promocionada por los profesionales médicos, particularmente por Tadeusz BoyŻeleński, médico y publicista muy reconocido, que describió en su libro Piekło kobiet [El infierno de las mujeres] (1930) las consecuencias de la penalización del aborto, como las muertes y daños irreversibles a la salud reproductiva relacionados con los abortos clandestinos. En el periodo de la transición, frente a la función casi anticonceptiva de la práctica del aborto en la Polonia comunista, la profesión médica, apoyada en la Iglesia, tomó la acción política directa para limitar el acceso al aborto: en 
1992 el Congreso Nacional de Profesionales Médicos aprobó la propuesta-elaborada en 1991-de limitar el aborto a las situaciones en las que el mismo estuviera justificado por motivos clínicos o criminales. De este modo, el acceso al aborto quedó restringido ya antes de la aprobación de la Ley Anti-aborto en 1993, aunque después de la intervención del portavoz del pueblo, esta iniciativa de la profesión médica fue pronunciada inconstitucional.

A partir de 1993 la mayoría de los médicos y hospitales públicos se declaran objetores de conciencia y dejan de practicar abortos incluso en los casos previstos por la Ley Anti-aborto. Por esas fechas, fuentes feministas denuncian la existencia de una red de servicios de aborto clandestino a un elevado coste. La información sobre cómo conseguir un aborto clandestino circula en redes y se anuncia en la prensa general bajo claves como "restitución de la menstruación", pero en el discurso oficial de la profesión médica domina la negación y el rechazo hacia el aborto. Esta situación de doble código de comportamiento es típica en el sistema sanitario polaco donde los servicios de salud que no se pueden hacer en hospitales públicos por falta de fondos, listas de espera etc., se acaban realizando en los mismos hospitales con regalos o dinero, o en las consultas privadas de los mismos médicos (Nowicka 2001).

En cuanto a la anticoncepción, aunque se encuentra a denuncias de médicos que se niegan a prescribir la píldora a sus pacientes, este tipo de reacciones se limitan a los ginecólogos de la seguridad social. En Polonia, los servicios de ginecología están en gran medida privatizados, es decir, la mayoría de especialistas tienen sus consultas 
privadas en las que atienden a pacientes que se lo pueden permitir. A menudo son también estas consultas privadas las que ofrecen abortos ilegales.

\subsection{El movimiento de mujeres y el movimiento feminista en Polonia en los años 1989-2004 en relación con las políticas de la reproducción}

Los papeles simbólicos de las mujeres polacas como madres y cuidadoras desinteresadas, que he descrito anteriormente, tuvieron, según Penn $(2005,321)$ un papel muy importante en la eliminación de las mujeres de los centros políticos decisivos en los primeros años de la década de 1990. Durante el periodo de la ley marcial 1981-1983, fueron las activistas del sindicato Solidarność [Solidaridad] las responsables de sostener el movimiento, ya que la mayoría de los líderes varones se encontraban encarcelados. Esta dedicación no se tradujo en la participación de mujeres en la creación del proceso democrático a principios de la década de 1990. Barbara Labuda, una de estas activistas, citada en la obra de Penn sobre las mujeres y Solidarność $(2005,278)$ apuntó que en la nueva cultura democrática pocas mujeres tenían la ambición política o demandaban ser representadas. Muchas de estas mujeres no consideraban su labor en el sostenimiento de Solidarność como algo excepcional, y afirmaban haber "hecho lo que se tenía que hacer". La alianza de los líderes varones de Solidarność con la Iglesia Católica, que pretendía llenar el vacío dejado por el Estado comunista para controlar la sociedad (Nowicka entrevistada por Penn 2005, 281), colocó a las mujeres fuera de las decisiones políticas, prometiendo que sus peticiones se tendrían en cuenta una vez solucionados los problemas más urgentes e importantes (Labuda entervistada por Penn 2005, 278). 
Un ejemplo de la trivialización de las peticiones políticas de las mujeres puede ser la historia de Sekcja Kobieca [Sección Femenina] de la Solidarność, fundada en 1989 bajo petición de la Confederación Internacional de Sindicados Libres, y con presidencia de una activista reconocida, Małgorzata Tarasiewicz. Cuando Sekcja Kobieca empezó a luchar por cuestiones de interés para las mujeres, como la eliminación de discriminación laboral, la promoción de la igualdad y la extensión de la baja maternal para los padres, defendiendo también el derecho al aborto, fue rápidamente silenciada por los líderes varones y finalmente cerrada en 1991. En este contexto Oleksy $(2005,179)$ recuerda el mural que apareció en la fábrica de naves en Gdańsk, la cuna de Solidarność en 1980: Kobiety, nie przeszkadzajcie nam. My walczymy o Polskę [Mujeres, no nos molestéis. Estamos luchando por Polonia].

Según Fuszara (1993, 242-251), el aborto fue el eje central sobre el cual se diferenciaron las fuerzas políticas embrionarias al principio de la década de 1990. En la década de 1980, Solidarność unía a los trabajadores e intelectuales que deseaban la democratización de Polonia. Entonces, el cristianismo fue sólo uno de los componentes ideológicos del movimiento, pero después de 1989 se convirtió progresivamente en la identidad dominante del sindicato. Sin embargo, no todos sus miembros estaban de acuerdo con propuestas tan radicales como la Ley de Protección del Niño no Nacido de 1989, lo cual provocó divisiones internas y la desintegración de Solidarność a principios de los 1990 (Fuszara 1994, 54). Una de estas divisiones está marcada por rasgos de género: las activistas de la Solidarność se opusieron 
explícitamente a las restricciones en la ley del aborto, pero fueron silenciadas por los líderes masculinos apoyados por la Iglesia Católica.

Este es también el primer momento en el que se habla en Polonia de "feminismo", aunque las mujeres abrazaron este término con una cierta desconfianza. El feminismo en aquella época se asociaba con una ideología forzada por un Estado totalitario y sus postulados sonaban como si formaran parte de la retórica engañosa del partido comunista. A pesar de ello, en la década de 1980 se formaron algunos grupos de autoconciencia, sobre todo en las universidades. Una de las principales activistas de Solidarność, Barbara Labuda (en figura 19 con Lech Wałęsa, líder de Solidarność, ganador del premio Nobel de la Paz y presidente de Polonia 1991-1995) también tuvo contacto con el feminismo francés durante los años que vivió en Paris en la década de 1970 (Penn 2005, 69). 


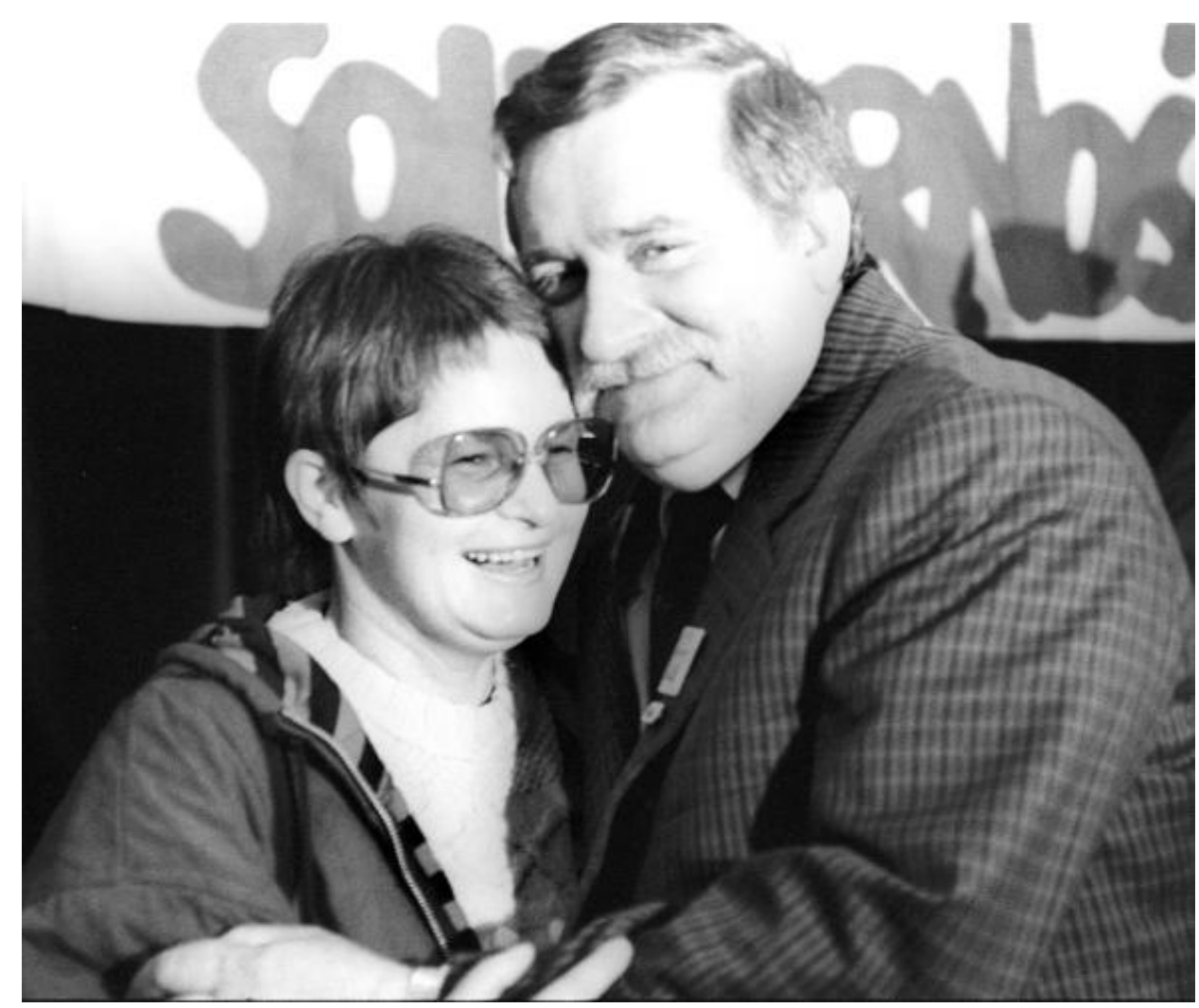

Figura 19 Barbara Labuda con Lech Wałęsa, 1989. En el fondo el logo de la Solidarność. Edición online del diario Dziennik, http://www.dziennik.pl; último acceso 03/07/2009.

Aquí cabe destacar la posición difícil del feminismo en la Europa postcomunista, ya que ni el feminismo occidental ni el postcolonial ofrecían herramientas teóricas o prácticas para abarcar la situación de las mujeres en la transición democrática después del régimen comunista. Una posible razón para ello puede ser la falta de división entre los ámbitos público y doméstico, sobre el que se basaba la crítica feminista occidental de la segunda ola. En Polonia, la esfera pública fue en gran medida una esfera de represión, mientras que la esfera privada se consideraba un espacio de libertad. En los ámbitos domésticos se organizaban encuentros intelectuales, educativos y religiosos, y los hombres protagonizaban muchos de ellos (Penn 2005, 199). 
En el clima de fuerte hostilidad y trivialización de las peticiones femeninas para mantener el aborto legal, se crearon treinta grupos feministas independientes, de los cuales los más fuertes fueron: Polska Organizacja Feministyczna, Pro Fémina y Neutrum, que postulaban la separación del Estado y la Iglesia (Penn 2005, 280). Todas estas organizaciones se juntaron en 1991 constituyendo la Federación Polaca por las Mujeres y la Planificación Familiar (logo en figura 21), cuya presidenta, Wanda Nowicka (figura 22), sigue siendo la defensora más importante de los derechos reproductivos en Polonia y representa al país como experta independiente en muchos foros internacionales.
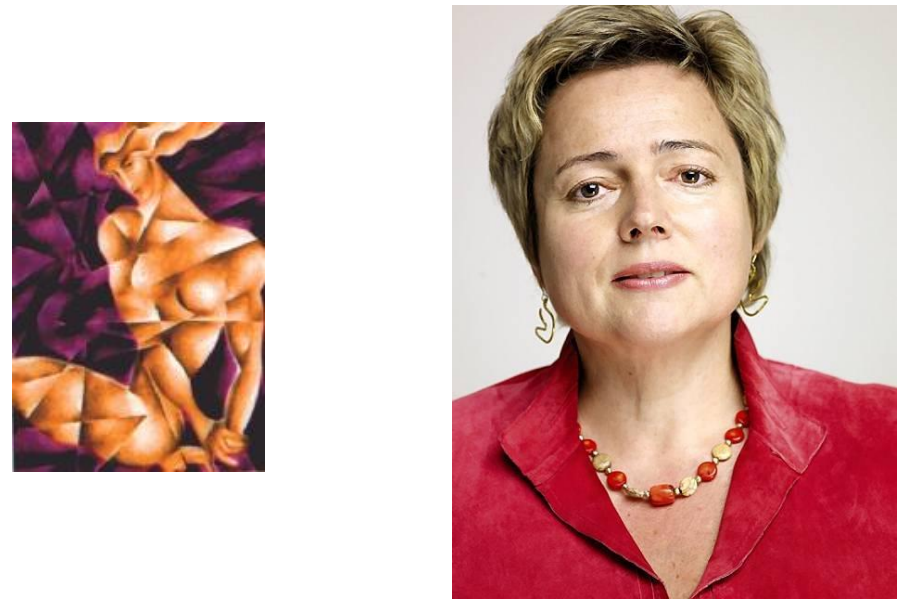

Figura 20 (izquierda) Logo de la Federación Polaca por las Mujeres y la Planificación Familiar, http://www.federa.org.pl; último acceso 29/07/2009.

Figura 21 (derecha) Wanda Nowicka, presidenta de la Federación Polaca por las Mujeres y la Planificación Familiar. Edición online del diario Gazeta Wyborcza, http://www.gazeta.pl; último acceso 10/09/2009.

La lucha del feminismo polaco recién constituido contra la deslegalización del aborto contaba con el apoyo de la opinión pública, las feministas consiguieron recoger firmas en contra de los proyectos de la restricción de la ley del aborto y a favor de 
convocar un referéndum popular para decidir sobre el destino de la ley. Estos esfuerzos no fueron reconocidos por la presidenta del gobierno Hanna Suchocka y el presidente de la república, Lech Wałęsa, quienes en 1993 aprobaron la ya descrita Ley Anti-aborto ${ }^{52}$.

Después de esta derrota, el movimiento feminista polaco no consiguió movilizar a la sociedad alrededor de los derechos reproductivos, aunque siguiera reivindicándolos. Progresivamente, los valores promocionados por la Iglesia en el campo reproductivo se iban implementando en la esfera política y después de la decisión de la Corte Constitucional de 1997 que proclamó ilegal el aborto por motivos económicos, no hubo otro intento del cambio de la Ley Anti-aborto de carácter masivo, pero la ley, junto a la falta de subvención del Estado a los caros anticonceptivos hormonales y la falta de educación sexual, es objeto de constante crítica feminista $^{53}$. Esta crítica, sin embargo, no consigue movilizar a la sociedad para transformar la situación.

\footnotetext{
${ }^{52}$ Para más información sobre las vidas reproductivas de las mujeres como recursos simbólicos en la Europa Central y Oriental (estudios de caso de Polonia, Serbia y Alemania Oriental) durante y después del comunismo, véase Alsop y Hockey 2001.

${ }^{53}$ En 2007 se constituyó en Polonia Partia Kobiet [El Partido de Mujeres] bajo liderazgo de la escritora feminista Manuela Gretkowska. El impulso para Gretkowska de crear el movimiento Polska Jest Kobietq [Polonia Es una Mujer], que luego se institucionalizó como partido, fue precisamente la cuestión del aborto clandestino. Cuando se constituyó el partido, fui a un mitin del Partido de Mujeres en mi cuidad de origen, Łódź, en abril de 2007. En el mitin, el público empezó a preguntar si la revisión de la Ley Antiaborto se iba a incluir en el programa del partido. Gretkowska contestó que las cuestiones reproductivas en Polonia son temas que causan divisiones sociales y para atraer más apoyo para el partido no se van a incluir en el programa. Sin embargo, en el manifiesto Polska jest kobietq, se juntan muchos postulados que abarcan la salud reproductiva, como:
}

- asistencia médica a las mujeres, sobre todo durante el embarazo, y el parto, 


\subsection{Discurso del feminismo polaco: sacando a la luz abusos y testimonios}

El discurso del feminismo polaco durante el periodo analizado tiene un enfoque más práctico que teórico. Tomando como punto de partida la Ley Anti-aborto del 1993, la reflexión feminista se concentra en denunciar la situación legal y real creada por dicha ley, es decir, las situaciones de precariedad reproductiva que tienen que afrontar las mujeres polacas en las condiciones de casi inaccesibilidad del aborto gratuito, ni siquiera de carácter terapéutico. Las primeras denuncias Ilaman la atención al hecho de que, a pesar de que la Ley Anti-aborto permite la interrupción del embarazo cuando este pone en peligro la vida o la salud (física) de la mujer, se sospechan graves e irreversibles malformaciones en el feto o el embarazo es el resultado de un acto penalizado, en la práctica es casi imposible conseguir abortar en un hospital público, incluso presentando documentos o certificados que confirman la legalidad de la intervención. Al mismo tiempo, existe una amplia y bien organizada red de centros que ofrecen abortos clandestinos:

- mejor asistencia del Estado a la familia y niños en familias pobres,

- liquidación de orfanatos y su sustitución por servicios de cuidado dentro de las familias profesionales de recogida,

- igualación de los salarios de hombres y mujeres,

- aumento de penas para violadores,

- asistencia a las madres solteras,

- educación sexual,

- ayuda del Estado para la refundación de los métodos anticonceptivos y los tratamientos de infertilidad,

- posibilidad de autogestión en las cuestiones de la planificación familiar (http://www.polskajestkobieta.org; último acceso 10/09/2009).

Como vemos, el partido apoya el acceso real (es decir, subvencionado por Estado, lo cual incluye también a las mujeres pobres) a los métodos anticonceptivos y la educación sexual, pero para el derecho al aborto se utiliza un eufemismo "autogestión en las cuestiones de planificación familiar". Este eufemismo refleja el bloqueo del lenguaje y la invasión de valores católicos respeto a las cuestiones reproductivas en la esfera política polaca, de la que hablaré más adelante en este capítulo. 


\begin{abstract}
El fariseísmo, la cobardía y el servilismo hacia la única verdadera fuerza ideológica (la Iglesia Católica-mi comentario-) han dado origen a los servicios del aborto clandestino. Para complacer a la jerarquía eclesiástica, los directores de los hospitales públicos declaraban uno por uno que su conciencia no les permitía que se practicaran abortos, incluso legales, en estos establecimientos. Y el hecho de que el mismo médico después de las seis de la tarde en su consulta privada, bien remunerado, "provocara la menstruación" con el método de aspiración, era un secreto a voces y se mantenía si ningún competidor envidioso llamaba a la policía ${ }^{54}$ (Dąbrowska-Szulc, 2003).
\end{abstract}

Por otro lado, la Ley Anti-aborto incluye el deber del Estado de facilitar a las parejas el acceso a la planificación familiar y, a los y a las jóvenes, la educación sexual. Estas promesas no se han cumplido en el periodo que he estudiado y este hecho también se coloca en el centro de la atención feminista. Como causas de esta situación, las feministas polacas destacan: el discurso pro-vida como discurso dominante en Polonia, la resistencia de los médicos tanto a la anticoncepción como al aborto, y la falta de voluntad política para introducir cambios por parte de los partidos liberales.

El primer elemento de referencia para el discurso feminista es el discurso provida, que se ha convertido en el discurso público sobre el aborto y la anticoncepción en Polonia. Las feministas denuncian que como consequencia de la Ley Anti-aborto, el discurso pro-vida, su reconocimiento de la subjetividad fetal, y la percepción del feto como portador de derechos se ha convertido en el único discurso legítimo sobre la reproducción:

\footnotetext{
${ }^{54}$ Fałsz i zakłamanie, tchórzostwo i serwilizm wobec jedynie słusznej siły ideologicznej doprowadziły do rozkwitu podziemia aborcyjnego. Dla wkupienia się w taski hierarchii kościelnej ordynatorzy kolejnych państwowych, publicznych szpitali deklarowali, że sumienie tychże obiektów nie przyzwala na przeprowadzanie w nich zabiegów przerywania ciq̨ży nawet wówczas, gdy sq dozwolone ustawq. A że ten sam pan doktor po godzinie 18.00 w swoim prywatnym gabinecie za odpowiedniq opłatq "wywoła period" metoda próżniowq, to było tajemnica poliszynela, chyba że zawistny konkurent doniósł na policję.
} 
En Polonia se ha legitimizado un modo de pensar, hablar y valorar el aborto que tiene sentido solamente a un nivel religioso. Durante los últimos años han desaparecido prácticamente del lenguaje público palabras como "feto" y "embarazo". Su lugar lo han ocupado palabras como "niños no nacidos" y "protección de la vida no nacida". Al aborto se le llama "asesinato", y a la mujer embarazada simplemente "madre" ${ }^{55}$ (Graff 2001, 112);

El feto es una criatura del espacio, un mensajero de Dios, un ser puro, metafísico, separado. Y la mujer - ha desaparecido ${ }^{56}$ (Graff 2001, 117);

Los que están contra del derecho a la elección no tienen ya porque usar términos como "vida no nacida" o "vida concebida". Es suficiente decir simplemente "vida". Eso quiere decir que aquellos que reconocen el derecho moral de la mujer a decidir si continuar con un embarazo no deseado, se han convertido en los "enemigos de la vida" o simplemente asesinos ${ }^{57}$ (Graff 2001, 119).

Este proceso se inició en 1989 con las primeras propuestas de ley que extendía al feto los derechos de ciudadanía, luego desembocó en la Ley Anti-aborto de 1993 y progresivamente esta idea se ha ido transfiriendo al lenguaje cotidiano. Agnieszka Graff lo comenta de siguente modo:

Hemos perdido la guerra sobre el lenguaje. Las expresiones como "libre elección" o "el derecho de la mujer a decidir", usadas por los liberales en Occidente, nunca se han hecho funcionales en el idioma polaco. Estuvieron por aquí durante una temporada, pero después de la aprobación de la presente ley (Anti-aborto) no se las escuchó más. Los que están contra esta ley hablan ahora de "decisiones trágicas", o de que el aborto es a veces "el mal necesario". Es un lenguaje pésimo, igual que la argumentación. Porque si estamos de acuerdo en que una parte del conflicto es "la vida", la otra tiene que ser "la muerte" ${ }^{58}$ (Graff 2001, 121).

\footnotetext{
${ }^{55}$ W Polsce uprawomocnit się taki sposób myślenia, mówienia i wartościowania w kwestii aborcji, który ma rację bytu wyłącznie na gruncie religijnym. W ciqgu ostatnich kilku lat z języka publicznego praktycznie znikły słowa takie jak "płód" $i$ "ciqża". Ich miejsce zajęły "dzieci nienarodzine" $i$ "ochrona życia poczętego". Aborcję nazywa się "zabijaniem", a kobieta w ciq̨ży to dziś po prostu "matka".

${ }^{56}$ Płód jest przybyszem z kosmosu, wysłannikiem od Pana Boga, bytem czystym, metafizycznym, całkowicie odrębnym. A kobieta - znikła.
}

${ }^{57}$ Przeciwnicy prawa do wyboru nie muszq już używać terminów "życie nienarodzone” ani też “życie poczęte". Wystarczy "życie”. Oznacza to, że ci, którzy uznaja moralne prawo kobiety do decydowania, czy chce donosić niechcianq ciążę, zostali zepchnięci na pozycję "wrogów życia", czyli po prostu morderców.

Przegraliśmy wojnę o język. Frazy takie jak "wolny wybór" lub "prawo kobiety do decydowania", którymi posługujq się liberalne środowiska na Zachodzie, nigdy nie zadomowiły się w polszczyźnie. Przez chwilę 
Según el discurso feminista, este proceso fue posible gracias a la posición privilegiada de la Iglesia Católica, que impidió que se abriera la discusión política sobre la Ley Antiaborto. En cambio, la lógica y el lenguaje pro-choice [libre elección en las cuestiones reproductivas] se han convertido, en este contexto, en propuestas que parecen muy radicales:

La prohibición del aborto después de casi cuarenta años de una ley liberal me parecía imposible. Entonces no me parecía que lo que estaba haciendo era algo radical. Solamente después, cuando como un resultado de una agresiva campaña ideológica el centro se ha movido hacia la derecha, las opiniones compartidas por la mayoría y públicamente expresadas por muchas personas conocidas y respetadas (actores, científicos, abogados, médicos) han empezado a ser tratadas como extremas y radicales $^{59}$ (Sitkowska entrevistando a Nowicka 2003).

El segundo aspecto de las consecuencias de la Ley Anti-aborto que se destaca en el discurso feminista es la falta de voluntad por parte de los médicos para prescribir la anticoncepción hormonal y certificar la necesidad de practicar abortos terapéuticos en hospitales públicos, mientras que es bastante fácil conseguir un aborto clandestino. Los médicos, junto a los políticos, se convierten en el objeto principal del ataque feminista: según su discurso se niegan a solicitar a las mujeres análisis prenatales,

migały tu i ówdzie, ale wkrótce po uchwaleniu obecynej ustawy przestało się je słyszeć. Przeciwnycy ustawy mówiq teraz o "tragicznych decyzjach", o tym, że aborcja to czasem "zło konieczne". Marny to język, marna argumentacja. Bo jeśli już przystaliśmy na to, że po jednej stronie jest "życie", to po drugiej stronie może być tylko "śmierć".

${ }^{59}$ Wprowadzenie zakazu aborcji po prawie czterdziestu latach liberalnego prawa wydawało się niemożliwe. Nie miałam więc wtedy żadnego poczucia, że robię coś radykalnego. Dopiero potem, kiedy na skutek krzykliwej i wszechobecnej kampanii ideologicznej centrum przesunęło się na prawo, poglaqdy akceptowane wtedy przez zdecydowanq większość i publicznie wypowiadane przez wiele osób znanych $i$ szanowanych (aktorów, naukowców, prawników, lekarzy itp.) zaczęły być traktowane jako skrajne czy radykalne.

Cabe mencionar que el discurso pro-choice y el discurso feminista no son en el caso polaco discursos iguales; por ejemplo, el discurso del feminismo católico polaco, que no es objeto de este estudio, apoya la igualdad de género pero se opone, precisamente, al derecho de las mujeres al acceso al aborto y algunas formas de la anticoncepción (Tomaszewska 2002, 5-8). 
incluso las mujeres que ya tienen hijos con enfermedades genéticas, igual que a practicar abortos a las mujeres cuyo embarazo lleva consigo riesgos para su vida y su salud, como en el caso de Alicja Tysiąc ${ }^{60}$. Además, no informan a las parejas sobre las malformaciones fetales para no tener que practicar el aborto (Godlewska y Solik 2001; Federacja na Rzecz Kobiet i Planowania Rodziny 2004). Por otro lado, se denuncia que muchos médicos practican abortos en sus consultas privadas, a las que acuden también las mujeres que deberían tener abortos terapéuticos gratuitos en hospitales públicos. En cuanto a la anticoncepción, muchos médicos son igualmente objetores de conciencia para la anticoncepción, sobre todo para la píldora del día después.

El último elemento de la denuncia feminista es la decepción con los partidos de izquierdas (sobre todo SLD) que incluyeron el postulado de la liberalización de la Ley Anti-aborto, la mejora del acceso a la anticoncepción y la educación sexual en su programa antes de las elecciones de 2001. Sin embargo, las cuestiones de interés para las mujeres nunca han sido abordadas seriamente por los políticos:

Dentro de la cuestión de la liberalización de la interrupción del embarazo estoy preocupada no porque el gobierno consecuentemente se niega a ocuparse de este tema, porque nosotras esperamos la iniciativa del Parlamento. Lo que es particularmente escandaloso es la repetición por parte de varias voces de que el cambio de la Ley Anti-aborto no es un asunto importante, que otras cuestiones tienen prioridad sobre el derecho de las mujeres a la autodeterminación o las situaciones dramáticas vividas por miles de mujeres por culpa de esta ley ${ }^{61}$ (Nowicka 2002).

\footnotetext{
${ }^{60}$ Tysiąc perdió la vista después de que se le hubiera negado un aborto y acudió al Tribunal Europeo de Derechos Humanos presentando una demanda contra Polonia. El Tribunal reconoció que se había violado su derecho a la privacidad en una sentencia de 2007.

${ }^{61}$ W sprawie liberalizacji przerywania ciqż̇y niepokoi nawet nie to, że rzqd konsekwentnie podkreśla, że nie zamierza się tym zajqć, ponieważ inicjatywy w tej sprawie oczekujemy raczej od Parlamentu. To, co
} 
Se presta atención en particular al supuesto acuerdo entre la Iglesia y el gobierno motivando que los proyectos de cambios en la materia de derechos reproductivos se han suspendido para que la Iglesia apoye al gobierno para el referéndum en el que se decidía la entrada de Polonia en la Unión Europea:

Es difícil creer en las declaraciones del gobierno y de la Conferencia Episcopal de que no hubo ningún tipo de acuerdo sobre este asunto (la liberalización del aborto suspendida para ganarse el apoyo de la Iglesia en el referéndum europeo-mi comentario-) ${ }^{62}$ (Nowicka 2002)

Las prácticas feministas que aparecen en las fuentes que son, sobre todo la denuncia de las consecuencias de la Ley Anti-aborto a través de testimonios personales y denuncias dirigidas a la comunidad internacional. En todos los libros que he analizado se presentan historias contadas por mujeres que tuvieron dificultades al demandar la prescripción de anticonceptivos orales o el aborto terapéutico en la sanidad pública, o hacen públicas sus experiencias del aborto clandestino por motivos terapéuticos, económicos o personales. Entre ellas se cuentan relatos de abortos clandestinos caros, pero practicados con compasión y en buenas condiciones, y casos que acabaron con la vida de la mujer (Godlewska y Solik 2001). Los testimonios de la ya mencionada Alicja Tysiąc y del matrimonio Wojnarowscy (Godlewska y Solik 2001; Koral 2001; Szczuka 2004) se han incorporado en el discurso feminista polaco como ejemplos de las malas

szczególnie bulwersuje, to nieustanne powtarzanie wielogłosowo, że zmiana ustawy antyaborcyjnej nie jest sprawq ważnq, że wszystkie inne problemy sq znacznie ważniejsze niż prawo kobiet do samostanowienia czy dramaty tysięcy kobiet spowodowane tq ustawq.

${ }^{62}$ Trudno bowiem uwierzyć w zgodne zapewnienia rzq̨du i Episkopatu, że nie doszło do żadnych wspólnych uzgodnień w tej sprawie. 
consecuencias de la Ley Anti-aborto. Estas historias pretenden hacer públicas las experiencias privadas de las mujeres e desvelan la práctica del aborto clandestino en Polonia, que se convirtió durante el periodo que he analizado en una especie de "secreto a voces".

El discurso de las feministas polacas traspasa las fronteras nacionales y pretende llegar a la comunidad internacional (Fuszara 1991): de hecho, a principio de la década de 1990, cuando se forman las primeras organizaciones feministas para oponerse a las propuestas de la prohibición completa del aborto, se publican más artículos en libros y revistas académicas extranjeras que en Polonia. Esta situación se puede explicar de dos maneras. En primer lugar, el primer movimiento feminista polaco a comienzos de la década de 1990 todavía no había creado espacios para una producción feminista propia, como revistas feministas. En segundo lugar, este movimiento no creía en la posibilidad de que la prevalencia del discurso pro-vida, iniciada en este periodo, fuera permanente. En la segunda mitad de los noventa, cuando el protagonismo del discurso pro-vida en los debates sobre aborto y anticoncepción en Polonia se ha consolidado, el movimiento feminista polaco empieza a analizar las experiencias del movimiento feminista francés y estadounidense en los procesos de la liberalización de las leyes del aborto, para buscar inspiración y ejemplos (Szczuka 2004, 58-78), y mantiene una estrecha conexión con las estructuras y colectivos feministas internacionales que se ocupan de derechos reproductivos, como 
Women on Waves ${ }^{63}$. La parte activista del movimiento participa en las conferencias internacionales sobre las mujeres, donde constituye una representación de Polonia alternativa respecto al gobierno (Nowicka 1999; Kobiety 2000 - Konferencja ONZ [Mujeres 2000 - Conferencia de la ONU] 2000). Estos esfuerzos tienen una doble función: por un lado llamar la atención de la Unión Europea y las organizaciones que se dedican a la defensa de los derechos humanos sobre la situación en Polonia que, según las feministas no cumple las recomendaciones comunitarias en cuanto a la inclusión de los derechos reproductivos en el catálogo de derechos universales. Por otro lado, es una búsqueda de ayuda concreta, como fue en el ya mencionado caso de Alicja Tysiąc.

Las denuncias documentadas por testimonios de mujeres se centran en la doble moral que se ha creado acerca del aborto: como ya he dicho, mientras que es muy difícil conseguir un aborto terapéutico en los hospitales públicos, existe, sobre todo en las ciudades, una amplia oferta de servicios, generalmente seguros, aunque caros. Entonces, la decisión de abortar es una decisión de carácter económico:

\begin{abstract}
Si una tiene los dos mil (zlotys, el precio típico de un aborto clandestino-mi comentario-) o sabe de dónde sacarlos, entonces se puede permitir el lujo de tomar las decisiones autónomas de carácter moral. Tienes la pasta-eres un sujeto, no la tienes-te conviertes en un objeto. Y pido a las mujeres que sí pueden conseguir los dos mil, no me cuenten historias sobre la libertad verdadera que florece cuando (el Estado) protege a la vida no nacida. Porque con esta libertad "verdadera" tienen también esta otra libertad "peor" - la libertad de (no tener) hijos. (...) Hoy en día es
\end{abstract}

\footnotetext{
${ }^{63}$ Women on Waves es una organización activista feminista fundada en los Países Bajos, con la misión de proveer servicios de abortos seguros y información sobre ellos para los países donde el aborto voluntario es ilegal. El colectivo realiza sus actividades a través de la página web y un barco, que, invitado por las organizaciones feministas locales viaja a los países donde el aborto no es legal y lleva a las mujeres al mar internacional para practicar abortos farmacológicos. Sin embargo, el objetivo principal de estos viajes es la sensibilización sobre el problema del aborto clandestino. Women on Waves visitaron Polonia en el verano de 2003 (Szczuka 2004, 235). Para más información, consúltese la pagina web de Women on Waves, http://www.womenonwaves.org.
} 


\title{
Agata Ignaciuk \\ DISCURSOS FEMINISTAS SOBRE EL ABORTO Y LA ANTICONCEPCIÓN EN ITALIA \\ (AÑOS SETENTA) Y POLONIA (AÑOS NOVENTA)
}

\begin{abstract}
muy complicado encontrar un hospital, en el que se practiquen abortos legales, porque muy a menudo la conciencia de los médicos les impide practicar abortos gratuitos. (...) Estoy pensando, cómo serían las discusiones (sobre el aborto) si no existiera el aborto clandestino, lo cual es muy sencillo de cambiar. Si, y estamos cerca de ello, todos los hospitales se negaran a practicar abortos. Además, se debería prohibir a todas las mujeres en la edad reproductiva salir del país. Entonces nosotras, las mujeres que tenemos la libre elección, también las mujeres pro-vida, nos encontraríamos en una situación igual a la que se encuentran muchísimas mujeres polacas. Las que no tienen pasaportes, ni los dos mil, ni ningún apoyo cuando van a buscar un aborto a la sanidad pública ${ }^{64}$ (Dunin 2001).
\end{abstract}

En cuanto a la anticoncepción, las feministas consideran que el acceso a ella está "fuertemente dificultado por razones económicas" (Zieliński 1998) o "bloqueado" (Antykoncepcja... [Anticoncepción] 2001) porque el Estado no subvenciona ningún tipo de la anticoncepción hormonal de la última generación. Además de las barreras económicas, las mujeres encuentran obstáculos por parte de los médicos, que aplican su derecho a la objeción de conciencia también a la prescripción de la anticoncepción hormonal (Federacja na Rzecz Kobiet i Planowania Rodziny 2004), y se tienen que enfrentar a la presión ideológica de la Iglesia. Otro motivo por el que las mujeres no

\footnotetext{
${ }^{64}$ Jeśli ma się te dwa tysiqce lub wiadomo, skąd je wygrzebać, można sobie pozwolić na luksus podejmowania autonomicznych decyzji moralnych. Masz szmal - jesteś podmiotem, nie masz - stajesz się przedmiotem. I proszę, żeby kobiety, które potrafiq zdobyć dwa tysiqce, nie zawracały mi głowy opowieściami o prawdziwej wolności, która rozkwita, gdy chroni się nienarodzone życie. Bo poza tq prawdziwq wolnościq majq jeszcze tę gorszq wolność - czyli wolność od przymusu rodzenia. (...) Bardzo trudno jest dziś znaleźć szpital, w którym można dokonać legalnej aborcji, sumienie lekarskie często zabrania bowiem wykonywania zabiegów za darmo. (...) Jestem przekonana, że nawet największa przeciwniczka aborcji czuje się jednak lepiej, majq̨ w zapasie takq furtkę. I w Polsce jq ma. Dlatego uważam, że dyskusje o aborcji sq tak nieuczciwe. Toczq się one w gronie tych, którzy bez większych konsekwencji mogq spierać się o abstrakcyjne zasady. Ciekawa jestem, jakby wyglqdały te dyskusje, gdyby zlikwidowano podziemie aborcyjne, co jest przecież całkiem proste. Gdyby - do czego nie jest nam daleko - wszystkie szpitale odmawiały wykonywania zabiegów. No i trzeba by wydać zakaz opuszczania kraju przez kobiety w wieku reprodukcyjnym. Wówczas my, kobiety majqce wolny wybór, również te pro life, znalazłybyśmy się w sytuacji będqcej udziałem ogromnej rzeszy polskich kobiet. Tych, które nie majq paszportów, dwóch tysięcy i żadnego wsparcia, gdy usiłuja wyegzekwować swoje prawa w oficjalnej służbie zdrowia.
} 
acuden a la anticoncepción que plantea el discurso feminista es la educación sexual, que se realiza hasta 2002 en institutos a base de manuales basados en valores católicos, que recomiendan abstinencia como el mejor método anticonceptivo y reproducen estereotipos de género y visiones negativas de la homosexualidad y sexualidad pre matrimonial (Graff 2001; Środa 1999/2000; Solik 2001).

Este tipo de discurso holístico de derechos reproductivos, o discurso que se centra en los tres pilares de la salud reproductiva: derecho a la anticoncepción, educación sexual y aborto, fue expresado durante la manifestación feminista el 8/03/2002 cuyo eslogan fue Trzy razy tak: dla antykoncepcji, edukacji seksualnej $i$ prawa do aborcji [Tres veces sí: por la anticoncepción, la educación sexual y el derecho al aborto]. La manifestación, representada en la portada del número 11/2002 de la revista Zadra (figura 22) se convocó con el poster (figura 23) que luego formó parte de la muestra Moje Życie Mój Wybór [Mi Vida Mi Decisión] organizada por la Federación Polaca por las Mujeres y la Planificación Familiar en Varsovia en 09/2002 (luego la exposición se presentó en otras ciudades polacas). 


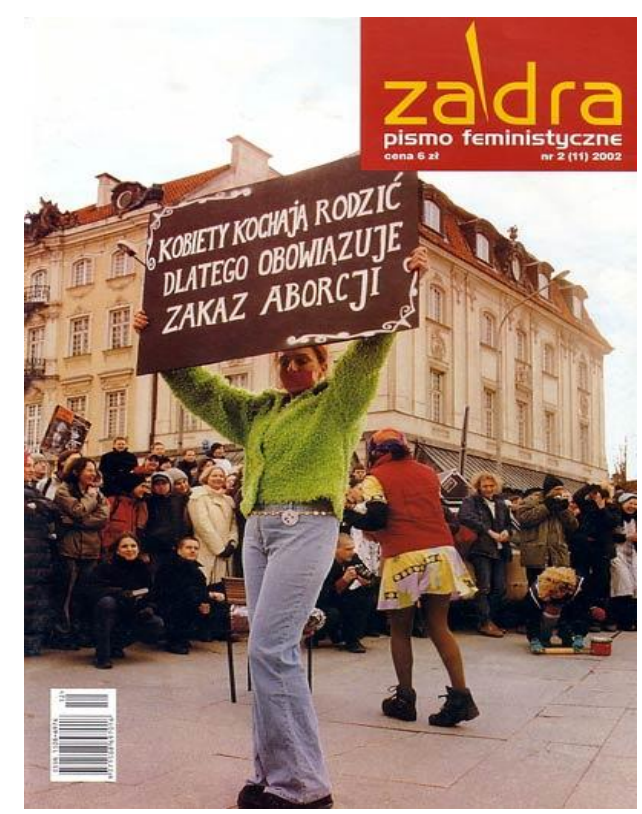

Figura 22 [A las mujeres les encanta parir, por eso sigue la prohibición del aborto]. La foto de la manifestación feminista Trzy razy tak de 8/03/2002 en Varsovia. Portada de la revista Zadra 11/2002. Imagen tomada de la página de la Fundación Efka, http://efka.org.pl/index.php?action=z spt; último acceso 13/09/2009.

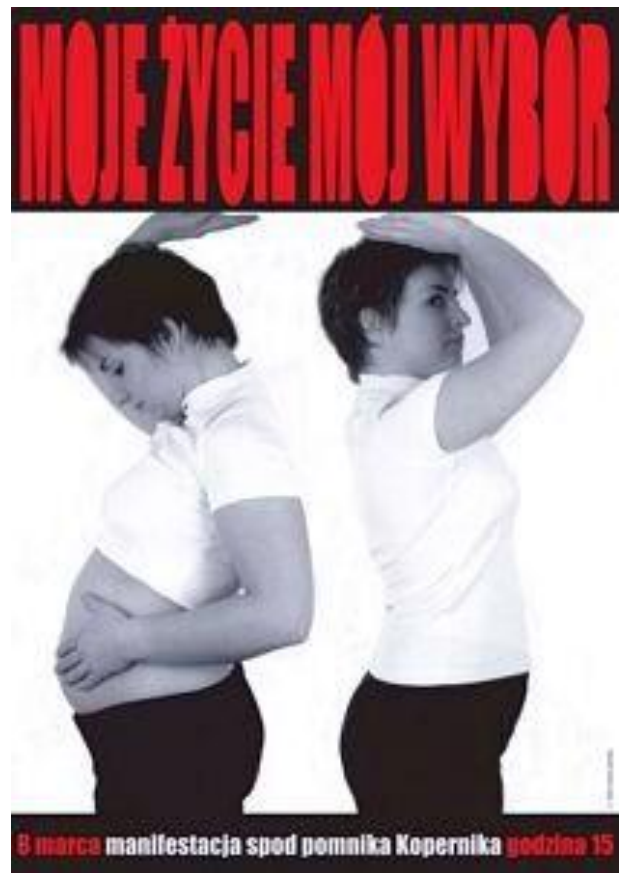

Figura 23 Zielińska, Monika. 2002.[Mi vida mi decisión]. Póster para convocar a la manifestación feminista del 8 de marzo de 2002, http://www.federa.org.pl; último acceso 29/07/2009. 
Para resumir mi análisis del discurso feminista polaco sobre la anticoncepción y el aborto es preciso detenerse en una reflexión sobre cómo se plantean las relaciones del poder y de género en este discurso. Las feministas polacas del periodo de la transición identifican como discurso dominante del debate sobre el aborto y la anticoncepción el discurso pro-vida, adoptado incluso por partidos que se declaran liberales o de izquierdas. En tan solo cuatro años después de la recuperación de la democracia en Polonia la Iglesia Católica y las fuerzas políticas de carácter conservador han conseguido universalizar su ideología relacionada con los derechos del feto y el concepto de "vida concebida", convirtiéndolos en una Ley Anti-aborto. Pero la misma ley ha generado o fortalecido, según leo en el discurso feminista polaco, otras relaciones de poder: la jerarquización en la relación entre las mujeres y los médicos (porque en el sistema público los médicos tienen poder de negar a las mujeres abortos legales y la anticoncepción), y la relación entre las mujeres y los políticos (porque estos dejan de lado sus promesas electorales en cuestiones importantes para las mujeres, para arreglar primero otras, de máxima urgencia para el Estado y todos los ciudadanos, la repetición de la situación de los postulados de las mujeres de Solidarność). El discurso feminista polaco no relaciona aparentemente las dificultades en el acceso a la anticoncepción y el aborto experimentadas por las mujeres con desigualdades de género; el patriarcado no aparece en las fuentes que he revisado como un motivo de esta situación. Sin embargo, una segunda lectura de las fuentes aporta una reflexión sobre una pregunta que se repite en el discurso feminista una y otra vez: ¿Por qué las necesidades de las mujeres no son políticamente importantes? ¿Porque las mismas 
mujeres no se movilizan acerca de sus derechos reproductivos y no los reclaman públicamente? Detrás de esta situación está sin duda la desigualdad de género y los roles establecidos y fortalecidos por la influencia de la Iglesia Católica. En este contexto, parece que la escala de abortos clandestinos no interesa al Estado, permaneciendo como un secreto de mujeres que no se puede compartir con nadie. 


\section{Conclusiones}

Como he querido demostrar en este trabajo, las prácticas del aborto y de la anticoncepción, analizadas de acuerdo con el modelo propuesto por Joan Scott, permanecen en íntima conexión con los papeles de género y se formulan a través de los símbolos, las normas, y las instituciones, y tienen implicaciones finales distintas para cada individuo que las usa. Los debates sobre el control de la reproducción en Italia en la década de 1970 y en Polonia en el periodo de la transición (1989-2004), tal como he expuesto a base de fuentes y bibliografía utilizadas en mi análisis, están marcados por la presencia de los actores y estructuras sociales, y la relación entre ellos (la Iglesia Católica, la profesión médica, el movimiento feminista, el movimiento provida), así como los roles de género fundamentados durante los procesos históricos vividos en estos países (fascismo en Italia, comunismo estatal en Polonia).

La tarea de comparar los discursos feministas en Italia en la década de 1970 y en Polonia en el periodo de la transición supone confrontar fuentes heterogéneas producidas en contextos diferentes, tanto temporales como sociales y culturales. Sin embargo, la comparación de los dos discursos permite ver las limitaciones y las oportunidades de los movimientos feministas en su reivindicación de los derechos reproductivos, influidas por otros agentes implicados en los procesos de la formulación de los debates sobre el aborto y la anticoncepción, como la Iglesia Católica y la profesión médica. 
Aunque tanto en Polonia como en Italia el catolicismo fue una religión mayoritaria durante los periodos analizados, existen importantes diferencias en la posición política y social de la Iglesia Católica. En Polonia, un país que estuvo durante más de cuarenta años bajo la dictadura comunista, la Iglesia Católica fue percibida como una institución liberadora y democrática. Durante el proceso de la transición hacia la democracia, esta posición se tradujo en un real poder político, de modo que la delegalización del aborto se convirtió en un acto que legitimaba el poder del nuevo gobierno democrático y el triunfo histórico de la Iglesia Católica sobre el régimen comunista.

En cambio, en la Italia de los setenta la transición que ocurrió es de carácter social, y llevó consigo desmembramiento radical de las leyes fascistas opresivas para las mujeres. Las prohibiciones del aborto y de la anticoncepción codificadas en el código penal fascista reflejaban la enseñanza moral de la Iglesia Católica, pero para sostenerlas el Vaticano no contaba con un apoyo social vasto. Al contrario, la mayoría de la sociedad italiana en esta época pedía la separación de la Iglesia del Estado y expresaba un interés por combatir el fenómeno del aborto clandestino.

La profesión médica participó activamente en los debates sobre el aborto y la anticoncepción tanto en Polonia como en Italia. Sin embargo, mientras en Italia los profesionales de la medicina generalmente apoyaban al movimiento feminista en sus esfuerzos para la legalización de la anticoncepción y el aborto, en Polonia el sector sanitario tomaba sus propias acciones policías para limitar el acceso al aborto en los 
hospitales públicos. Por otro lado, en ambos países los discursos feministas critican los abusos relacionados con el derecho a la objeción de conciencia para los médicos que no quieren prescribir la anticoncepción oral o de emergencia, o practicar abortos en estructuras sanitarias públicas.

Las posturas distintas de estos agentes activos en la formulación de los debates sobre el control de la reproducción, junto con los roles de género y los símbolos de feminidad presentes en las sociedades polaca e italiana, han influido en el desarrollo del movimiento feminista y en los modos en los que este construye su discurso sobre el aborto y la anticoncepción. El discurso del feminismo italiano tiene un carácter expansivo, es decir, promociona los cambios pero funciona dentro de la voluntad general que da la bienvenida a la transformación hacia la sociedad más liberal e igualitaria. Este discurso, procedente de varias organizaciones y colectivos feministas (CRAC, UDI, MDL), interviene contra la opresión de las mujeres, cooperando con la sociedad y los políticos, para cumplir, por lo menos sobre el plano legal, con el objetivo de legalizar el acceso a la anticoncepción y el aborto voluntario.

Por otro lado, en Polonia, veinte años después, la posición feminista en este debate se construye, sobre todo, haciendo públicas las historias personales de las mujeres como víctimas de un sistema represivo de derechos reproductivos en Polonia. El movimiento feminista no está muy organizado, y su discurso proviene más bien de personas concretas y de una única organización, la Federación Polaca por las Mujeres y la Planificación Familiar. 
La oposición al patriarcado toma forma distinta en Italia y Polonia: mientras en el discurso feminista italiano se elabora una reflexión profunda sobre el patriarcado en relación a la sexualidad y la maternidad, en Polonia la reflexión se vuelve hacia el patriarcado político, es decir en contra de los partidos políticos que tratan las cuestiones reproductivas y las peticiones de las mujeres en general como si no merecieron un abordaje serio.

Igualmente, el mismo aborto clandestino es otro punto focal de ambos discursos que he analizado. En el discurso feminista italiano, el aborto clandestino se presenta como una forma de violencia contra las mujeres; en Polonia se destaca más bien el aborto clandestino en relación con las desigualdades económicas y la necesidad de acudir al mismo incluso en los casos en los que se debería poder practicar un aborto gratuito en un hospital público. El rol de la anticoncepción es central en ambos discursos feministas, que destacan el carácter imprescindible de la planificación familiar como un medio de evitar embarazos no deseados y abortos. En el caso de Polonia las feministas destacan también la educación sexual como otro elemento de la maternidad responsable y planeada.

He observado una continuación del discurso feminista italiano con otros discursos feministas relacionados con el aborto y la anticoncepción de la segunda ola del feminismo occidental. Las mismas feministas italianas retoman ejemplos de Estados Unidos y Francia y utilizan métodos muy parecidos, como trabajo en grupos de autoconciencia, prácticas de autoayuda en el campo de la salud para recuperar el 
control de las mujeres sobre sus cuerpos y sistemas reproductivos, y autogestión de la anticoncepción y el aborto como prácticas feministas y de desobediencia civil. El discurso feminista polaco se encuentra en un lugar distinto. Haciendo referencia a las mismas experiencias de feminismo en Estados Unidos y Francia, no encuentra en el feminismo occidental los modelos de acción en la situación política en la que durante la transformación del sistema económico comunista hacia el capitalismo y la democracia se reprime el derecho al aborto. Las prácticas feministas del pasado vuelven en el discurso feminista polaco como ejemplos de éxitos en la lucha de las mujeres por la autonomía reproductiva. Sin embargo, los métodos no pueden ser los mismos: el feminismo polaco opera en un contexto distinto y por ello emplea técnicas diferentes, como el uso de testimonios y denuncias de hechos $y$, si toma acciones directas, las mismas se centran en el campo de la autogestión de la educación sexual (como los programas ofrecidos por la Federación) ${ }^{65}$.

El discurso feminista italiano de la década de 1970 y el discurso polaco del periodo 1989-2004 están separados por distancia geográfica y temporal. Sin duda los distintos contextos sociales influyen en las formas en las que aparece en cada país el movimiento feminista y cómo se expresa acerca del control de la reproducción. Dentro del mismo movimiento feminista se abordan las cuestiones del aborto y la

\footnotetext{
${ }^{65}$ El eco del movimiento por la autonomía de las mujeres en la salud estadounidense e italiano se pueden observar en la acción "Dar a luz de manera humana" que se inició en Polonia en 1994. Iniciada por un grupo de periodistas y activistas, la acción denunciaba el tratamiento humillante durante los partos en algunos hospitales públicos en Polonia y tuvo un enorme apoyo social. A base de esta acción se formó una fundación con el mismo nombre (1996) (http://www.rodzicpoludzku.pl; último acceso 13/09/2009) que sigue promocionando activamente los cambios en la práctica médica de la atención al embarazo y parto. Sin embargo, las mismas medidas no se han adoptado en la situación de la prevención del embarazo y el aborto.
} 
anticoncepción desde ángulos diferentes, respondiendo a los diferentes actores sociales que en su conjunto modelan el discurso sobre la reproducción en una época y país dado.

\subsection{Propuestas de la futura investigación}

Una manera de profundizar en este estudio sería ampliar el análisis del discurso feminista polaco e italiano incluyendo la elaboración de discursos concurrentes producidos por la Iglesia Católica y el ambiente médico. De esta manera, se crearía una imagen más completa del estado de los hechos; se también podría ubicar y valorar mejor el papel del movimiento feminista en los procesos de formulación de las leyes y políticas acerca del control de la reproducción. En este caso, sería fundamental realizar entrevistas a las personas del movimiento feminista, jerarquía de la Iglesia Católica, la comunidad católica laica, y sector sanitario, activas en los debates sobre el aborto y la anticoncepción en los países analizados.

Otra propuesta es ampliar este estudio por otros países Europeos con prevalencia de la religión católica y con experiencias de ocupaciones (Irlanda) o dictaduras de derechas (España). Asimismo, se podría analizar el papel del movimiento feminista en un espectro más amplio de interacciones con las jerarquías políticas, los discursos pro-vida y la Iglesia Católica. Tal estudio podría iluminar cómo las diferentes posiciones de la Iglesia Católica, y las experiencias de transición política y social, influyen en la formación y empoderamiento del movimiento feminista y en su interés por la legalización del aborto y la anticoncepción. 


\section{Fuentes}

\subsection{Italia}

(Anticoncezionali.) Dove, come, quando: Ecco gli indirizzi. 1974. Effe (1): 47.

Abortire a Washington. 1973. Effe (1): 4-6.

Aborto a quindici anni pro e contro. 1974. Effe (1): 23-25.

Aborto. Le ultime leggi hanno radici antiche. 1978. Quotidiano Donna (1): página de cubierta.

Aborto. Madonne non piangete. II senato decide l'esame degli articoli: Via libera all'aborto. 1978. Quotidiano Donna (2): página de cubierta.

Anna Maria. 1978. Contro di noi i vescovi rispolveranno la scomunica. Quotidiano Donna (3): página de cubierta.

Anticoncezionali. Quando la fifa ci mette lo zampino. 1974. Effe (2): 41.

Anticoncezionali: Indirizzi dei consultori. 1975. Effe (5): 40.

Ascoli, Giulietta. 1979. Dossier aborto. Sposate sì, nubili no. Noi Donne (16): 17-31.

Assemblea del Consultorio della XIX Circoscrizione. 1978. La unica realtà: Occupazione. Quotidiano Donna (22): página de cubierta.

Bellonzi, Bruna. 1974. Le difficoltà dei pionieri. Noi Donne (35): 38-39.

Benemeglio, Rosanna. 1979. Da leggere per essere più informate. Noi Donne (16): 3031.

Cambira, Adele y Daniela Colombo. 1973. Aborto/Non lo fo per piacer mio. Effe (1): 2.

Cambira, Adele. 1973. Intervista con una giornalista cattolica (Nicoletta Roscioni). Effe (2): 42-43.

Cari vescovi vi abbiamo denunciato. 1979. Quotidiano Donna (1): página de cubierta.

Carla. 1979. Stato e Chiesa dicono: Non lasciamole sole, controlliamole. Quotidiano Donna (2): página de cubierta. 
Comitato Romano per l'Aborto e la Contraccezione. 1975. Vogliamo consultori autogestiti. Effe (11): 7-8.

- - 1981 [1975]. Documento constitutivo. En Oltre l'aborto. Posizioni e documenti del movimento delle donne. Metodi di controllo della fecondità. Chiesa e "dissenso". La legge e le proposte di modifica, eds. Cristina Damiani, Marina Graziosi, Valeria Moretti, Re Nucci, Stella Rosetta y Alessandra Zito, 19-21. Roma: Cooperativa Editoriale Ottanta.

- - 1981 [1976]. Piattaforma per i consultori. En Oltre l'aborto. Posizioni e documenti del movimento delle donne. Metodi di controllo della fecondità. Chiesa e "dissenso". La legge e le proposte di modifica, eds. Cristina Damiani, Marina Graziosi, Valeria Moretti, Re Nucci, Stella Rosetta y Alessandra Zito, 21-24. Roma: Cooperativa Editoriale Ottanta.

Continuamo a pubblicare le firme di adesione alla denuncia fatta da Quotidiano Donna contro i vescovi della CEI el invitiamo le compagne a presentare denunce uguagli nelle loro città. 1979. Quotidiano Donna (5): página de cubierta.

Contro le minacce dei vescovi. La nostra denuncia. 1979. Quotidiano Donna (3): página de cubierta.

Coordinamento Consultori Governo Vecchio. 1981 [1979]. Lettera aperta alle Reggione Lazio. En Oltre l'aborto. Posizioni e documenti del movimento delle donne. Metodi di controllo della fecondità. Chiesa e "dissenso". La legge e le proposte di modifica, eds. Cristina Damiani, Marina Graziosi, Valeria Moretti, Re Nucci, Stella Rosetta y Alessandra Zito, 57-59. Roma: Cooperativa Editoriale Ottanta.

Coordinamiento Donne Università Scuola. 1978. Legge sull'aborto. Perchè continuano a nasconderci le liste dei medici obiettori? Quotidiano Donna (21): página de cubierta.

Cosa c'è dietro di un gesto disperato. 1978. Quotidiano Donna (19): página de cubierta.

Cristiani per il Socialismo. 1981 [1976]. Dal documento uscito dal seminario nazionale. En Oltre l'aborto. Posizioni e documenti del movimento delle donne. Metodi di controllo della fecondità. Chiesa e "dissenso". La legge e le proposte di modifica, eds. Cristina Damiani, Marina Graziosi, Valeria Moretti, Re Nucci, Stella Rosetta y Alessandra Zito, 24-34. Roma: Cooperativa Editoriale Ottanta.

Cristina y Coordinamento Donne della Provincia di Gorizia. 1978. È una brutta legge in mano a gente cattiva. Quotidiano Donna (11): página de cubierta.

D. T. 1972. Anticoncezionali. Non basta la legge. Effe (0): 38. 
Dal opuscolo "Roma Policlinico": Un reparto occupato dalle donne. En Oltre l'aborto. Posizioni e documenti del movimento delle donne. Metodi di controllo della fecondità. Chiesa e "dissenso". La legge e le proposte di modifica, eds. Cristina Damiani, Marina Graziosi, Valeria Moretti, Re Nucci, Stella Rosetta y Alessandra Zito, 46-52. Roma: Cooperativa Editoriale Ottanta.

Dal Pozzo, Giuliana. 1974. Libera di non avere o di avere un figlio. Noi Donne (35): 2539.

Di Paolo, Leila. 1979. I punti neri, anzi nerissimi. Noi Donne (16): 26-30.

Elena M. 1978. Denunciamoli, si fa così. Quotidiano Donna (10): página de cubierta.

Elena. 1978. La legge sull'aborto. L'autodeterminazione è inconstituzionale? Quotidiano Donna (9): página de cubierta.

- - 1979. E, se sei povera, ti tolgono anche i figli. Quotidiano Donna (4): página de cubierta.

Fancescato, Donata. 1975. Tanto il dopo-aborto me lo godo io... Effe (11): 5-6.

Fancescato, Grazia. 1975. NO al compromesso sul nostro corpo. NO al compromesso sull'aborto. Effe (11): 9-10.

Giovannetti, Patrizia. 1979. Non lo posso dire ai miei, ma lo posso dire al giudice? Noi Donne (16): 22-25.

Grazia y Marina B. 1978. Come smascherare medici opportunisti prima cucchiai d'oro e ora obiettori di conscienza? Quotidiano Donna (6): página de cubierta.

Grossetto. Licenziata perchè ha abortito. 1978. Quotidiano Donna (0): página de cubierta.

Indirizzi dei centri nei quali si ottengono consigli e visite sugli anticoncezionali. 1972. Effe (0): 37.

Irene. 1978. I nuclei aborto non smobilitano. Quotidiano Donna (8): página de cubierta.

La pillola maschile. 1975. Effe (3): 22.

Leonelli, Leslie. 1972. Anticoncezionali. Dove trovarli, quando usarli. Intervista con Luigi de Marchi. Effe (0): 36-37.

- - . 1973. Anticoncezionali...ma non troppo. Effe (2): 47. 
Magda. 1975. Compagno, dimmi con chi vai... Effe (11): 11-12.

Manisco, Paola. 1975. SPUC: Contro l'aborto. Effe (3): 40.

Marina G. 1978. La corsa dei sacchi. Come fare una legge che approvi l'aborto per vietare l'aborto. Quotidiano Donna (3): página de cubierta.

- - . 1978. La legge è in ferie, rispettare la legge. Quotidiano Donna (13-14): página de cubierta.

Mercoledì si riuniranno a Roma i nuclei aborto. 1978. Quotidiano Donna (7): página de cubierta.

Movimiento di Liberazione della Donna. 1981 [1978]. Manifesto (A tutte le donne...). En Oltre l'aborto. Posizioni e documenti del movimento delle donne. Metodi di controllo della fecondità. Chiesa e "dissenso". La legge e le proposte di modifica, eds. Cristina Damiani, Marina Graziosi, Valeria Moretti, Re Nucci, Stella Rosetta y Alessandra Zito, 53. Roma: Cooperativa Editoriale Ottanta.

- - 1981 [1979]. Documento (aborto libero e gratuito...). En Oltre l'aborto. Posizioni e documenti del movimento delle donne. Metodi di controllo della fecondità. Chiesa e "dissenso". La legge e le proposte di modifica, eds. Cristina Damiani, Marina Graziosi, Valeria Moretti, Re Nucci, Stella Rosetta y Alessandra Zito, 54-57. Roma: Cooperativa Editoriale Ottanta.

Nuova Zelanda. II Movimento dei Bambini Non Nati ha partorito una legge-mostro. 1978. Quotidiano Donna (24): página de cubierta.

Queste le proposte di leggi. 1974. Noi Donne (35): 27-32.

Remiddi, Laura. 1974. Aborto. Cosa significa per noi il progetto Legge Fortuna. Effe (1011): $44-46$

Rivolta Femminile y Carla Lonzi. 1974 [1970]. Sputiamo su Hegel. En Sputiamo su Hegel. La donna clitoridea e la donna vaginale, 13-22. Milano: Rivolta Femminile.

- - . 1991 [1972]. Sessualità femminile e l'aborto. En Italian feminist thought: $A$ reader, eds. Sandra Kemp, Paola Bono, 37-40. Oxford: Basil Blackwell.

Roscioni, Nicoletta. 1973. Aborto. Il disagio del mondo cattolico. Effe (2): 40-41.

Sabatini, Alma. 1974. Anticoncezionali. Tra due fuochi. Effe (10-11): 49.

Sassarolli, Sandra e Isabella Rosselini. 1975. Commento sulla legge-truffa. Effe (11): 2. 
Sopravvivere in Borgata. 1973. Effe (1): 6.

Stati Uniti. Tra venti giorni le donne tutte in piazza per l'aborto. 1979. Quotidiano Donna (10): página de cubierta.

Testimonianze. Dopo l'aborto un modo di crescere insieme. 1975. Effe (11): 3-5.

Testimonianze. L'aborto terapeutico in Austria. 1975. Effe (6-7): 19.

Testimonianze. Perchè faccio aborti. 1975. Effe (6-7): 18.

Tiziana. 1978. Diario di un aborto. Quotidiano Donna (17): página de cubierta.

Un aborto si dovrebbe fare così. 1979. Noi Donne (16): 18-25.

Unione Donne Italiane. 1981 [1976]. Aborto come violenza. En Oltre l'aborto. Posizioni e documenti del movimento delle donne. Metodi di controllo della fecondità. Chiesa e "dissenso". La legge e le proposte di modifica, eds. Cristina Damiani, Marina Graziosi, Valeria Moretti, Re Nucci, Stella Rosetta y Alessandra Zito, 24-34. Roma: Cooperativa Editoriale Ottanta.

\subsection{Polonia}

Antykoncepcja - fragmenty dyskusji z listy internetowej Gender [La anticoncepción fragmentos de la discusión de la lista Gender]. 2001. Zadra (2): 38-39.

Antykoncepcja w praktyce [Anticoncepción en la práctica]. 1999. Mam Prawo (4). Accesible online en http://www.federa.org.pl/mamprawo.php?catid=165\&lang=1; último acceso 12/09/2009.

Ciszek, Małgorzata. 1994. Pamiętnik z czasów obowiązywania ustawy antyaborcyjnej [El diario de los tiempos de la ley anti-aborto]. Pełnym Głosem (2). Accesible online en http://efka.org.pl/index.php?action=p art\&ID=3; último acceso 13/09/2009.

Dąbrowska-Szulc, Ewa. 2003. SLD-owskie obiecanki [Las promesas de SLD]. Zadra (1314): $46-47$

Dunin, Kinga. 2001. Buńczuczny plemnik? Sprytne jajo? [¿¿Un espermatozoide rebelde, un óvulo listo?]. Zadra (1): 9-14.

- - . 2001. Dwa tysiące na skrobankę [Dos mil para la intervención]. Wysokie Obcasy (110). Accesible online en http://www.wysokieobcasy.pl/wysokieobcasy/1,96856,320252.html; último acceso 10/09/2009. 
Federacja na Rzecz Kobiet i Planowania Rodziny. 2004. Piekło kobiet trwa [El infierno de las mujeres continua]. Accesible online en http://www.federa.org.pl/publikacje/pieklo2.pdf; último acceso 12/09/2009.

Fuszara, Małgorzata. 1991. Will the abortion issue give birth to feminism in Poland? En Women's issues in social policy, eds. Mavis Maclean, Dulcie Groove, 205-228. London: Routledge.

Głosuj świadomie [Vota conscientemente]. 2004. Mam Prawo (2). Accesible online en http://www.federa.org.pl/mamprawo.php?catid=181\&lang=1; último acceso 12/09/2009.

Godlewska, Barbara y Aleksandra Solik, eds. 2001. Piekło kobiet. Historie współczesne [El infierno de mujeres. Las historias contemporáneas]. Warszawa: Federación Polaca por las Mujeres y la Planificación Familiar. Accesible online en http://www.federa.org.pl/publikacje/podrecznik/pieklo kobiet/index.htm; último acceso 12/09/2009.

Graff, Agnieszka. 2001. Znikająca kobieta. Polskie rozmowy o prawie do aborcji [La mujer desaparece. las conversaciones polacas sobre el derecho al aborto]. En Świat bez kobiet. Płeć w polskim życiu publicznym [El mundo sin mujeres. El género en la vida pública polaca], 115-151. Warszawa: W. A. B.

Interwencja policji gabinecie ginekologicznym w Lublińcu. List do RPO [La intervención en la consulta ginecológica en Lubiniec. Carta al Portavoz del Pueblo]. 2000. Mam Prawo (2). Accesible online en http://www.federa.org.pl/mamprawo.php?catid=168\&lang=1; último acceso 12/09/2009.

Jawień, Bożena. 2002. Marketing u ginekologa [Marketing en la consulta del ginecólogo]. Zadra (1): 38.

Kobiety 2000 - Konferencja ONZ [Mujeres 2000 - Conferencia de la ONU]. 2000. Mam Prawo (3). Accesible online en http://www.federa.org.pl/mamprawo.php?catid=169\&lang=1; último acceso 12/09/2009.

Kobiety na Falach (Women on Waves). 2000. Mam Prawo (4). Accesible online en http://www.federa.org.pl/mamprawo.php?catid=170\&lang=1; último acceso 12/09/2009.

Komitet Ster. 2003. Solidarne z kobietami. Trzy razy tak [Solidarias con las mujeres. Tres veces si]. Mam Prawo (2). Accesible online en http://www.federa.org.pl/mamprawo.php?catid=178\&lang=1; último acceso 12/09/2009. 
Koral, Jolanta. 2001. Tutaj lekarz jest Bogiem [Aqui el médico es Dios]. Wysokie Obcasy (145). Accesible online en http://www.wysokieobcasy.pl/wysokieobcasy/1,53662,553147.html; último acceso 10/09/2009.

Kowbasiuk, Natalia. 2004. Ta straszna wystawa [Esta exhibición tan horrible]. Zadra (1): 27-28.

Mity o aborcji [Los mitos sobre el aborto]. 2003. Zadra (4-1): 54.

Nowicka, Wanda. 1993. Ban on abortion in Poland. Women's Global Network for Reproductive Rights Newsletter (43): 49.

Nowicka, Wanda. Skutki ustawy antyaborcyjnej [Las consecuencias de la Ley Antiaborto de 1993]. 1996. Federación Polaca por las Mujeres y la Planificación Familiar. Accesible online en http://www.federa.org.pl/publikacje/raporty/rapab96.htm; último acceso 12/09/2009.

- - . 1998. 50 lat Powszechnej Deklaracji Praw Człowieka [Cincuenta años de la Declaración Universal de Derechos Humanos]. Mam Prawo (3). Accesible online en http://www.federa.org.pl/mamprawo.php?catid=164\&lang=1; último acceso 12/09/2009.

- - . 1999. Komitet Praw Człowieka wobec dyskryminacji kobiet w Polsce [La Comisión de Derechos Humanos frente a la discriminación de las mujeres en Polonia]. Mam Prawo (5). Accesible online en http://www.federa.org.pl/mamprawo.php?catid=166\&lang=1; último acceso 12/09/2009.

- - . 2002. Komentarz bieżący [Comentario sobre la actualidad]. Mam Prawo (1). Accesible online en http://www.federa.org.pl/mamprawo.php?catid=175\&lang=1; último acceso 12/09/2009.

- - . 2003. Przyszedł czas na otwartą debatę [Ha llegado el tiempo para un debate abierto]. Mam Prawo (3). Accesible online en http://www.federa.org.pl/mamprawo.php?catid=179\&lang=1; último acceso 12/09/2009.

- - - 2003. Wychowanie seksualne po polsku [Educación sexual en Polonia]. Federación Polaca por las Mujeres y la Planificación Familiar. Accesible online en http://www.federa.org.pl/publikacje/mat info/zeszyt3.pdf; último acceso 12/09/2009.

- - - 2004. Genewa a sprawa polska [La cuestión polaca en Ginebra]. Mam Prawo (3). Accesible online en 
http://www.federa.org.pl/mamprawo.php?catid=739\&lang=1; último acceso 12/09/2009.

- - - 2004. Obietnica ostatniej szansy [La promesa del último recurso]. Mam Prawo (1). Accesible online en http://www.federa.org.pl/mamprawo.php?catid=180\&lang=1; último acceso 12/09/2009.

Realizacja ustawy antyaborcyjnej - krytyka z lewa i z prawa [La realización de la Ley Anti-aborto - las críticas de la izquierda y de la derecha]. 2001. Mam Prawo (2). Accesible online en http://www.federa.org.pl/mamprawo.php?catid=172\&lang=1; último acceso 12/09/2009.

Sitkowska, Klaudia. 2003. Wywiad z Wandą Nowicką, przewodniczącą Federacji na Rzecz Kobiet i Planowania Rodziny [Entrevista con Wanda Nowicka, presidenta de la Federación Polaca por las Mujeres y la Planificación Familiar]. Mam Prawo (1). Accesible online en http://www.federa.org.pl/mamprawo.php?catid=177\&lang=1; último acceso 12/09/2009.

Solik, Aleksandra. 2001. Edukacja seksualna po polsku [Educación sexual en Polonia]. Mam Prawo (4). Accesible online en http://www.federa.org.pl/mamprawo.php?catid=174\&lang=1; último acceso 12/09/2009.

Spurek, Sylwia y Marcin Anaszewicz. 2003. Kultura aborcji [La cultura del aborto]. Zadra (2): 9-10.

Środa, Magdalena. 1999/2000. Błogosławiona nieświadomość [Bendita falta de conciencia]. Mam Prawo (1). Accesible online en http://www.federa.org.pl/mamprawo.php?catid=167\&lang=1; último acceso 12/09/2009.

Stępniak, Ewa. 2001. Wolność od dziecka [La libertad de (no tener) hijos]. Zadra (3-4): 31-32.

Szczepańska, Sonia. 2002. Kobiety przy nadziei [Las mujeres en la esperanza]. Zadra (3): 52-53.

Szczuka, Kazimiera. 2003. Milczenie owieczek [El silencio de los corderos]. Zadra (2): 58.

-- - 2004. Milczenie owieczek. Rzecz o aborcji [El silencio de los corderos. Sobre el aborto]. Warszawa: W. A. B. 
Technokracja nie wystarczy - wywiad z Markiem Balickim, kandydatem na prezydenta Warszawy [Entrevista con Marek Balicki, el candidato para el puesto del alcalde de Varsovia]. 2002. Mam Prawo (2). Accesible online en http://www.federa.org.pl/mamprawo.php?catid=176\&lang=1; último acceso 12/09/2009.

Tomaszewska, Joanna. 2002. Katoliczki i feministki [Las católicas y las feministas]. Zadra (2): 5-8.

Zieliński, Adam. 1998. List Rzecznika Praw obywatelskich do Ministra Zdrowia i Opieki Społecznej [Carta del Portavoz del Pueblo al Ministro de Salud y Asuntos Sociales]. Mam Prawo (2). Accesible online en http://www.federa.org.pl/mamprawo.php?catid=163\&lang=1; último acceso 12/09/2009. 


\section{Bibliografia}

Alsop, Rachel y Jennifer Hockey. 2001. Women's reproductive lives as a symbolic resource in Central and Eastern Europe. European Journal of Women's Studies 8 (4): 454-71.

Anderson, Benedict. 1996 [1983]. Imagined communities. Reflections on the origin and spread of nationalism. London: Verso.

Armeni, Rita. 2006. La colpa delle donne. Dal referendum sull'aborto alla fecondazione asistita: Storie, battaglie e riflessioni. Milano: Ponte alle Grazie.

Asbell, Bernard. 1995. The pill: A biography of a drug that changed the world. New York: Random House.

Baker, Maureen. 2008. Restructuring reproduction: International and national pressures. Journal of Sociology 44 (1): 65-81.

Barreiro Pérez-Pardo, Bélen. 2000. Democracia y conflicto moral: La política del aborto en Italia y España. Madrid: Ediciones ISTMO.

Bassnett, Susan McGuire. 1986. Chapter 3: Italy. En Feminist experiences: The women's movement in four cultures, 91-131. London: Allen and Unwin.

Beauvoir, Simone de. 1982 [1949]. El segundo sexo. Buenos Aires: Siglo XXI.

Becker, Gaylene. 2000. The elusive embryo. How women and men approach new reproductive technologies. Berkeley: University of California Press.

Black, Edwin. 2003. War against the weak: Eugenics and America's campaign to create a master race. New York: Four Walls Eight Windows.

Bock, Gisela. 1996. Antinatalismo, maternidad y paternidad en el racismo nacionalsocialista. En Maternidad y políticas de género. La mujer en los estados de bienestar europeos, 1880-1950, eds. Gisela Bock, Pat Thane, 401-437. Madrid: Cátedra.

Boltanski, Luc. 2008. Le dimezioni antropologiche dell'aborto. En La condizione fetale. Una sociologia della generazione e dell'aborto, 155-46. Milano: Feltrinelli.

Bose, Ashish. 2007. Female foeticide: A civilisational collapse. En Sex-selective abortion in India: Gender, society and new reproductive technologies, ed. Tulsi Patel, 80-90. New Delhi; Thousand Oaks: Sage. 
Boyle, Mary. 1997. Re-thinking abortion: Psychology, gender, power and the law. Women and psychology. London: Routledge.

Boy-Żeleński, Tadeusz. 1930. Piekło kobiet. Warszawa: Alfa.

Broberg, Gunnar y Nils Roll-Hansen, eds. 1996. Eugenics and the welfare state: Sterilization policy in Denmark, Sweden, Norway, and Finland. East Lansing: Michigan State University Press.

Brodie, Janet Farrell. 1994. Contraception and abortion in nineteenth-century America. Ithaca: Cornell University Press.

Butler, Judith P. 1999 [1990]. Gender trouble: Feminism and the subversion of identity. New York: Routledge.

Calabrini, Emanuela y Elisabetta Vaccaro. 1996. Two generations of Italian women: Shifts in life choices, reproductive health and sexuality. En Reproduction and gender. The intergenerational transfer of knowledge, ed. Wendy Hardcourt, 140159. London: Zed Books.

Calloni, Marina. 2001. Debates and controversies on abortion in Italy. En Abortion politics, women's movement and the democratic state. A comparative study of state feminism, ed. Dorothy McBride Stetson, 181-203. Oxford: Oxford University Press.

Casanova, José. 2000. Religiones públicas en el mundo moderno. Madrid: PPC.

Chesler, Ellen. 1992. Woman of valor: Margaret Sanger and the birth control movement in America. New York: Simon and Schuster.

Cook, Hera. 2004. The long sexual revolution: English women, sex, and contraception, 1800-1975. Oxford: Oxford University Press.

- - . 2005. The English sexual revolution: Technology and social change. History Workshop Journal 59: 109-28.

Culler, Jonathan D. 1982. On deconstruction: Theory and criticism after structuralism. Ithaca: Cornell University Press.

Curran, Kathleen Sweeney. 2006. The perfection of women as maternal and the anthropology of Karol Wojtyła. Logos 9 (2): 129-53.

Dalmia, Sonia y Pareena G. Lawrence. 2005. The institution of dowry in India: Why it continues to prevail. The Journal of Developing Areas 38 (2): 71-93. 
Damiani, Cristina, Marina Graziosi, Valeria Moretti, Re Nucci, Stella Rosetta y Alessandra Zito, eds. 1981. Oltre l'aborto. Posizioni e documenti del movimento delle donne. Metodi di controllo della fecondità. Chiesa e "dissenso". La legge e le proposte di modifica. Roma: Cooperativa Editoriale Ottanta.

Darroch, Jacqueline E. 2000. The pill and men's involvement in contraception. Family Planning Perspectives 32 (2): 90-1.

David, Henry P., Jochen Fleischhacker y Charlotte Hohn. 1988. Abortion and eugenics in Nazi Germany. Population and Development Review 14 (1): 81-112.

Davies, Norman. 1997 [1996]. Europe: A history. London: Pimlico.

Delerq, Eugene y Kirsi Viisainen. 2001. Birth by design: Pregnancy, maternity care and midwifery in North America and Europe. New York: Routledge.

Dickens, Emma. 2000. Immaculate contraception: A history of birth control from the first fumblings to the present day. London: Robson Books.

Djerassi, Carl. 1980. The politics of contraception. New York: Norton.

Enloe, Cynthia. 2000. Nationalism and masculinity. En Bananas, beaches and bases: Making feminist sense of international politics, 42-64. Berkeley: University of California Press.

Faludi, Susan. 1992 [1991]. Backlash: The undeclared war against American women. New York: Anchor Books.

Feldt, Gloria. 2004. Exporting extremism. En The war on choice: The right-wing attack on women's rights and how to fight back, 199-223. New York: Bantam Books

Fisher, Kate. 2006. Birth control, sex and marriage in Britain, 1918-1960. Oxford; New York: Oxford University Press.

Fisher, Kate y Simon Szreter. 2003. "They prefer withdrawal": The choice of birth control in Britain, 1918-1950. Journal of Interdisciplinary History XXXIX (2): 263-91.

Flamigni, Carlo. 2008. L'aborto: Storia e attualità di un problema sociale. Roma: Nuova Iniziativa Editoriale.

Foucault, Michel. 1987 [1977]. Historia de la sexualidad. Madrid: Siglo XXI de España.

- - 1997 [1970]. La arqueología del saber. México: Siglo XXI. 
Franks, Angela. 2005. Margaret Sanger's eugenic legacy. The control of female fertility. Jefferson: MacFarland \& Company.

Fried, Marlene Gerber. 2006. The politics of abortion: A note. Indian Journal of Gender Studies 13 (2): 229-45.

Funk, Nanette. 1993. Introduction: Women and post-communism. En Gender politics and post-communism. Reflections from Eastern Europe and the Soviet Union, eds. Nanette Funk, Magda Mueller, 1-14. New York: Routledge.

Fuszara, Małgorzata. 1991. Legal regulation of abortion in Poland. Signs Journal of Women in Culture and Society 17 (1): 117-128.

- - . 1991. Will the abortion issue give birth to feminism in Poland? En Women's issues in social policy, eds. Mavis Maclean, Dulcie Groove, 205-228. London: Routledge.

- - 1993. Abortion and the formation of the public sphere in Poland. En Gender politics and post-communism. Reflections from Eastern Europe and the former Soviet Union, eds. Nanette Funk, Magda Mueller, 241-251. New York: Routledge.

- - - Debata o aborcji a kształtowanie się sceny politycznej w Polsce po upadku komunizmu. En Polityka i aborcja, ed. Mirosław Chałubinski, 53-67. Warszawa: Scholar.

Gaiotti de Biase, Paola. 2004. Cattoliche e cattolici di fronte all'aborto e il mutamento degli equilibri della repubblica. Genesis. Rivista Della Società Italiana Delle Storiche 3 (1): 57-86.

Galeotti, Giulia. 2003. Storia dell'aborto. I molti protagonisti della lunga vicenda. Bologna: II Mulino.

Gehmacher, Johanna. 2006. Re/production of a nation. En The policies of reproduction at the turn of the 21st century. The cases of Finland, Portugal, Romania, Russia, Austria and the US, eds. Maria Messer, Gudrun Wolfgruber, 207-217. Insbruck: Studienverlag.

Georges, Eugenia. 2008. Bodies of knowledge. The medicalization of reproduction in Greece. Nashville: Vanderbilt University Press.

Geppert, Alexander C. T. 1998. Divine sex, happy marriage, regenerated nation: Marie Stopes's Marital manual on married love and the making of a best seller, 19181955. Journal of the History of Sexuality 8: 389-433. 
Girard, Françoise y Wanda Nowicka. 2002. Clear and compelling evidence: The Polish tribunal on abortion rights. Reproductive Health Matters 10 (19): 22-30.

Githens, Marianne. 1996. Reproductive rights and the struggle with change in Eastern Europe. En Abortion politics: Public policy in cross cultural perspective, eds. Marianne Githens, Dorothy McBride Stetson, 55-74. New York; London: Routledge.

Glass, Christy y Éva Fodor. 2007. From public to private maternalism? Gender and welfare in Poland and Hungary after 1989. Social Politics: International Studies in Gender, State and Society 14 (3): 323-50.

Gordon, Linda. 2002. The moral property of women: A history of birth control politics in America. Urbana; Chicago: University of Illinois Press.

- - . 2006. "Choice" versus "right to life": Political contestation about reproductive rights in the United States. En The policies of reproduction at the turn of the 21st century. The cases of Finland, Portugal, Romania, Russia, Austria, and the US, eds. Maria Messer, Gudrun Wolfgruber, 67-90. Insbruck: Studienverlag.

Grabes, Rolande. 2001. Born to procreate. Women and childbirth in France from the Middle Ages to the eighteenth century. New York: Peter Lang Publishing.

Graff, Agnieszka. 2001. Świat bez kobiet. Płeć w polskim życiu publicznym. Warszawa: W. A. B.

Grant, Nicole J. 1993. The selling of contraception: The Dalcon Shield case, sexuality, and women's autonomy. Columbus: Ohio State University Press.

Gray, Madeline. 1979. Margaret Sanger: A biography of the champion of birth control. New York: R. Marek.

Greenhalgh, Susan. 2008. Preface. En Just one child: Science and policy in Deng's China, XI-XVIII. Berkeley: University of California Press.

Greer, Germaine. 1984. Sex and destiny: The politics of human fertility. London: Vintage.

Gruppo Donne del Palazzo di Giustizia di Milano. 1978. Aborto. Quando, come e dove. La legge 22 maggio 1978 n. 194. Milano: Teti Editore.

Hadley, Janet. 1996. Abortion: Between freedom and necessity. London: Virago.

Harding, Sandra G. 1991. Whose science? Whose knowledge? Thinking from women's lives. Ithaca: Cornell University Press. 
Hausner, Ewa, Barbara Heynes y Jane Mansbridge. 1993. Feminism in the interstices of politics and culture: Poland in transition. En Gender politics and post-communism. Reflections from Eastern Europe and the former Soviet Union, eds. Nanette Funk, Magda Mueller, 257-273. New York: Routledge.

Heinen, Jacqueline y Monika Wator. 2006. Child care in Poland before, during, and after the transition: Still a women's business. The Author Summer: 189-216.

Hicks, Karen M. 1994. Surviving the Dalkon Shield IUD: Women v. the pharmaceutical industry. New York: Teachers College Press.

Holc, Janina P. 2004. The purest democrat: Fetal citizenship and subjectivity in the construction of democracy in Poland. Signs Journal of Women in Culture and Society 29 (3): 755-82.

Hurst, Jane. 1989. The history of abortion in the Catholic Church: The untold story. Washington: Catholics for a Free Choice.

Huston, Perdita. 1992. Motherhood by choice: Pioneers in women's health and family planning. New York: Feminist Press at the City University of New York.

Ignaciuk, Agata. 2007. Abortion debate in Poland and its representation in press. Universidad de Łódź; Federación Polaca por las Mujeres y la Planificación Familiar. Accesible online en http://www.federa.org.pl/dokumenty/mgr\%20A.\%20lgnaciuk.pdf; último acceso 12/09/2009.

Jankowska, Hanna. 1993. Report. The reproductive rights campaign in Poland. Women's Studies International Forum 3: 291-6.

John Paul II. 1995. Pope John Paul II on abortion, contraception, and euthanasia. Population and Development Review 21 (3): 689-96.

Jolly, Margaret y Kalpana Ram, eds. 2001. Borders of being: Citizenship, fertility, and sexuality in Asia and the Pacific. Ann Arbor: University of Michigan Press.

Jütte, Robert. 2008. Contraception: A history. Cambridge: Polity.

Kaplan, Laura. 1995. The story of Jane. New York: Pantheon.

- - - 1998. Beyond safe and legal. The lessons of JANE. En Abortion wars. A half century of struggle, ed. Rickie Solinger, 33-42. Berkley: University of California Press. 
Kemp, Sandra y Paola Bono. 1991. History of two laws. En Italian feminist thought: $A$ reader, 211-259. Oxford: Basil Blackwell.

- - . 1991. Introduction: Coming from the South. En Italian feminist thought: $A$ reader, 1-29. Oxford: Basil Blackwell.

Kennedy, David M. 1970. Birth control in America: The career of Margaret Sanger. Yale publications in American studies, 18. New Haven: Yale University Press.

Kline, Wendy. 2001. Building a better race: Gender, sexuality, and eugenics from the turn of the century to the baby boom. Berkeley: University of California Press.

Kulagina, Yelena. 2006. Socio-economic problems of families in Russia: Gender aspect. En The policies of reproduction at the turn of the 21st century. The cases of Finland, Portugal, Romania, Russia, Austria and the US, eds. Maria Messer, Gudrun Wolfgruber, 145-155. Insbruck: Studienverlag.

Marks, Lara. 2000. Parenting the pill: Early testing of the contraceptive pill. En Bodies of technology. Women's involvement with reproductive medicine, eds. Ann Rudinow Saetnan, Nelly Oudshoorn y Marta Kirejczyk, 146-176. Columbus: The Ohio State University Press.

- - - 2001. Sexual chemistry. A history of the contraceptive pill. New Haven; London: Yale University Press.

Marland, Hilary, ed. 1993. The art of midwifery: Early modern midwives in Europe. History of medicine. New York: Routledge.

Marland, Hilary y Anne Marie Rafferty, eds. 1997. Midwives, society and childbirth. Studies in the social history of medicine. New York: Routledge.

Mayer, Tamar. 1999. Gender ironies of nationalism. Setting the stage. En Gender ironies of nationalism: Sexing the nation, ed. Tamar Mayer, 1-22. London: Routledge.

Mazur, D. Peter. 1981. Contraception and abortion in Poland. Family Planning Perspectives 13 (4): 195-8.

McLaren, Angus. 1991. A history of contraception: From antiquity to the present day. Oxford: Basil Blackwell.

Mies, Maria. 1998. Nuevas tecnologías de reproducción: Sus implicaciones sexistas y racistas. En La praxis del ecofeminismo. Biotecnología, consumo, reproducción, eds. Maria Mies, Vendana Shiva, 27-58. Barcelona: Icaria. 
Moore, Gloria y Ronald Moore. 1986. Margaret Sanger and the birth control movement: A bibliography, 1911-1984. Metuchen: Scarecrow Press.

Moore, Henrietta. 1999. La mujer y el Estado. En Antropología y feminismo, 155-216. Madrid: Cátedra.

Morgen, Sandra. 2002. Into our own hands: The women's health movement in the united states, 1969-1990. New Brunshwick: Rutgers University Press.

Naciones Unidas. 1999. Abortion policies. A global review. Division de la Población de la ONU.

Nowicka, Wanda. 1993. Ban on abortion in Poland. Women's Global Network for Reproductive Rights Newsletter (43): 49.

- - - Skutki ustawy antyaborcyjnej. 1996. Federación Polaca por las Mujeres y la Planificación Familiar. Accesible online en http://www.federa.org.pl/publikacje/raporty/rapab96.htm; último acceso 12/09/2009.

- - . 2000. The anti-abortion law in Poland. The report on its functioning, social effects, attitudes and behaviours. Federación Polaca por las Mujeres y la Planificación Familiar. Accesible online en http://www.federa.org.pl/english/reports/report00/index.htm; último acceso 12/09/2009.

- - . 2007. Prawa reprodukcyjne w Polsce. En Czarna księga kobiet, ed. Christine Ockerent. Warszawa: W. A. B.

Oaks, Laury. 2000. Smoke-filled wombs and fragile fetuses: The social politics of fetal representation. Signs Journal of Women in Culture and Society 26 (1): 63-109.

Okolski, Marek. 1983. Abortion and contraception in Poland. Studies in Family Planning 14 (11): 263-74.

Oleksy, Elżbieta H. 2004. Women's pictures and the politics of resistance in Poland. NORA Nordic Journal of Women's Studies 3 (12): 162-171.

- - . 2005. "Women, don't interfere with us, we are fighting for Poland!" Polish mothers and transgressive others. En Women, activism and social change, 179197. New York: Routledge.

Ortiz Gómez, Teresa. 2006. Medicina, historia y género. 130 años de investigación feminista. Oviedo: KRK. 
- - - 2008. Maternidad voluntaria: Anticoncepción, ciencia y feminismo en el siglo XX. Ponencia presentada en el XIV Coloquio Internacional AEIHM, Oviedo, noviembre de 2008. [En proceso de publicación].

Oudshoorn, Nelly. 2000. Imagined men: Representations of masculinities in discourses on male contraceptive technology. En Bodies of technology. Women's involvement with reproductive medicine, eds. Ann Rudinow Saetnan, Nelly Oudshoorn y Marta Kirejczyk, 123-145. Columbus: The Ohio State University.

- - - 2003. The male pill: A biography of a technology in the making. Durham: Duke University Press.

- - . 2004. "Astronauts in the sperm world": The renegotiation of masculine identities in discourses on male contraceptives. Men and Masculinities 6 (4): 34967.

Patel, Tulsi. 2007. Introduction: Gender relations, NRT's and female foeticide in India. En Sex-selective abortion in India: Gender, society and new reproductive technologies, ed. Tulsi Patel, 27-60. New Delhi; Thousand Oaks: Sage.

Peel, Robert A., ed. 1997. Marie Stopes, eugenics and the English birth control movement. London: Galton Institute.

Penn, Shana. 2005. Solidarity's secret: The women who defeated communism in Poland. Ann Arbor: University of Michigan Press.

Peppis, Paul. 2002. Rewriting sex: Mina Loy, Marie Stopes, and sexology. Modernism/modernity 9 (4): 561-79.

Perez Delgado, Margarita y Massimo Livi-Bacci. 1992. Fertility in Italy and Spain: The lowest in the world. Family Planning Perspectives 24 (4): 162-71.

Pfeffer, Naomi. 1993. The stork and the syringe: A political history of reproductive medicine. Cambridge: Harvard University Press.

Reagan, Leslie J. 1997. When abortion was a crime: Women, medicine and law in the United States 1867-1973. Berkley; Los Angeles: University of California Press.

Riddle, John. 1999. Eve's herbs. A history of contraception and abortion in the West. Cambridge: Harvard University Press.

Roberts, Dorothy E. 1997. Killing the black body: Race, reproduction, and the meaning of liberty. New York: Pantheon Books.

Rose, June. 2007. Marie Stopes and the sexual revolution. Boston: NPI Media Group. 
Ruether, Rosemary Radford. 2008. Women, reproductive rights and the Catholic Church. Feminist Theology 16 (2): 184-93.

Ruiz Salguero, Magda Teresa. 2005. La anticoncepción y el aborto en diferentes momentos de la historia de España. En Anticoncepción y salud reproductiva en España: Crónica de una (r)evolución, eds. Magda Teresa Ruiz Salguero, Teresa Castro Martín y Montse Solsona Pairó, 23-57. Madrid: CSIC, Instituto de Economía y Geografía

Russell, Andrew y Mary S. Thompson. 2000. Introduction: Contraception across cultures. En Contraception across cultures. Technologies, choices, constraints, eds. Andrew Russell, Elisa J. Sobo y Mary S. Thompson, 3-25. Oxford: Berg.

Saetnan, Ann Rudinow. 2000. Women's involvement with reproductive medicine: Introducing shared concepts. En Bodies of technology. Women's involvement with reproductive medicine, 1-30. Columbus: The Ohio State University Press.

Sanger, Margaret, Peter Engelman, Cathy Moran Hajo y Esther Katz, eds. 2007. The selected papers of Margaret Sanger. Urbana: University of Illinois Press.

Saxonberg, Steven y Dorota Szelewa. 2007. The continuing legacy of the communist legacy? The development of family policies in Poland and the Czech Republic. Social Politics: International Studies in Gender, State and Society 14 (3): 351-79.

Scott, Joan W. 1986. Gender: A useful category of historical analysis. The American Historical Review 91 (5): 1053-75.

Seaman, Barbara. 1995 [1969]. The doctor's case against the pill. Alameda: Hunter House.

Sharp, Joanne P. 1996. Gendering nationhood. A feminist engagement with national identity. En BodySpace. Destabilizing geographies of gender and sexuality, ed. Nancy Duncan, 97-109. New York; London: Routledge.

Shrage, Laurie. 2003. Abortion and social responsibility: Depolarizing the debate. Studies in feminist philosophy. Oxford; New York: Oxford University Press.

Sinha, Geeta. 2008. A study of the socio-cultural and socio-economic factors in psyche of pre-natal sex selection in some communities in India. Ponencia presentada en la Conferencia Feminista Mundos de Mujeres, Madrid, junio de 2008.

Solinger, Rickie. 2001. Beggars and choosers: How the politics of choice shapes adoption, abortion, and welfare in the United States. New York: Hill and Wang. 
Stanworth, Michelle. 1990. Birth pangs: Conceptive technologies and threat to motherhood. En Conflicts in feminism, eds. Marianne Hirsch, Evelyn Fox Keller, 288-303. New York: Routledge.

Stopes, Marie. 2008 [1918]. Married love, ed. Ross McKibbin. Oxford: Oxford University Press.

Szczuka, Kazimiera. 2004. Milczenie owieczek. Rzecz o aborcji. Warszawa: W. A. B.

Thomson, Judith Jarvis. 1971. A defense of abortion. Philosophy \& Public Affairs 1 (1): 47-66.

Titkow, Anna. 1993. Political change in Poland: Cause, modifier or barrier to gender equality. En Gender politics and post-communism. Reflections from Eastern Europe and the former Soviet Union, eds. Nanette Funk, Magda Mueller, 253-256. New York: Routledge.

Tone, Andrea. 2001. Devices \& desires: A history of contraceptives in America. New York: Hill and Wang.

Tronto, Joan C. 1993. Moral boundaries: A political argument for an ethic of care. New York: Routledge.

Wall, Angela. 1999. Biting the magic bullet: Reproductive freedom and the promise of Norplant. En Playing Dolly: Technocultural formations, fantasies, and fictions of assisted reproduction, eds. E. Ann Kaplan, Susan Merrill Squier, 57-89. New Brunswick: Rutgers University Press.

Whitaker, Elizabeth Dixon. 2000. Measuring mamma's milk: Fascism and the medicalization of maternity in Italy. Ann Arbor: University of Michigan Press.

Woodcock, Leslie. 2005. Catholics and contraception: An American history. Ithaca: Cornell University Press.

Yuval-Davis, Nira. 2006. Intersectionality and feminist politics. Journal of Women's Studies 13 (3): 193-209. 


\section{Páginas web consultadas}

Barbara Kruger. 2008. http://www.barbarakruger.com/; último acceso 03/07/2009.

Biblioteca Nazionale di Napoli. 2009. http://www.bnnonline.it/; último acceso 10/09/2009.

Biblioteca Digitale delle Donne. 2008. http://www.bibliotecadigitaledelledonne.it/; último acceso 14/08/2009.

Catholics for Choice [Católicos por la Libre Elección]. 2008. http://www.catholicsforchoice.com/; último acceso 12/07/2009.

Diario Dziennik [El Diario]. 2009. http://www.dziennik.pl/; último acceso 03/07/2009.

Diario Gazeta Wyborcza [La Gaceta de las Elecciones]. 2008. http://www.gazeta.pl/; último acceso 10/09/2009.

Difusora Feminista Herstory. 2009. http://www.nodo50.org/herstory/; último acceso $10 / 09 / 2009$.

Federacja na Rzecz Kobiet i Planowania Rodziny [Federación Polaca por las Mujeres y la Planificación Familiar]. 2009. http://www.federa.org.pl/; último acceso 12/09/2009.

Fundación Rodzić po Ludzku [Dar a Luz de Manera Humana]. 2009. http://www.rodzicpoludzku.pl/; último acceso 13/09/2009.

Fundación Feminista Efka. 2009. http://efka.org.pl/; último acceso 13/09/2009.

Galeria Malarstwa Polskiego [Galería de la Pintura Polaca]. 2009. http://www.pinakoteka.zascianek.pl/; último acceso último acceso 03/08/2009.

Guerilla Girls. 2008. http://www.guerrillagirls.com/; último acceso 03/08/2009.

Instituto Statale per la Istruzione Professionale e Technica. 2009. http://www.racine.ra.it/; último acceso 27/07/2009.

Planned Parenthood. 2009. http://www.plannedparenthood.org/; último acceso 20/05/2009.

Polscy Malarze [Pintores Polacos]. 2009. http://www.malarze.pl/; último acceso 03/08/2009. 
Partia Kobiet [Partido de Mujeres Polacas]. 2009. http://www.polskajestkobieta.org/; último acceso 16/07/2009.

Revista Noi Donne. 2009. http://www.noidonne.org/; último acceso 10/09/2009.

Revista Wysokie Obcasy [Tacones Altos] (Semanal de Gazeta Wyborcza). 2009. http://www.wysokieobcasy.pl; último acceso 10/09/2009.

Women on Waves. 2009. http://www.womenonwaves.org; último acceso 12/09/2009. 


\section{Tabla de ilustraciones}

Figura 1 Kruger, Barbara. 1989. Your body is a battleground [Tu Cuerpo Es un Campo de Batalla], http://www.barbarakruger.com; último acceso 03/07/2009.

Figura 2 Kruger, Barbara. 2002/2004. Sin título (Pro-life for the unborn, pro-death for the born [Pro vida para los no nacidos, pro muerte para los nacidos]), http://www.barbarakruger.com; último acceso 03/07/2009.

Figura 3 Guerilla Girls. 1992. Sin título (Guerilla Girls demand a return to traditional values on abortion...) [Guerilla Girls demandan que vuelvan los valores tradicionales relacionados con el aborto. Descubre la verdad chocante sobre la posición de la Iglesia Católica sobre el aborto. Hasta mediados del siglo XIX el aborto fue legal durante los primeros meses del embarazo. La Iglesia Católica no lo prohibió hasta 1869], http://www.guerrillagirls.com; último acceso 03/08/2009.

Figura 4 Kruger, Barbara. 1992. Rage + women $=$ power $[$ Rabia + mujeres $=$ poder . Portada de la revista Ms. Magazine (1-2/2002), http://www.barbarakruger.com; último acceso 03/07/2009.

Figura 5 La portada de Quotidiano Donna, número 11/1878, http://www.bibliotecadigitaledelledonne.it; último acceso 14/08/2009.

Figura 6 Portada de la primera revista feminista polaca, Pełnym Głosem 2/1994. El número dedicado al aborto. Imagen tomada de la página de la Fundación Efka, http://efka.org.pl/index.php?action=p_spt; último acceso 13/09/2009.

Figura 7 Publicación online de la revista Mam Prawo 2/1998 en la página web de la Federación Polaca por las Mujeres y la Planificación Familiar, http://www.federa.org.pl/mamprawo.php?catid=163\&lang=1; último acceso $12 / 09 / 2009$.

Figura 8 La portada del manual de las scouts italianas del periodo fascista. La Caposquadra Piccola Italiana. 1935. Roma; Milano: Arti Grafiche Pizzi y Pizio. Colección de Wolfsonian en Florida International University.

Figura 9 El poster del Movimento di Liberazione della Donna, Roma, años setenta (Biblioteca Nazionale di Napoli, http://www.bnnonline.it; último acceso 10/09/2009.80

Figura 10 Poster de UDI para mantener en vigor la Ley 194 durante el referéndum en 1981 [Solo nosotras mujeres sabemos lo que es el aborto. Nosotras queremos combatirlo. Por ello, en los referéndums sobre el aborto contestamos dos veces NO]. 
Instituto Statale per la Istruzione Professionale e Technica [Instituto Estatal de la Educación Profesional y Técnica], http://www.racine.ra.it; último acceso 27/07/2009.

Figura 11 [Maniobras infames contra todas nosotras] Portada de la revista Effe 11/1975, http://www.bibliotecadigitaledelledonne.it; último acceso 14/08/2009.

Figura 12 Portada de la revista Effe 2/1974,

http://www.bibliotecadigitaledelledonne.it; último acceso 14/08/2009. 86

Figura 13 Smith, Patrizia. 1972. Se sucedesse a lui, ci starebbe più attento [Si pasara a él, estaría más atento] Publicado en revista Effe $(0 / 1972,38)$ para acompañar el artículo de D. T. Anticoncezionali. Non basta la legge....

Figura 14 Fragmento de la página 12 de la revista Effe 4/1975 con el eslogan del movimiento feminista italiano l'utero è mio e me lo gestisco io [il útero es mío y lo gestiono yo]. Arriba las pancartas de una manifestación feminista, debajo otro eslogan: aborto libero e gratuito [aborto libre y gratuito].

Figura 15 [¿̇Un hijo con quince años?]. Portada de la revista Effe 1/1974, http://www.bibliotecadigitaledelledonne.it; último acceso 14/08/2009.

Figura 16 Grottger, Artur. 1866. Pożegnanie powstańca [La despedida del guerrillero]. Museo Nacional de Cracovia, http://www.malarze.pl; último acceso 03/08/2009.... 105

Figura 17 Grotter, Artur. 1863. Po bitwie [Después del combate]. Ciclo Polonia, http://www.pinakoteka.zascianek.pl; último acceso 03/08/2009. 106

Figura 18 Grotter, Artur. 1866-7. Pożegnanie [Despedida]. Ciclo Wojna [Guerra], http://www.pinakoteka.zascianek.pl; último acceso 03/08/2009.

Figura 19 Barbara Labuda con Lech Wałęsa, 1989. En el fondo el logo de la Solidarność. Edición online del diario Dziennik, http://www.dziennik.pl; último acceso 03/07/2009.

Figura 20 Logo de la Federación Polaca por las Mujeres y la Planificación Familiar, http://www.federa.org.pl; último acceso 29/07/2009.

Figura 21 Wanda Nowicka, presidenta de la Federación Polaca por las Mujeres y la Planificación Familiar. Edición online del diario Gazeta Wyborcza, http://www.gazeta.pl; último acceso 10/09/2009. 
Figura 22 [A las mujeres les encanta parir, por eso sigue la prohibición del aborto]. La foto de la manifestación feminista Trzy razy tak de 8/03/2002 en Varsovia. Portada de la revista Zadra 11/2002. Imagen tomada de la página de la Fundación Efka, http://efka.org.pl/index.php?action=z_spt; último acceso 13/09/2009.

Figura 23 Zielińska, Monika. 2002. [Mi vida mi decisión]. Póster para convocar a la manifestación feminista del 8 de marzo de 2002, http://www.federa.org.pl; último acceso 29/07/2009 


\section{Traducciones de una selección de textos del feminismo italiano y polaco utilizados en el trabajo}

\subsection{Italia}

\subsubsection{Rivolta Femminile. Sputiamo su Hegel [Escupimos sobre Hegel], 1970}

Traducción al castellano de Francesc Parcerisas publicada como e-libro por la Diguspra Feminista Herstory, y elaborada por las mujeres-participantes de los talleres fem-elibros/ reatividadfeminista.org en México en 2004

(http://www.nodo50.org/herstory/textos/Escupamos\%20sobre\%20Hegel.pdf, último acceso 10/09/2009).

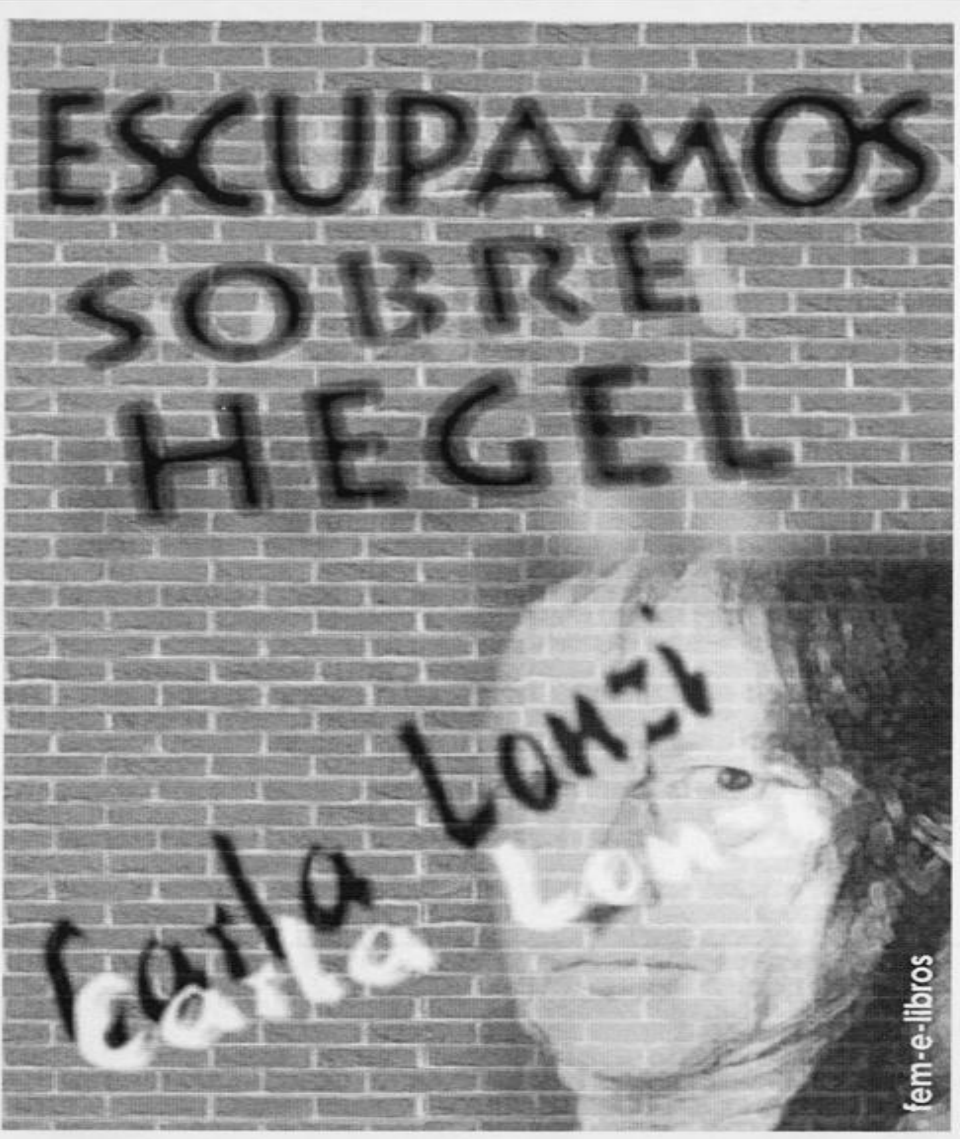




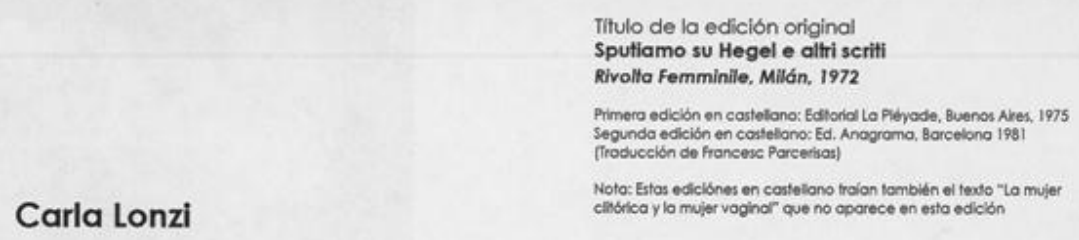

Escupamos sobre Hegel

Escritos de "Rivolta Femminile"

Lbro impreso electrónicamente por:

idadteminista.org

ittp://www, creattildadfeminista.

outorasecreatividadteminista.org

Mexico, 2004

tem-e-libros solo imprime electrónicamente esta obro.

lodos los derechos pertenecen o.

- Escritos de "Rivolta Femminile"

Esta edición está hecha sin fines de lucro, con el

único objetivo de difundir esta importante obra del

pensamiento ferminista. el aporte que se hace para

Carla Lonzi

\section{Escupamos} sobre
Hegel

Escritos de "Rivolta Femminile" 
- I problema femenino significa una relación entre cada mujer-carente de poder. de historia, de cultura, de rol- y cada hombre -con su poder, su historia, su cultura y su rol absoluto-

El problema femenino cuestiona todo lo hecho y pensado por el hombre absoluto, por el hombre que no tenia conciencia de que la mujer fuese un ser humano de su misma dimensión.

En el siglo XVIII pedimos la igualdad $y$ Olympe de Gouges fue condenada al patibulo por sus "Declaraciones sobre los derechos femeninos". La demanda de igualdad entre mujeres y hombres en el plano jurídico coincide. históricamente, con la afirmación de la igualdad de los hombres entre ellos. Hoy tenemos eficaz. La actuación de la mujer no implica una participación en el poder masculino, sino cuestionar el concepto de poder. Si hoy se nos reconoce nuestra imbricación a fítulo de igualdad es, precisamente, para alejar aque peligro.

La igualdad es un principio jurídico: el denominador común presente en todo ser humano al que se le haga justicia. La diferencia es un principio existencial que se refiere a los modos del ser humano, a la peculiaridad de sus experiencias, de sus finalidades y aperturas. de su sentido de la existencia en una situación dada y en la situación que quiere darse. La diferencia entre mujer y hombre es la básica de la humanidad.

El hombre negro es igual al hombre blanco, la mujer negra igual a la mujer blanca.

La diferencia de la mujer consiste en haber estado ausente de la historia durante miles de años. Aprovechémonos de esta diferencia: una vez lograda la inserción de la mujer, squién puede decimos cuántos milenios transcurrirán para sacudir este nuevo yugo? No podemo ceder a otros la tarea de derrocar el orden de la estructura patriarcal. La igualdad es todo lo que se les ofrece a los colonizados en el terreno de las leyes y los derechos. Es lo que se les impone en el terreno cultural. Es el principio sobre cuya bose el colono continúa condicionando al colonizado. El mundo de la igualdad es el mundo de la superchería legalzada, de lo unidimensional; el mundo de la diferencia es el mundo en el que el terrorismo depone las armas y la superchería cede al respeto de la variedad y multiplicidad de la vida. La igualdad entre los sexos es el ropaje con el que se disfraza hoy la inferioridad de la mujer.

Esta es la posición de alguien diferente que quiere operar un cambio global en la civilización que le ha recluido.

Hemos descublerto no sólo los datos de nuestra opresión sino la allenación que se ha originado en el mundo por habernos tenido prisioneras. La mujer ya no tiene pretexto alguno para adherirse a los objetivos del hombre.

En este nuevo estadio de conocimiento. la mujer rechaza, en tanto que dilema impuesto por el poder masculino, tanto el plano de la igualdad como el de la diferencia, afirmando que ningún ser humano, ni ningún grupo debe ser definido por referencia a otro ser humano o a otro grupo.

La opresión femenina es el resultado de largos milenios: el capitalismo mós que producirlo la ha heredado. ta aparición de la propiedad privada ha expresado un desequilibrio entre los sexos como necesidad del poder de cada 
hombre sobre cada mujer, mientras se definian las relaciones de poder entre los hombres. Interpreta sobre bases económicas el destino que nos ha acompañado hasta hoy significa apelar a un mecanismo, cuyo impulso motor se desconoce. Nosotras sabemos que, caracterológicamente. el ser humano orienta sus instintos hacia su satisfacción, al menos en sus contactos con el sexo opuesto. El materialismo histórico olvida la llave emotiva que ha deferminado el tránsito a la propledad privada. Esto es lo que queremo recalcar para que el arquetipo de la propiedad sea reconocido, para que se vea cuál es el primer objeto que el hombre concibe: el objeto sexual. La mujer, al retirar del inconsciente masculino su presa primera, desata los nudos originarios de patologia posesiva.

Las mujeres fienen conclencia del nexo político que existe entre la ideología marxista-leninista y los sufrimientos, necesidades y aspiraciones de las mujeres. Pero no creen que sea posible esperar que la revolución los solucione. No consideran válido que su propia causa esté subordinada al problema de clase. No pueden aceptar una impostación de su lucha y una perspectiva que pasen por encima de sus cabezas.

El marismo-leninismo necesita equipara a ambos sexos, pero el ajuste de cuentas entre las colectividades masculinas no puede sino traducirse en una dádiva paternalista de los valores masculinos a la mujer. Además se le pide ayuda más de lo que se está dispuesto a ayudarla.

La relación hegeliana amo-esciavo. es una relación interna del mundo humano masculino, y es a ella a la que se refiere la dialéctica, en términos deducidos exactamente de las premisas de la toma del poder. Pero la discordia mujer-hombre no es un dlema: para ella no se ha previsto ninguna solución, puesto que la cultura patriarcal no la ha considerado un problema humano, sino un dato natural. Es algo que viene de la jerarquia entre los sexos, a los que se les atribuye como esencia lo que es resultado de su oposición: la defínición de superior e inferior esconde el origen de un vencedor y un vencido. La visión masculina del mundo ha encontrado la Justificación inherente a los limites de su propia experiencia unilateral. Pero para la mujer el origen de la oposición entre los sexos continúa quedando inexplicado, de modo que busca en los motivos de su derrota primitiva la confirmación de la crisis del espiritu masculino.

Incluir el problema femenino dentro de una concepción de la lucha amo-esclavo. como lucha closista, es un error histórico por cuanto la mujer proviene de una cultura que excluia el punto de discriminación esencial de la humanidad, el privilegio absoluto del hombre sobre la mujer, y ofrecia a la humanidad perspectivas en términos de la problemática masculina (esto es: ofrecian perspectivas sólo a la colectividad masculina).

Para la mujer subordinarse al planteo clasistasignificareconocerentérminossemejantes en un tipo de esclavifud distinto al suyo, términos que son el testimonio más conveniente de su desconocimiento. La mujer, en cuanto tal, se halla oprimida a todos los niveles sociales: no sólo a nivel de clase, sino a nivel de sexo. Esta laguna del marxismo no es casual, ni podría ser subsanada ampliando el concepto de clase de modo que englobase a la masa femenina, a la nueva clase. ¿ PPor qué no se ha visto la relación de la mujer con la producción mediante su actividad de reconstitución de las fuerzas de trabajo en la familia? ąPor qué no se ha visto que su explotación dentro de la familia es una función esencial para el sistema de acumulación del capital? Confiando el futuro revolucionario a la clase obrera, el marxismo ha ignorado a la mujer como oprimida y como portadora de futuro: ha expresado una teoria revolucionaria cuya matriz se halla en la cultura patriarcal.

Examinemos la relación mujer-hombre en Hegel, el filósofo que ha visto en el esclavo el momento liberador de la historia. É, con mayor insidia que cualquier otro. ha racionalizado el poder patriarcal en la dialéctica entre un principlo divino femenino y un principio humano masculino. El primero preside la familia, el segundo la comunidad. "Mientras que la comunidad se da su subsistir sólo destruyendo la beatifud familiar y disolviendo la autoconciencio en la autoconciencia universal, aquélla produce lo que la oprime, y que, al mismo tiempo le es esencial, es decir, en la femineidad en genera su enemigo interno". La mujer no ultrapasa el estadio de la subjetividad: reconociéndose en sus parientes y allegados se hace inmediatamente universal, le faltan premisas para escindirse del ethos de la familia y unirse a la fuerza autoconsciente de la universalidad, gracias la cual el hombre se convierte en ciudadano. Esta condición femenina, fruto de la opresión. es considerada por Hegel como motor de la opresión: la diferencig entre los sexos viene constitur la base natural metafísica tanto de su oposición como de su reunificación. En el principio femenino Hegel coloca el a priori de una pasividad en la cual se anulan las pruebas del dominio masculino. La autoridad patriarcal ha tenido sometida a la mujer, y el único valor que se le reconoce es el de haberse adecuado a ella como a su propia naturaleza. 
En coherencia con la tradición del pensamiento occidental Hegel refiene a la mujer ligada a un estadio por su propia naturaleza. y atribuye a este estadio toda la resonancia posible, aunque su condición sea tal que el hombre preferiría no nacer si tuviese que considerarlo como algo para él.

De todos modos lo femenino, "eterna ironia de la comunidad", hace reir al pensador que, de avanzada edad, e indiferente al placer, piensa y se preocupa exclusivamente por lo universal: $y$ se vuelve a los jóvenes para encontrar un cómplice a su desprecio. La mujer, más allá de la ley divina que encarna, más allía del deber hacia los lares, más allá de los bellos gestos de tragedia griega con los que sale del averno hacia la luz de la existencia, la mujer. pues, revela una actitud que sólo su debilidad ha hecho que fuese considerada más extraña que amenazadora: su reacción al enfrentarse al hombre maduro y su inclinación hacia los jóvenes. Pero la identificación de Hegel con los valores de la civilización patriarcal hace que, en este pasaje, encuentre un significado puramente instrumental. De hecho interpreta esta elevación jerarquica de la juventud, es decir de la virilidad. efectuada por la mujer. como el estímulo que dispara en la comunidad el elemento con el que hay que contar para la actividad hacia el extranjero, la guerra. En realidad nosotras, a través de este gesto de la mujer, vemos con claridad el poder del patriarca sobre ella y sobre los jóvenes. Actualmente su intención se vuelve contra la familia y contra la sociedad, en la figura del representante del poder que domina sobre ambas. Mediante el escarnio se resalta la figura histórica del opresor de quien hay que librarse. Pero es precisamente él quien, como cabeza, puede jugar y orientar hacia sus fines, todo movimiento de la mujer o del joven: este último, encarifnado por las atenciones de ella. será verdaderamente un valeroso guerrero para la conservación de la comunidad.

En la manifestación de la mujer en tanto que "eterna ironila de la comunidad" nosotras reconocemos la presencia del ejemplo feminista de todos los tiempos.

En Hegel coexisten estas dos posiciones: una que ve el destino de la mujer ligado al principio de femineidad, y otra que descubre en el siervo, no ya un principio inmutable, una esencia, sino la condición humana que realiza en la historia la máxima evangélica "los úlimos serán los primeros". Si Hegel hublese reconocido el origen humano de la mujer, como reconoció la opresión del siervo, se hubiera visto obligado a aplicar al caso femenino la misma dialéctica amo-esclavo. Y para ello habria encontrado un serio obstáculo: de hecho, si el método revolucionario puede acoger los pasajes de la dinámica social, no hay duda alguna de que la liberación de la mujer no puede encajar dentro de los mismos esquemas: en el plano mujerhombre no existe una solución que elimine al otro, de ahi que la meta de la toma del poder sea totalmente vana.

Este tornarse vano de la toma del poder como meta es el elemento que distingue la lucha contra el sistema patriarcal como fase sucesiva y concomitante de la dialéctica amo-esclavo.

El axioma de que todo lo que es racional es real refleja la convicción de que la astucia de la razón no dejará de concordar con el poder. Y la dialéctica es el mecanismo que deja continuamente abierto el camino a esta operación. En un modo de vida que no esté dominado por el carácter patriarcal, la construcción triádica pierde su aferramiento a la psique humana.

La Fenomenologia del Espiritu es una fenomenología del espiritu patriarcal, encamación de la divinidad monotetsta en el tiempo. la mujer aparece como imagen cuyo nivel significante es el de ser hipótesis de otros.

La historia es el resultado de las acciones patriarcales.

Cristo representa la irreversibilidad del sentimiento de culpa sobre el que se funda la potencia del Padre. Al recorrerla hasta el fin él adquiere la certeza de que, inmolándose, ejecuta su voluntad. Y redime a la comunidad para mayor gloria del Padre.

Los dos mentís más colosales a la interpretación hegeliana están dentro de nosotras: la mujer que rechaza la familia, el joven que rechaza la guerra.

E joven intuye que el antiguo derecho de vida y de muerte que detentaba el padre sobre sus hijos, más que legalizar una praxis. explicitaba un deseo. Por eso la guerra le parece un expediente inconsciente para asesinarle, una conjura contra él.

No olvidemos este eslogan fascista: Familia y seguridad.

En la angustia de su inserción social el joven esconde un conflicto con el modelo patriarcal. Este conficto se revela en los ejemplos anárquicos en los que se expresa un no global, sin alternativa: la virlidad se niega a ser paternalista, chantajista. Pero sin la presencia de su aliado historico, la mujer, la experiencia anárquica del joven resulta veleidosa, y acaba cediendo ante el reclamo de la lucha de masa organizada. La ideología manista-leninista le ofrece la posibilidad de hacer constructiva su rebelión poniéndose del lado de la lucha proletaria, a la que delega, incluso, su liberación. 


\section{DISCURSOS FEMINISTAS SOBRE EL ABORTO Y LA ANTICONCEPCIÓN EN ITALIA} (AÑOS SETENTA) Y POLONIA (AÑOS NOVENTA)

Pero al obrar de este modo el joven vuelve a ser absorbido por una dialéctica prevista por la cultura patriarcal, que es la cultura de la toma del poder: mientros cree haber individualizado. junto con el proletariado al enemigo común: el capitalismo, en realidad está abandonando su propio terreno de lucha para posarse al del sistema patriarcal. Pone toda su confianza en el proletariado en tanto que portador de la posibilidad revolucionaria: quiere despertarlo cuando le parece adormecido por los éxitos sindicales y las tácticas de los partidos, pero jamás duda de que pueda no ser la nueva figura histórica. Luchando por cuenta de otro el joven se subordina una vez más, que es exactamente lo que siempre se ha pretendido de él. La mujer. cuya experiencia feminista es dos siglos más antigua que la del joven, y que, primero dentro de la revolución francesa, y luego de la rusa, ha intentado unir su problemática a la del hombre en el plano político. obteniendo tan sólo el papel de agregado, afirma que el proletariado es revolucionario en su enfrentamiento al capitalismo, pero reformista en suentrentamiento al sistema patriarcal.

Según unas notas de Gramsci, "los jovenes de la clase dirigente len el sentido mós amplio) se rebelan y pasan a la clase progresista que históricamente se ha convertido en capaz de tomar el poder: pero, en este caso, se trata de jóvenes que pasan, de ser dirigidos por los ancianos de una close, a serlo por los ancianos de otra: sea como sea la subordinación real de los jóvenes a los ancianos, como generación se perpetúa" (De Los intelectuales y la organización de la cultura)

Desde la República de Platón, a la Utopía de Tomas Moro y a los socialistas utópicos del 800 , el ideal de la comunidad de bienes siempre ha sido acompanado por el corolario lógico de la disolución de la familia como núcleo de los intereses particulares. Marx y Engels prosiguen esta corriente de pensamiento: pero de todos modos todavia insisten no sobre el hecho de que la supresión del elemento económico deba llevar "a cada hombre a disponer de todas las mujeres y a cada mujer a disponer de todos los hombres" (Fourier), sino sobre una relación carente de implicaciones utilitaristas. La primera formulación hecha por Engels en los Principios del comunismo, en 1847, es la siguiente: "La ordenación comunista de la sociedad hará que la relación entre ambos sexos sea simplemente una relación privada que afectará tan sólo a las personas involucradas, y en la que la sociedad no tendrá porqué injerirse. Podrá ser asl porque la propiedad privada se habrá eliminado, y se educará en común a los niños, destruyendo así los dos fundamentos del matrimonio tal como ha existido hasta ahora: dependencia de la mujer respecto al hombre y de los hijos respecto a los padres, debida a la propiedad privada". Al año siguiente encontramos en el Manifiesto del Partido Comunista, de Marx y Engels: "iAbolición de la familial Incluso los más radicales se aterrorizan ante proyectos tan vergonzosos de los comunistas. żCuál es el fundamento de la familia actual, de la familia burguesa? $\mathrm{E}$ capital, la ganancia privada... Pero vosotros, comunistas, intentáis adoptar la comunidad de mujeres, nos grita a coro toda la burguesía. El burgués no ve en su mujer mós que un instrumento de producción. Oye que los instrumentos de producción deben ser disfrutados en común y naturaimente se siente autorizado a creer que las mujeres también correrán idéntica suerte. Ni siquiera piensa que el problema reside en esto: abolir la posición de la mujer como simple instrumento de producción". Casi cuarenta años después. en Los origenes de la familia. Engels precisa las relaciones entre la estructura económica y la familia según el materialismo histórico. y hace explicita su convicción de que el matrimonio encontraró, en el ámbito de la caida del capitalismo, su realización más humana: "Una vez disminuidas las consideraciones económicas.... se habrá llegado asi a la igualdad de la mujer. y según todas las experiencias que hasta ahora conocemos, actuarb. en medida muchisimo mayor que la hasta ahora conocida, para que los hombres se conviertan efectivamente en monógamos, antes que hacer que las mujeres sean políndricas. Pero lo que seguramente desaparecerá de la monogamia son todos los caracteres que lleva impresos por haber nacido de las relaciones de propiedad:es decir, en primer lugar, el predominio del hombre; en segundo, la indisolubilidad... lo que hoy podemos presumir acerca de la ordenación de las relaciones sexuales, en cuanto el modo de producción capitalista haya sido liquidado, lo cual no puede tardar mucho en suceder, es principalmente de caracter negativo, y se limita en su mayor parte a aquellos que será suprimido. Pero, squé se logrará? Esto se decidirá en cuanto haya madurado una nueva generación... La plena libertad para contraer matrimonio sólo puede ser conseguida en general cuando la eliminación de la producción capitalista y de las relaciones de propiedad que ella crea hoyan alejado todas las consideraciones económicas secundarias, que todavía hoy ejercen una infuencia tan potente sobre la elección del cónyuge. Entonces, en verdad. no existirá otro motivo de elección que la simpatía reciproca" Lenin actúa con ventaja al catequizar a las mujeres y los jóvenes que 


\section{DISCURSOS FEMINISTAS SOBRE EL ABORTO Y LA ANTICONCEPCIÓN EN ITALIA} (AÑOS SETENTA) Y POLONIA (AÑOS NOVENTA)

velan una relación directa entre la eliminación de la propiedad privada y el amor llbre: "Bonito marxismo aquel para el que todos los fenómenos y todas las modificaciones que intervienen en la superestructura ideológica de la sociedad se deducen inmediatamente..., únicamente de la base económica. Un cierto Friedrich Engels, ya hace mucho tiempo. subrayó en qué consiste verdaderamente el materialismo histórico... En su Origen de la familia señala la importancia propia del desarrollo y del refinamiento del impulso sexual en relación con el individuo". (De un coloquio con Lenin relatado por Clara Zetkin. en el Kremlin en 1920).

En los paises del área comunista la socialización de los medios de producción apenas si ha cambiado la estructura familiar tradicional, más bien la ha reforzado, en la medida en que ha reforzado el prestigio y el papel de la figura patriarcal. El contenido de la lucha revolucionaria ha asumido y expresado personalidad $y$ valores típicamente patriarcales y represivos, que han repercutido en la organización de la sociedad. primero como estado paternalisto, y luego como un verdadero estado autoritario y burocrático. La concepción clasista, y por ello la exclusión de la mujer como parte activa en la elaboración de los temas del socialismo, ha hecho de esta teoría revolucionaria una teoria inevitablemente patricéntrica. Sexofobia, moralismo, conformismo, terrorismo, han cerrado sus redes sobre los roles sociales impidiendo aquella disolución que durante siglos habia sido anhelada como resultado obvio de la eliminación de la propiedad privada. La familia es piedra angular del sistema patriarcal: está fundada, no sólo en los intereses económicos, sino también en los mecanismos síquicos del hombre que en todas las épocas ha tenido a la mujer como objeto de dominio y como pedestal para sus empresas más elevadas. E mismo Marx se comportó en vida como un marido tradicional, absorbido por su trabajo de estudioso e idé́logo, cargado de hijos, uno de los cuales lo tuvo con la doncella. La abolición de la familia no significa, de hecho, ni comunidad de mujeres, como Marx y Engels ya hablan aclarado, ni ninguna otra fórmula que haga de la mujer un instrumento ejecutivo del "progreso", sino la liberación de una parte de la humanidad que habrá hecho oir su voz y se habrd enfrentado por primera vez en la historia, no sólo con la sociedad burguesa, sino con cualquier tipo de sociedad proyectada que tenga al hombre como protagonista. situándose así mucho más allá de la lucha contra la explotación económica denunciada por el marismo. La continuación de la liberación de la mujer no se produce hoy en los paises socialistas, en los que la estructura social ha alcanzado el rigor del alto medioevo. a causa de la imposición autoritario de los mitos patriarcales rehabilitados por la revolución, sine dentro de los estados burgueses en los cuales el derrumbe de los valores sólo puede lograrse con la intervención femenina. Esto, de hecho. se produce como derrumbe de la concepción y la realidad patriarcales, cuyo éxito manifiesta la corrosión no sólo de la burguesía, sino de todo un tipo de civilización masculina. E marxismo se ha movido dentro de una dialéctica amo-esclavo. como contraste fundamental individualizado de la cultura de la naciente burguesía, a la que ha dado su concreción de clase. Pero la dictadura del proletariado ha demostrado con creces no ser portadora de la disolución de los roles sociales: ha mantenido y consolidado la familia como centro en el que se repite ia estructura humana incompatible con cualquie mutación sustancial de los valores. La revolución comunista se ha logrado sobre unas bases polífico-culturales masculinas, con la represión y la instrumentalización del feminismo, y ahora tiene que enfrentarse a aquella rebelión contra los valores masculinos que la mujer desea llevar hasta el fondo, más allá de la dialéctica de clases interna al sistema patriarcal.

E feminismo, incluso en el momento culminante de la lucha por la dictadura del proletariado, se ha enfrentado de modo directo con la situación de la mujer, utilizando intuiciones y métodos de una gran apertura. Peroen aquellas circunstancias los "verdaderos" problemas y su impostación no desviacionista les eran exigidos a las mujeres, exigidos por la autoridad creando en ellas aquella frustración que las abocaba. sobre todo, a su propio holocausto.

Vuelve a ser Lenin quien habla con Clara Zetkin: "La lista de vuestros pecados, Clara, todavia no se ha terminado. He oido que en vuestras reuniones nocturnas dedicadas a la lectura y a las discusiones con las obreros, os ocupáis sobre todo de problemas sexuales y matrimoniales. Este argumento se hallario en el centro de vuestras preocupaciones, de vuestra ensenanza politica y de vuestra acción educadora. No podía dar crédito a lo que ola... Me han dicho que lo problemas sexuales también son argumento favorito de vuestras organizaciones juveniles. Nunca falta quien quiera extenderse sobre este particular. Esto resulta especialmente escandaloso y pernicioso para el movimiento juvenil. Estas discusiones pueden contribuir fácilmente a estimular y excitar la vida sexual de clertos individuos, a destruir la fuerza y la salud de la juventud. También debéis luchar contra esta tendencia. E movimiento de las mujeres y de los jóvenes tiene 
muchos puntos de contacto. Por eso las mujeres comunistas y los jóvenes deben emprender un trabajo sistemático. Un trabajo que tenga por objetivo elevarles, transportarles del mundo de la maternidad individual al de la maternidad social... Las formas matrimoniales y las relaciones entre ambos sexos en el sentido burgués ya no son safisfactorias. En este campo se aproxima una revolución que corresponde a la revolución proletaria. Se comprende que toda esta madeja de problemas, tan extraordinariamente intrincados, preocupe profundamente tanto a las mujeres como a los jóvenes... Muchos jóvenes denominan su posición como "revolucionaria" y "comunista". Y creen sinceramente que lo son. Pero nosotros, que somos viejos, no nos podemos engañar. Aunque yo no sea exactamente un asceta melancólico, esta nueva vida sexual de la juventud, e incluso de los adultos, me parece muy a menudo algo perfectamente burgués, uno de los múltiples aspectos de un lupanar burgués... Sin duda conocéis la famosa teoria. según la cual en la sociedad comunista la satisfacción de los propios instintos sexuales y el mismo impulso amoroso son tan simples y tan insignificantes como beber un vaso de agua... Pero un hombre normal, en condiciones igualmente normales. sse echará por los suelos en la carretera para beber de un charco de agua sucia? zO beberd en un vaso cuyos bordes llevan las marcas de decenas de labios ajenos?... Esta teoría del "vaso de agua" ha enloquecido a nuestra juventud, la ha enloquecido de verdad".

En la carta de Lenin a Ines Armand de enero de 1915 leemos: "Dear Friend: recomiendo encarecidamente que el esquemo del opúsculo sea escrito con mayor extensión.. Hasta ahora debo hacer una sola observación: la "reivindicación (femenina) de la libertad amorosa" aconsejo que sea totalmente suprimida. En efecto, ésta se basa no en una relvindicación proletaria, sino burguesa" ia contraposición propuesta por Lenin al "vulgar y cochino matrimonio campesino, intelectua y pequento burgués, carente de amor" era "el matrimonio civil proletario con amor". A consecuencia de este intercambio epistolar con Lenin, Ines Armand renunció a la publicación de su opúsculo para las trabajadoras.

¿en qué difiere la "reivindicación de la libertad amorosa" del "matrimonio civil proletario con amor"? La diferencia estriba en que el primero era formulado por las mujeres y acogido por los jóvenes como un tema de conducto revolucionaria el segundo cristaliza los valores represivos y edificantes del hombre nuevo ligado al partido y a la ortodoxia religiosa. El amor libre era la versión feminista de la crítica a la familia: el matrimonio proletario la consecuencia viril llena de orden, salida de las premisas del comunismo. según Engels. Cuando una mujer comunista de Viene publica un opúsculo sobre los problemas sexuales, Lenin se indigna: "Este opúsculo. qué necedad. las pocas nociones exactas que contiene, las obreras ya las conocen por Bebel, y sin un esquema árido $y$ pesado. Las hipótesis freudianas mencionadas en el opúsculo en cuestión le confieren un carácter pretendidamente "cientifico", pero en el fondo se trata de un embrollo superficial. La misma teoria de freud hoy sólo es un capricho de la moda" (Clara Zetkin, op. cit.)

Para Lenin la mujer podia desarrollarse para alcanzar la igualdad efectiva con el hombre cuando, en la sociedad comunista, se hubiese librado del trabajo doméstico improductivo para enfrentarse al trabajo productivo.

Nosotras reconocemos en la competitividad productivista el plano del poder al que se halla vinculada la sociedad capitalista, sea de capitalismo privado o estatal. En ambas las gestiones de los medios de producción operan bajo la cobertura de una gama de valores económicos e ideológicos que sirven para que se pueda contar con el rendimiento máximo. Hoy en día la humanidad aparece definitivamente bloqueada por el automatismo masculino como función de una disposición de la sociedad, cuya diferenciación interna consiste en procurar no admitir la crudeza de una condición de hecho: la instrumentalización.

Ninguna ideologia revolucionaria podró convencernos de que las mujeres y los jóvenes tienen deberes y soluciones en la lucha. el trabajo, la sublimación y el deporte, Los hombres adultos perpetúan el privilegio de su control sobre aquéllos.

Nosotras vemos en el apoliticismo de la mujer tradicional la respuesta espontónea a un universo de ideologías y reivindicaciones en las que sus problemas no aparecen más que a duras penas, mientras que, desde la cumbre del paternalismo, se la interpela como masa de maniobra.

Mientras los jóvenes trabajan por una revolución politico social que les evite malograr sus vidas administrando una sociedad en la cual no se reconocen, hay alguien que cuenta con el entusiasmo neofito de las mujeres para solventar la crisis de la sociedad masculina: se les concede que ocupen aquellos cargos y se hace aparecer a esta maniobra como la compensación debida a su exclusión desde siempre, como una victoria del movimiento femenino. La industria ha necesitado una reserva de mano de obra que se encontraba en las mujeres, la sociedad de 


\section{DISCURSOS FEMINISTAS SOBRE EL ABORTO Y LA ANTICONCEPCIÓN EN ITALIA} (AÑOS SETENTA) Y POLONIA (AÑOS NOVENTA)

consumo tiene el proyecto de cargarnos con sus prestaciones en el sector terciario.

En la relación conclusiva de la Children's employement comission de 1866. citada por Max en el capitulo XIII del volumen I de EI Capital, se afirma a propósito del trabajo del menor: "Niños y adolescentes fienen derecho a ser protegidos por la legislación contra el abuso de la autoridad paterna que quebranta prematuramente su salud física. y los degrada en la escala de los seres morales e intelectuales". Marx prosigue comentando: "De todos modos no ha sido el abuso de la autoridad paterna el que ha creado la explotación directa $e$ indirecta de la fuerza de trabajo inmadura por parte del capital; todo lo contrario, ha sido el mundo capitalista de la explotación el que ha convertido en abuso la autoridad de los progenitores, eliminando el fundamento económico que le correspondia. Por eso, por más terrible y repelente que parezca la disolución de la familia de viejo estilo dentro del sistema capitalista, a pesar de ello, la gran industria crea el nuevo fundamento económico para una forma superior de la familia y de la relación entre ambos sexos, con la parte decisiva que otorga a las mujeres, a los adolescentes y a los nifnos, tanto varones como hembras, en los procesos productivos socialmente organizados más allá de la esfera doméstica". Desde los ritos de iniciación de los pueblos primitivos, a la guerra, la patria potestad, el aprendizaje y el trabajo, la autoridad paterna siempre se ha manifestado como aquello que caracteriza a toda autoridad: un abuso, diferente según cada circunstancia, pero cuyo objeto, mujeres y jóvenes siempre han guardado una relación entre ellos. En su utilización por parte del capitalismo Marx ve las premisas de una forma superior de familia, una vez derrocada la propiedad de los medios de producción. La previsión de la cultura revolucionaria ha quedado, a todas luces, contradicha: despreciaba las exigencias de aquella categoría de oprimidos cuya liberación era pospuesta por todo desarrollo de la sociedad masculina. incluido el manista, a base de proyectar una autoridad patriarcal que tuviese todo el aspecto de ser una igualdad. La rebelión femenina lleva en si misma la condición para desatascar al mundo de las alternativas en las que se halla paralizado: la gran industria ha creado el fundamento económico no para una familia de fipo superior, sino para la ruptura del contrato y del modelo familiar. Ruptura que sólo la mujer puede alcanzar, puesto que ha sido condenada a perpetuidad en las instituciones que constituyen la base del dominio masculino.

La maternidad se ha desnaturalizado por el desprecio entre ambos sexos, por el mito impersonal de la continuación de la especie, $y$ por la rendición forzada de la vida de la mujer. pero, a pesar de todo, ha sido nuestra fuente de pensamientos y sensaciones, la circunstancia de una iniciación particular. No somos responsables de haber engendrado a la humanidad desde nuestra esclavitud: quien nos ha hecho esclavas no ha sido el hijo, sino el padre.

Antes de ver en la relación madre-hijo un compás de detención de la humanidad. recordemos la cadena que siempre nos ha oprimido con un único lazo: la autoridad paterna. Contra ella se ha creado la alianza de la mujer y el joven.

Que no nos pregunten qué pensamos del matrimonio y de su paliativo histórico, el divorcio. Las instituciones creadas para asegurar el privilegio del hombre reflejan una impostación no más tolerable que las relaciones entre los sexos. Nosotras hacemos saltar todos, absolutamente todos los instrumentos de tortura de la mujer.

"Nosotras odiamos, si, odiamos, todo cuanto tortura y oprime a la mujer trabajadora. al ama de casa, a la aldeana, a la mujer de pequefo comerciante $y$, en muchos casos, a la mujer de las clases pudientes. Reivindicamos de la sociedad burguesa una legislación social a favor de la mujer porque nosotras comprendemos su sifuación y sus intereses, y a ellos dedicaremos nuestra atención durante la dictadura del proletariado" (Lenin, en el coloquio referido por C. Zetkin.)

La familia es la institución en la cual se han expresado los tabúes con los que el hombre adulto siempre ha circundado las relaciones libres entre la mujer adulta y el joven. El sicoanálisis ha vuelto a plantear esta situación en términos de la tragedia que le habla decretado la antigüedad. La tragedia es una proyección masculina porque en el momento en que el hombre es empujado de sus ciclos vitales hacia nuevos objetos sexuales, no soporta que la mujer manifieste sus deseos y que cualquier repercusión se verifque en el ámbito de sus posesiones.

El mito del amor materno se desata en el instante en que la mujer, en la época mós pleno de su vida, encuentra auténticamente, en el intercambio natural con la juventud, el sentido de alegría, placer y diversión, que los tabúes de la organización patriarcal le permiten transferir sólo a sus hijos.

Tras el complejo de Edipo no se halla el tabú del incesto, sino el goce por parte del padre de este tabú con el fin de salvaguardarse.

Se destruye una imagen significativa del pasado: una escalera que por un lado es ascendida orgullosamente por el hombre. mientras que por el otro la mujer la va 
descendiendo fatigosamente. Aquella pizca de orgullo que se le concede en una fase de su vida no es sufficiente para sostenerla hasta su conclusión.

Cuando la causa de la mujer se plantea. ya está vencida.

De la cultura a la ideología. a los códigos. a las instituciones, a los ritos y a las costumbres, existe una circularidad de supersticiones varoniles sobre la mujer: toda situación privada estó contaminada por este territorio interior del que el hombre va extrayendo presunción y arrogancia.

El joven está oprimido por el sistema patriarcal, pero al mismo tiempo ofrece su candidatura como opresor; el estallido de intolerancia de los jóvenes tiene este carácter de ambigüedad interna.

La cultura patriarcal mantiene la acción falsificadora de sus esquemas incluso dentro de los modos en los que se articula la rebelión juvenil: interpretando ef movimiento "hippie" como un movimiento religioso, los estudiantes comprometidos se sirven de una etiqueta politicamente desacreditada para obrar con paternalismo. Desde la cumbre de sus certidumbres ideológicas afirman: he aqui un episodio significativo, un momento no dialéctico de la sociedad. Pero nosotras incluso reconocemos el mérito de esto. de esta huida disgustada del sistema patriarcal: tal actitud representa el abandono de la cultura de la tomo del poder y de los modelos pollticos de los grupos de participación masculina. Los "hippies" no escinden la existencia entre momentos privados y públicos, y su vida es un amasijo de masculino y femenino. La muchacha que se aleja frustrada de los grupos politicos estudiantiles o acepta. frustrada. su adecuación al comportamiento cultural revolucionario de sus compañeros, se encuentran en una alternativa cuyas premisas se refieren a la colectividad varonil: ellos escudriñan como un sector separado lo que desde siempre ha sido su campo de acción. La olobalídad de los problemas es una ficción mientras los hombres mantengan el monopolio, no sólo de la cultura burguesa, sino también de la cultura revolucionaria y socialista. Lo irrisorio de esto Jerarquía se ha puesto de manifiesto con los "hippies", muchachos y muchachas, que han formado una comunidad de tipo no viril sobre los despojos desprestigiados de los comportamientos agresivos y violentos, historia de la belicosidad de los padres, a quienes la ideología siempre había dado los instrumentos racionales necesarios para justificar su conducta en vista a los fines de una modificación del mundo. La ausencia forzada de la mujer de todo el arco vital de la comunidad ha agigantado los comportamientos aberrantes del hombre en la lucha por un modo de vivir y pensar. La reaparición de la mujer ha dado empuje a una marginación voluntaric de la juventud que manifiesta, de todos los modos posibles, destructivos, pero pacificos, la convicción de que se debe partir de cero. Que los "hippies" puedan ser reabsorbidos por la sociedad establecida, como muchos profetizan y esperan, no disminuye la furbación que su aparición improvisada e inesperada ho provocado en la escena mundial.

Ya ha sucedido antes que los muchachos y muchachas que por primera vez combatian por ellos mismos en las montañas, durante la guerra de guerrillas, han visto desaparecer "su" horizontes de autogestión y de sociedad inmune de paternalismo, con la organización postbélica sobre las consabidas plataformas del poder politico, económico y cultural, que temporalmente ha cancelado la sensación de haberse liberado del nazi-fascismo. En lugar de prever el tipo de fragilidad sobre la que se mantienen los "hippies", nosotras observamos que el poder patriarcal les persigue $y$ asila, no sólo en tanto que imperialismo. sino incluso dentro de la aristocracia cultural de los jovenes progresistas.

Toda la estructura de la civilización. como una cacería, empuja la presa hacia los puntos en los que será capturada: el matrimonio es el momento conclusivo en el que se produce su cautiverio. Mientras los estados aprueban el divorcio y la iglesia católica se debate por negarlo, la mujer revela su madurez denunciando la absurda reglamentación de las relaciones entre los sexos. La crisis del hombre se demuestro en su aferramiento a las fórmulas: porque en ellas se encuentra la consagración que le hace superior.

La mujer se halla sometida, toda la vida. a la dependencia económica, primero de la familia, del padre, luego del marido. Pero su liberación no consiste en lograr la independencia económica, sino en demoler aquella institución que la ha hecho más esclava y durante más fiempo que los esclavos. Todo pensador que ha dirigido una amplia mirada a la situación humana ha remachado con su propio punto de vista la inferioridad de la mujer. Incluso Freud ha encontrado la tesis de la maldición femenina en el presunto deseo de una completitud que es identificada con el pene. Mostramos nuestra incredulidad ante el dogma siconalitico que atribuye a la mujer, en su más tierna edad. el sentido de comenzar en desventaja por la angustia metafísica de su diferencia.

En todas las familias el pene del nino es una especie de hijo del hijo, al que se alude con 


\section{DISCURSOS FEMINISTAS SOBRE EL ABORTO Y LA ANTICONCEPCIÓN EN ITALIA} (AÑOS SETENTA) Y POLONIA (AÑOS NOVENTA)

complacencia y sin inhibiciones. El sexo de la nina, sin embargo, es ignorado: no tiene nombre. ni alecto, ni carácter, ni literatura. Se aprovecha su ocultamiento fisiológico para callar su existencia: la relación entre macho y hembra no es, pues, una relación entre dos sexos, sino entre un sexo y su carencia.

En el epistolario de freud con su novia leemos: "Querido tesoro, mientras tó te solazas con los cuidados domésticos, yo me siento atraido por el placer de resolver el enigma de la estructura del cerebro"

Indaguemos en la vida privada de los grandes hombres: la vecindad de un ser humano considerado en los momentos más desaposionados inferior, ha colmado los gestos más comunes de una aberración a la que nadie se ha sustraido.

Nuestra observación directa es que no vemos genios ni individuos que hayan realizado globalmente, sobre todos los frentes, la posición justa. Nadie ha desmentido las trampas de la naturaleza humana.

Nosotros vivimos en este momento, y éste es un momento excepcional. Queremos que ef futuro sea imprevisto, no excepcional.

Nos importa muchisimo que sea salvaguardado aquel impulso extraordinario de la osadia emotiva de la mujer que pertenece al período vital de la juventud, y con el cual los individuos sientan las bases de la creatividad que dará impronta a su vida. El engaño que puede extraviar a la muchacha es pensar que es recuperable en el tiempo una experiencia slquica de la que ha sido privada en su juventud. La mujer emancipada es un modelo estér porque propone el ajuste de una personalidad que no ha tenido sus escapes en el momento oportuno.

Si miramos hacia atrós podemos reconocernos en las ocasiones de creatividad que han aparecido casualmente en el mundo femenino. pero, sobre todo, en la dispersión de inteligencias que se producido en todas las épocas con la coerción y la domesticidad cotidianas. Sobre esta hecatombe el idealismo ha continuado haciendo proliferar los mitos de la femineidad.

Nosotras no queremos que se haga un distingo entre mujeres mejores o peores, porque lo que nos interesa es el punto más interno que cada una tiene en común con las otras y que para todas es tan vivo y doloroso.

E movimiento feminista no es internacional, sino planetario. La escisión entre Infraestructura y superestructura ha sancionado una ley según la cual las mutaciones de la humanidad, desde siempre y para siempre. han sido y serón mutaciones de estructura: io superestructura ha reflejado y reflejarb esta mutaciones. Este es el punto de vista patriarcal. Según nosotras, la creencia en los reflejos ha periclitado. Nuestra acción es la desculturación por la que optamos. No se trata de una revolución cultural que sigue e integra la revolución estructural, no se basa en la verificación a todos los niveles de una ideología. sino en la carencia de necesidad ideológica. La mujer no ha contrapuesto a las construcciones del hombre más que su dimensión existencial: no han salido de entre ellos jefes, pensadores, cientificos, pero ha poseido energía . pensamiento, coraje. decisión, atención, sentido, locura. Las huellas de todo esto se han borrodo porque no estaban destinadas a perdurar, pero nuestra fuerza estriba en no poseer ninguna mistificación de los hechos: actuar no es una especialización de casta. qunque se convierte en ello mediante el pode por el que está orientada la acción. La humanidad masculina se ha adueñado de este mecanismo cuya justificación ha sido la cultura. Desmentir la cultura significa desmentir la valoración de los hechos que constituyen la base del poder.

La maternidad es el momento en el que la mujer, recorriendo las etapas iniciales de la vida en simbiosis con el hijo, se desculturiza. Ve el mundo como un producto extraño a las exigencias primarias de la existencia que está reviviendo. La maternidad es su "vuelo". La conciencia de la mujer se vuelca espontáneamente hacia adentro, hacia los origenes de la vida, y se interroga

El pensamiento masculino ha ratificado el mecanismo que hace parecer necesaria la guerra, el caudiliaje, el heroismo, el abismo generacional. E inconsciente masculino es un receptáculo de sangre y de temor. Porque reconocemos que el mundo se halla habitado por estos fantasmas de muerte $y$ vemos en la piedad el papel impuesto a la mujer, nosotras abandonamos al hombre para que toque el fondo de su soledad.

"...La guerra preserva la salud éfica de los pueblos en su indiferencia hacia el hábito y la inmovilidad; del mismo modo como el movimiento de los vientos preserva el agua de los lagos de la putrefacción que se produciria si existiese una prolongada bonanza, as una paz prolongada, o aun peor perpetua, llevaría a los pueblos a la putrefacción- puesto que le hombre es negativo-o-negador por su propia naturaleza, y debe continuar siendo negativo-o-negador, y no convertirse en algo fijo-y-estable". (Hegel, del Derecho natural, 1802.)

Incluso los más recientes análisis sicológicos y sicoanaliticos sobre los origenes y motivos 


\section{DISCURSOS FEMINISTAS SOBRE EL ABORTO Y LA ANTICONCEPCIÓN EN ITALIA} (AÑOS SETENTA) Y POLONIA (AÑOS NOVENTA)

de la institución de la guerra aceptan como ley natural de la raza humana la sumisión de la mujer al hombre. Se estudia el comportamiento de los individuos y de los grupos primitivos $y$ actuales dentro del absoluto patriarcal, sin reconocer, en el dominio del hombre sobre a mujer. la circunstancia del engano en la que ya se manifiesta un curso síquico alterado. E padre y la madre de los que confinuamente se habla como sujeto y objeto de los procesos de proyección que invisten y deforman la que podría ser una elaboración normal de los datos de la realidad, no son dos entidades primarias. sino el producto de una prevaricación entre los sexos que ha encontrado su asentamiento en la familia. Sin estas premisas, se elude la supresión de las causas slquicas de la guerra como amenaza atómica, bien postulando un retorno a los valores privados como la negación de la soberanía del estado, bien promoviendo una institución que prohiba la guerra como delito indlvidual. Pero de este modo se olvida, por un lado, que los valores privados son los valores de la famlilia y que la familia ha firmado la rendición incondicional de la mujer al poder masculino. consolidando aquel mecanismo de angustias patológicas y de defensos relativas a partir de las cuales se desarrolla la vida de la comunidad como vicariante, $y$, por otro, que la enfermedad mental de la humanidad no puede elegir por si misma su salvación en una forma autoritaria y someternos a ella.

En L'Unitá del 4 de junio de 1944 se lee: "Italia es nuestra Patria y nuestra madre común: y es nuestro deber. deber de todos los ciudadanos italianos, hombres y mujeres, jovenes y adultos. combatir por su honor y su libertad". Togliatti.

Con motivo de la muerte de Nasser (acontecida estos dias, sefiembre de 1970) un periódico llbanés ha escrito: "Clen millones de árabes se han sentido inesperadamente huérfanos"

El fantasma obsesivo que utiliza la propagandaracistaes elestuprador el del superdotado sexual que roba y viola a las mujeres.

En la concepción hegelana, Trabajo y tucha son la acciones de las que parte el mundo humano como historia masculina. Sin embargo. el estudio de los pueblos primitivos sirve para constatar que el trabajo es atributo femenino. y la guerra oficio específico del macho. Hasta tal punto que cuando se halla privado de la guerra. o vencido y reducido al trabajo, el hombre afrma haber dejado de serlo, $y$ sentise transtormado en mujer. En los orígenes, por tanto, la guerra aparece estrechamente conexa a la posibilidad de identificarse y de ser identificado como sexo. superando asi, mediante una prueba externa, la ansiedad interior por el fallo de la virlidad propia. Nosotras nos preguntamos en qué consiste esta angustia del hombre que recorre luctuosamente toda la historia del género humano, devolviendo siempre a un punto de insolubilidad todo estuerzo por salir de la disyuntiva de la violencia. La especie masculina se ha expresado matando, la femenina trabajando y protegiendo la vida: el sicoanálisis interpreta las razones por las que el hombre ha considerado la guerra como tarea vil, pero no nos dice nada sobre la concomitancia con la opresión de la mujer. Y las razones que han llevado a hombre a institucionalizar la guerra, como válvula de escape de sus conflictos interiores, nos hacen creer que tales conflictos son fatales para él, que son un primun de la condición humana. Pero la condición humana de la mujer no manifiesta la misma necesidad: al contrario, ela llora por la suerte de los hijos que han sido enviados al matodero $e$, incluso en la misma pasividad de su pietas, escinde su papel de aquél del hombre.

Hoy nosotras intuimos una solución para la guerra mucho más realista que las ofrecidas por los estudiosos: ruptura del sistema patriarcal mediante la disolución de la institución familiar por obra de la mujer. Así se podrá verificar aquel proceso de renovación de la humanidad a partir de la base, proceso que ha sido invocado muchas veces sin que se supiese a santo de qué milagro debla producirse una normalización de la humanidad.

El Trabajo como Lucha señala el paso de la supremacía de la cultura masculina.

La mujer sabe lo que es la atmósfera de tensión de la familia: de ahí parte la tensión de la vida colectiva. Devolvámonos a nosotras mismas la grandiosidad de la ruina histórica de una institución que, en cuanto condena simulada de la mujer, ha terminado por revelarse como condena auténtica del género humano.

Que no nos consideren ya más las continuadoras de la especie. No demos hijos a nadie, ni al hombre ni al Estado: démoslos a si mismos, resfituyámonos nosotras a nosotros mismas.

En el moralismo y en la razón de Estado reconocemos las armas legalizadas para subordinar a la mujer; en la sexofobla la hostilidad y el desprecio para desacreditarla.

El veto contra la mujer es la primera regla de la que los hombres de Dios extraen la conciencia de ser ejército del Padre. El celibato de la iglesia católica es el nudo angustioso en el que la postura negativa de hombre hacia lo mujer deviene institución.

Durante siglos se ha ensañado sobre ella casi inexplicablemente a través de los concilios. disputas, censuras, leyes y violencios. 


\section{DISCURSOS FEMINISTAS SOBRE EL ABORTO Y LA ANTICONCEPCIÓN EN ITALIA (AÑOS SETENTA) Y POLONIA (AÑOS NOVENTA)}

La mujer es la otra cara de la tierra.

La repetición de las previsiones filosóficas lleva a un universo homologado por la sabiduría: asi es proyectada la amarga felicidad del genio cuando es viejo. Pero el hombre y la mujer no podrán ser homologados, la sabiduría es el paraiso masculino de la filosofia,

La cultura ha definido el sentido religioso y elsentido estético. dos actitudes de la humanidad discordantes con el poder, y ha hecho encajar el comportamiento relativo a ellas en dos grandes categorías del poder: la institución religiosa y la institución artistica. Nosotras observamos en la transferencia religiosa un modo de vivir las leyes patriarcales en una zona metafisica que desprecia los sucesos del mundo histórico y se opone a ellos; y en la actuación artística observamos un operar confuso de los valores autoritarios que son sometidos al capricho de la propia y libre insubordinación. Mientras el religioso y el artista dan la máxima importancia al hecho de actuar en el sentido con el que congenian, la sociedad continúa aplicando, incluso a ellos, el cánon del éxito para utilizar su prestigio.

Nosotros elegimos libremente nuestros amigos, no entre aquellos que alardean de nuestro causa, sino entre los que no se han manchado con las culpas excesivas secundando el curso de la represión. La afinidad caracterológica que encontramos conlo artistas estádenla coincidencia inmediata entre el hacer y el sentido del hacer, sin la angustia que todos los otros tienen de recurrir a una garantía de la cultura.

Leamos la respuesta de freud a Karl Abraham, que le habia enviado un dibujo expresionista, en diciembre de 1922: "Querido amigo, he recibido el dibujo que seguramente quería representar su cabeza. Es horroroso. Sé que es una excelente persona y me siento herido más profundamente por el hecho de que una pequena laguna en su personalidad, como su tolerancia o simpatía por el "arte" moderno, haya de ser castigada tan cruelmente.... personas como estos artistas no se les debería permitir el acceso a los círculos analificos porque ilustran del modo más desagradable la teoría de Adler según la cual son precisamente los individuos nacidos con graves defectos de la vista los que se convierten en pintores o dibujantes. Permitame olvidarme del retrato al mandarle mis mejores deseos para el año 1923".

La mujer no se halla en una relación dialéctica con el mundo masculino. Las exigencias que viene clarificando no implican ung antitesis, sino un moverse en otro plano. Este es el punto en el que más costará que seamos comprendidas, pero es esencial no dejar de insistir en ét.
Incluso en las revoluciones socialstas, vemos cómo se prolonga aquel mecanismo de disfunción de la sique humana, que polificamente es considerado herencia de las condiciones burguesas, y al que continua oponiéndoseles, como antídoto, la meditación sobre los datos de sabiduria y de realismo elaborados por el Padre. En este sentido la ideología polifica ha sustituido a la teología en la confrontación con las masas.

La corrupción de la democracia tanto sobre bases capitalistas como comunistas estriba en que cada uno se ejercita en aquel paternalismo que se produce en el poder. como si debiese ser cada uno de ellos quien lo regentose.

日 movimiento feminista está lleno de intrusos politicos y filantrópicos. Protejámonos, que los abservadores masculinos no nos vayan a convertir en tema de estudio. El consenso y la polémica nos son indiferentes. Lo que creemos más digno para ellos es no entrometerse.

No debemos tragar la pildora dorada de aquellos que nos azuzan contra los representantes de su propio sexo. Cada una de nosotros posee en su experiencia privada la dosis de desdén, de comprensión y de intransigencia suficiente para encontrar soluciones más imaginativas.

Nuestra insistencia fiene un carácter de apropiación de nosotras mismas y su legitimidad viene justificada por el hecho de que en cada laguna nuestra siempre se ha introducido alguien que ha sido más veloz para apropiarse de nosotras.

Para la muchacha de la universidad no es el lugar en el que se produce su liberación gracia a la cultura, sino el lugar en el que se perfecciona su represión, ya tan excelentemente cultivada en el ámbito familiar. Su educación consiste en inyectarle lentamente un veneno que la inmoviliza en el umbral de los gestos más responsables, de la experiencias que dilatan el sentido de uno mismo.

Nuestro trabajo especifico consiste en buscar por doquier, en cualquier problema o suceso del pasado o del presente, la relación con la opresión de la mujer. Sabotearemos todo aspecto de la culfura que continúe ignorándolo tranquilamente.

Nosotras vemos como si el hombre. después de las atrocidades colectivas del nazismo, del fascismo, del estalinismo y las que todavía llevan a cabo los imperialistas, todavía creyese posible poder rescatar estos terribles acontecimientos verificados sobre el escenario histórico.

Su probabilidad siempre está presente, aun cuando tengamos en cuenta todo el trabajo realizado para circunscribir el fenómeno. 
En realidad el drama del hombre consiste en que, habituado desde siempre a encontrar en el mundo exterior los motivos de su angustia como datos de una estructura hosti contra la que luchar. ha llegado al umbral de la conciencia de que el nudo insoluble de la humanidad está dentro de él, en la rigidez de una estructura síquica que ya no consigue contener por más tiempo su carga destructiva. Asi se ha establecido en el mundo la sensación de estar viviendo una crisis irreversible para la que siempre resulta una alternativa la vieja bandera socialista. La autocrítica emanada de la cultura parece haberse encarilado por un camino de presunción e inconsciencia. El hombre debe abandonarla para romper la continuidad histórica del protagonista. Esta es la transformación que queremos que acontezca.

Desde las primeras feministas hasta hoy han pasado ante los ojos de las mujeres las gestas de los últimos patriarcas. Ya no veremos nacer a otros. Esta es la nueva realidad en la que nos movemos todos. De ella parte la reconsideración de los fermentos, agitaciones y temas de la humanidad femenina que habia sido mantenida aparte.

La mujer, tal como es, es un individuo completo: la transformación no debe producirse en ella. sino en cómo ella se ve dentro del universo y en cómo la ven los otros.
Hemos perdidoconcienciadelsignificado de las contraposiciones del pensamiento: cuando efectuamos nuestras observaciones no pretendemos ponerias en el ámbito de los contrarios, sino progresivamente, una después de la otra, para reconstruir el conjunto de todos los datos que hemos encontrado y hacer nuestro inventario. Consideramos nocivo el consumo, incluso el de las ideas que nos gustan, por la inmediata colocación dialéctica que la hace comestibles.

Hacemos todaslas operaciones subjetivas que nos procuren espacio a nuestro alrededor. Con esto no queremos aludir a la identificación: ésta tiene un carócter obligatorio masculino que destroza el florecimiento de una existencia y la tiene bajo el imperativo de una racionalidad con la que se controla dramáticamente, dia a día, el sentido del fracaso o del éxito. El hombre se halla vuelto sobre si mismo, sobre su pasado. sobre su finalidad, sobre su cultura. La realidad le parece agotada, buena prueba de ello son los viajes espaciales. Pero la mujer afirma que la vida. para ella, sobre este planeta, aun está por iniciarse. Ella es capaz de ver all donde el hombre ya no ve nada.

El espiritu masculino ha entrado defi: ni-fivamente en crisis al desencadenar un mecanismo que ha tocado el limite de seguridad de la supervivencia humana. La mujer abandona su futela reconociendo como centro propulsor de la peligrosidad la estructura caracterológica del patriarca y su cultura.

"Cada uno debe conocer necesa riamente si el otro es una conciencia absoluta: debe ponerse necesariamente en sus enfrentamientos con el otro en una relación tal que eso salga a la luz: debe ofenderlo. $Y$ cada cual puede saber si el otro es totalidad soblo obligándole a asomarse hacia la muerte: y. del mismo modo, cada uno se muestra a sí mismo como totalidad sólo asomándose a la muerte. Si se detiene en sí mismo, más acá de la muerte... entonces es para el otro, de manera inmediata, una no totalidad... se convierte en esclavo del otro... Este reconocimiento de los particulares es pues, en si mismo, contradicción absoluta: el reconocimiento no es otra cosa que el ser-dado por la Conciencia como totalidad, en otra conciencia, pero en cuanto la primera conciencia se hace objetivamente real, suprime dialécticamente a la otra Conciencia: de este modo el reconocimiento se suprime dialécticamente por si mismo. No se realiza sino que, por el contrario, cesa de ser en cuanto es. Y. no obstante, la Conciencia sólo es al mismo tiempo en cuanto acto-de-ser-reconocida por otro, y al mismo tiempo sólo es Conciencia en cuanto unidad numérica absoluta, y debe ser reconocida como tal; pero esto significa que debe tener necesariamente como fin la muerte del otro y la muerte propia, y que ésta sóllo es en la realidad objetiva de la muerte" (Hegel).

La especie masculina ha desafiado continuamente la vida y ahora desafía la supervivencia: la mujer ha permanecido en la esclavitud por no haber aceptado; ha continuado siendo inferior, incapaz, impotente. La mujer reivindica la supervivencia como valor. 日 hombre ha buscado el sentido de la vida más allá de la vida y en contra de la propia vida: para la mujer vida y sentido de la vida superponen continuamente. Hemos tenido que esperar miles de años para que la angustia del hombre ante nuestra postura dejase de ser considerada como prueba de nuestra inferioridad. La mujer es inmanencia, el hombre trascendencia: en esta contraposición la filosofia ha espiritualizado la jerarquía de los destinos. En cuanto era el trascendente quien hablaba no podía existir dudas sobre la excelencia de su gesto; $y$, si la femineidad es inmanencia, el hombre ha tenido que negarla para dar inicio al curso de la historia. Por eso el hombre ha prevaricado, pero sobre un dato de oposición necesario. La mujer sólo tiene que poner su trascendencia. En verdad los filósofos 
han hablado en exceso: sen qué se han basado para reconocer el acto de trascendencio masculino, en qué para negárselo a la mujer? Frente a la eflcacia de los hechos se recurre una trascendencia y se la considera como acto originario, mientras que se la niega alli donde no existe la confirmación de un poder constituido.

Pero considerar la trascendencia a partir de la confirmación de los hechos es típico de la civilización patriarcal: como civilización absoluta del hombre se admiten dentro de ello todas las alternativas, y la mujer ha tenido que sufrir su condicionamiento al ser reconocida como principio de inmanencia, de quietud. y no como otro modo de trascendencia que ha permanecido reprimido, a instigación de la supremacia del hombre. Hoy la mujer enjuicia Abiertamente esa cultura y esa historia que tienen como supuesto la trascendencia masculina, y enjuicia esa trascendencia. A través de todo tipo de traumas conscientes e inconscientes, también el hombre ha empezado a considerar en crisis su papel de protagonista. Pero la autocritica del hombre no pierde de vista el axioma de que todo lo que es real es racional. y continúa presentando su candidatura ustificándola como necesidad de superación. La mujer ya está harta de los modos en que el hombre se ha superado en oprimirla, $y$, hoy en dia, al deplorar su inmanencia. La autocrifica debe dejar paso a la imaginación.

Al hombre, al genio, al visionario racionol nosotras le decimos que el destino del mundo no es andar siempre adelante, como se lo prefigura su apetencia de superación. El destino imprevisto del mundo está en recomenzar el camino para recorrerlo con la mujer como sujeto.

Reconocemos en nosotras mismas lo capacidad para convertir este instante en una modificación total de la vida. Quien no pertenece a la dialéctica amo-esclavo tome conciencia e introduce en el mundo el Sujeto imprevisto.

Nosotras negamos, por considerarlo absurdo, el mito del hombre nuevo. El concepto de poder es el elemento de confinuidad del pensamiento masculino $y$, por eso, de las soluciones finales. 1 concepto de la las soluciones finales. El concepto de la sombra. Toda profecia que se monte sobre estos postulados es falsa.

El problema femenino es, por si mismo. medio y fin de las mutaciones sustanciales de la humanidad. No necesita un futuro. No hace distingos entre proletariado, burguesía, tribu. clan, raza, edad, cultura. No viene ni de ambo ni de abajo, ni de la élite ni de la base. No estó dirigido ni organizado no es difundido ni tiene

propaganda. Es una palabra nueva que un sujeto nuevo pronuncia, y contia al instante mismo su difusión. Actuar se convierte en algo simple y elemental.

No existe la meta, existe el presente. Nosotras somos el pasado oscuro del mundo. nosotras realizamos el presente.

Verano de 1970 


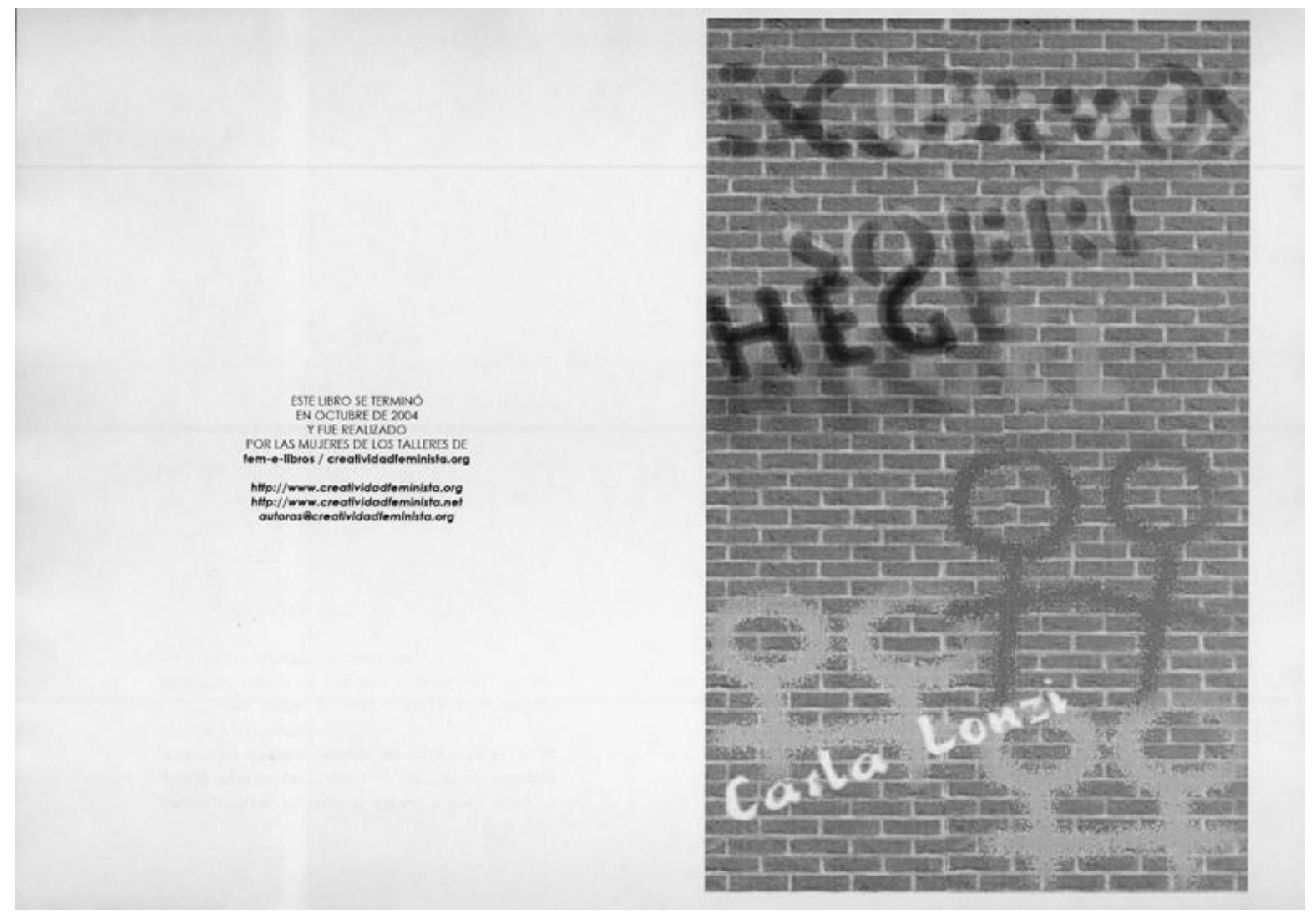

10.1.2 Documento constitutivo del Comitato Romano per l'Aborto e la Contraccezione[La Comisión Romana por el Aborto y la Anticoncepción], noviembre de 1975

Publicado en Damiani, Cristina et al., eds. 1981. Oltre l'aborto. Posizioni e documenti del movimento delle donne. Metodi di controllo della fecondità. Chiesa e "dissenso". La legge e le proposte di modifica, 19-21. Roma: Cooperativa Editoriale Ottanta.

Traducción mía. 
Esta Comisión intenta hacerse con el fin de promocionar en Roma una campaña para la liberalización del aborto, campaña que tiene su origen en la lucha propuesta durante los últimos años por el Movimiento Feminista.

No es casualidad que hoy en la primera fila de esta lucha estén las militantes del Movimiento Feminista, las compañeras de las organizaciones feministas, y las mujeres que, fuera de cualquier tipo de organización, pelean contra este aspecto dramático de su opresión, y con ellas se juntan hoy las organizaciones políticas más conscientes de la importancia de esta batalla contra uno de los elementos que caracterizan la condición femenina.

El aborto siempre es una violencia, a la que las mujeres se ven obligadas a acudir por falta de alternativas reales. Por ello la Comisión, implicada en la campaña para la liberalización del aborto, no puede no tener en cuenta la lucha más general que abarca todos los problemas relacionados con la libre elección de la maternidad.

El aborto presenta de manera particularmente dura los elementos coercitivos de naturaleza material e ideológica:

material, porque las mujeres están obligadas a abortar en condiciones deshumanas, en la clandestinidad total, arriesgando su vida y su salud;

ideológica, porque la clandestinidad y el riesgo, así como cualquier otro elemento que caracteriza la condición femenina, están vividos como un precio a pagar por las elecciones y las experiencias individuales, que casi nunca se perciben como relacionadas con los hechos sociales. 
El aborto es, en cambio, un hecho social, una realidad masiva: en la situación actual, caracterizada por la falta de alternativas, el aborto y la violencia que lo caracteriza es el precio que las mujeres están todavía a día de hoy obligadas a pagar por su rechazo de una sexualidad cuya única finalidad es la reproducción.

El aborto clandestino es una violencia de clase, del que las mujeres obreras son otra vez las que pagan de modo más dramático las consecuencias

Las fuerzas políticas, que quieren mantener al aborto como un "delito", en la ilegalidad y en la clandestinidad son las mismas que protegen el mercado negro del aborto que se desarrolla y se alimenta de la piel de las mujeres, impulsando un movimiento de billones de liras cada año.

Las mujeres se rebelan contra una sociedad en la que, mientras se les imponen todas las responsabilidades relacionadas con la maternidad y el cuidado de los hijos, no se les garantizan medidas para que la maternidad sea una elección libre y consciente.

Las mujeres pelean por el derecho a la maternidad libre contra:

- quien especula sobre sus vidas imponiendo el aborto clandestino;

- quien contribuye a que millones de mujeres tengan abortos blancos causados por las intolerables condiciones de trabajo;

- la ideología reaccionaria del poder en cuanto a las mujeres, la familia y la sexualidad. 
La comisión, con el apoyo general de la lucha de las mujeres, se implica en sacar adelante la batalla por la liberación del aborto.

La comisión se ha formado para:

- Obtener el derecho al aborto libre, gratuito e insertado dentro de las estructuras sanitarias públicas para todas las mujeres, también las menores de edad, regulado por la decisión de la mujer y no las intervenciones censuradoras de los Ilamados expertos;

- Desarrollar una política de prevención, con una red de consultorios controlados por las mujeres, para la información y distribución gratuita de los anticonceptivos seguros y no dañinos.

\section{La comisión se compromete a:}

- Practicar la autogestión del aborto como un momento de la lucha en los centros donde el aborto será practicado en las condiciones higiénicas y sanitarias seguras, gratuitamente, en relación con el desarrollo del movimiento de las mujeres y que gire alrededor del objetivo de una más amplia movilización de masas.

- Difundir la información sobre los anticonceptivos y sobre la sexualidad en los consultorios controlados por las mujeres que serán reconocidos por el Estado para el desarrollo de una información sobre la sexualidad más amplia, que no tenga como su único fin la procreación; para que a las mujeres no les sea 
asignado como un rol esencial la maternidad y la educación de los hijos antes que otras actividades sociales y políticas;

- Implicar en los problemas del aborto y de la anticoncepción al personal médico y paramédico, para que tome una posición clara y lo convierta en un objeto de batalla dentro del sector sanitario e intervenga para una orientación de la investigación científica sobre los métodos anticonceptivos seguros y sencillos sean para hombres o para mujeres;

- Utilizar todos los espacios accesibles previstos por la legislación actual hasta que se introduzca la práctica del aborto en las estructuras sanitarias públicas y, en particular, sacar adelante la batalla sobre el aborto terapéutico, justificado por motivos tanto psicológicos como físicos debido a la sentencia del Tribunal Constitucional, para que este sea accesible para todas las mujeres que lo necesiten

- Promocionar una ley de iniciativa popular que garantice el cumplimento de los objetivos arriba enumerados, retirando el apoyo otorgado previamente a la propuesta del PSI [Partido Socialista Italiano] dado que este Partido no parece tener intención de presentar y defender las enmiendas anunciadas en enero [de 1975: A. I.].

- Luchar contra todas las denuncias, los procesos y las tentativas de represión, haciendo acción política y de movilización, denunciando a los responsables de los abortos blancos y luchar por las condiciones de trabajo y de la higiene adecuadas para evitarlos. 
Colectivo feminista comunista italiano

Colectivo feminista magliana

Colectivo feminista romano

Movimiento por la liberación de la mujer autónomo

Núcleo feminista medicina

Lucha continua

Vanguardia obrera

Partido de la unidad proletaria por el comunismo

\subsubsection{Manifiesto del Movimento di Liberazione della Donna [Movimiento de}

la Liberación de la Mujer], septiembre de 1978

Publicado en Damiani, Cristina et al., eds. 1981. Oltre l'aborto. Posizioni e documenti del movimento delle donne. Metodi di controllo della fecondità. Chiesa e "dissenso". La legge e le proposte di modifica, 19-21. Roma: Cooperativa Editoriale Ottanta.

Traducción mía.

A todas las mujeres:" en estos últimos tiempos el provecho que sacan los partidos políticos del tema del aborto se hace cada vez más evidente". Una parte del Movimiento feminista que antes se juntaba en la plaza gritando "no al compromiso 
sobre nuestra piel" hoy pide junto con Unione Donne Italiane [La Unión de las Mujeres Italianas] una buena ley que regule el aborto.

No queremos que se privilegie en el debate a quienes puedan tener una tentación de actuar como un feminismo de Estado.

Por ello queremos con este manifiesto hacer conocer a la nuestra posición sabiendo que esto sirve para abrir un debate entre las mujeres.

Estamos más que nunca convencidas que no queremos leyes sobre nuestro cuerpo.

Pensamos que cualquier tipo de ley daría al Estado el poder de decidir por nosotras.

Queremos derogar la ley fascista que iguala el aborto con un delito. Esto se puede conseguir únicamente a través de un Referéndum, para el que hemos recogido 800.000 firmas con las compañeras feministas y otras fuerzas políticas.

No hay regulaciones ni sobre el parto, ni sobre la apendicitis, ni sobre la extracción de las muelas - entonces no debería haberlas en la materia del aborto.

Ninguna mujer necesita una ley para decidir si quiere o no ser madre.

Es verdad que a pesar de las leyes, la cárcel, el riesgo de muerte, las mujeres han abortado siempre. 
La liberalización del aborto es el único modo para acabar con la especulación que deriva de la clandestinidad.

Para que el aborto sea no solamente libre, sino también gratuito y asistido, sería suficiente insertarlo dentro de las intervenciones previstas a cargo de la asistencia sanitaria.

Aborto libre no quiere decir el aborto obligatorio, respetamos las consciencia altruistas, queremos que se respete nuestra voluntad de ser madres solamente cuando lo deseamos. 


\subsection{Polonia}

\subsubsection{Dunin, Kinga. 2001. Dwa tysiące na skrobankę [Dos mil para la intervención]. Wysokie Obcasy (110). Accesible online en http://www.wysokieobcasy.pl/wysokie- obcasy/1,96856,320252.html; último acceso 10/09/2009.}

Kinga Dunin (n. 1954) es una de las intelectuales feministas más conocidas en Polonia, profesora de sociología de la medicina en la Universidad Médica en Varsovia. Durante el comunismo miembra de la oposición, actualmente miembra del Partido Verde Polaco. Autora de libros Tao gospodyni domowej [Tao de la ama de casa] (1996), Tabu [Tabú] (1998), Obciach [La verguenza] (1999), Karoca z dyni [La caroza de calabaza] (2000), Czego chcecie ode mnie, "Wysokie Obcasy" [Que quereís de mi, "Tacones Altos"] (2002), Czytajq̨c Polskę Literatura polska po roku 1989 wobec dylematów nowoczesności, [Leyendo Polonia. La literatura polaca después del 1989 y los dilemas de la actualidad] (2004), Zadyma [La bronca] (2007).

Traducción mía.

Me ha preguntado últimamente mi amiga Agnieszka Graff [una de las feministas actualmente más conocidas en Polonia: A. I.] porque nunca en mis artículos he tratado el tema del aborto. Sé que se lo ha preguntado también a muchas mujeres públicamente activas, quizás queriendo recordarnos que se acercan las elecciones y es un asunto al que hay que volver.

Con razón lo dice. Porque si en la fiebre electoral se harán otra vez promesas y cambiará el equipo que está en el poder, puede resultar que el tema del aborto se sacrifique después con facilidad sobre el altar de la coalición o plataforma [hace 
alusión a Platforma Obywatelska [Plataforma Ciudadana], un nuevo partido del centro que surge en el 2001: A. I.].

¿Entonces porque hasta ahora no he escrito nada sobre esto? A Angieszka le contesté al principio - de un modo un tanto evasivo - que estoy cansada de este tema. Hubo tantas discusiones, se han utilizado todos los argumentos y estoy hasta las narices de charlar sobre esto. $Y$ entonces me acordé de una conversación larga y intensa en la que yo y mi amigo, un periodista italiano, discutimos con una amiga, que tiene una postura radicalmente pro-vida. Nosotros obviamente somos pro-choice, es decir, apoyamos la libre elección de la mujer. Esto pasó hace ya un tiempo, al principio de los noventa. Las horas pasaban, las emociones se calentaban, nadie consiguió convencer a nadie. Al final miré el reloj. Era ya muy tarde. Mañana es otro día, y hay que llevar los niños al colé. Sin embargo, el dilema necesitaba una solución. Le pregunto entonces a mi colega italiano “¿Me ayudaríais con esto, si lo necesitara?”. "Claro, te invitaría al vuelo a Roma, el aborto, y el vuelo de vuelta".

No sé realmente se si lo necesitara de verdad, sería tan generoso, pero por aquella tarde esto fue suficiente. "Escuchad - digo. - Yo me voy a dormir, porque mi problema se ha solucionado. Que me importa la ley de aquí, ¿si yo tengo la posibilidad de elegir?"

Ahora pienso que es por esto que a muchas mujeres este tema les da igual. Nosotras tenemos la libre elección. Y la ejercemos también dando a luz. Conozco a mujeres católicas, que tuvieron hijos, pero reconocían, que tuvieron en cuenta la 
posibilidad de la interrupción del embarazo. Tuvieron en cuenta el aborto, pero no cómo y donde hacerlo. Porque la idea de irse a Italia es una de las opciones más caras, se puede hacer de modo mucho más fácil. Bastan los estúpidos dos mil [zlotys, el precio medio del aborto clandestino: A. I.].

Conozco entonces a mujeres católicas que en situaciones dramáticas decidían abortar.

Si una tiene los dos mil o sabe de dónde sacarlos, entonces se puede permitir el lujo de tomar las decisiones autónomas de carácter moral. Tienes la pasta -eres un sujeto, no la tienes- te conviertes en un objeto. Y pido a las mujeres que sí pueden conseguir los dos mil, no me cuenten historias sobre la libertad verdadera que florece cuando [el Estado: A.I.] protege a la vida no nacida. Porque con esta libertad "verdadera" tienen también esta otra libertad "peor" - la libertad de [no tener: A. I.] hijos.

Hoy dicen [los políticos, los médicos: A. I.] una cosa - por ejemplo en el caso de una violación por un enfermo de AIDS [cuando el aborto es supuestamente legal: A. I.], mañana no se sabe que harán. Pero que no se diga, que en estas situaciones la mujer tiene derecho a decidir. La ley le otorga este derecho, pero en la práctica todo es diferente.

Hoy en día es muy complicado encontrar un hospital, en el que se practiquen abortos legales, porque muy a menudo la conciencia de los médicos les impide practicar abortos gratuitos. Normalmente intento evitar hablar en el nombre de todas las mujeres, pero hoy me arriesgaré. No existe una mujer que en una situación dada no 
quiera tener la posibilidad de elegir, independientemente de lo que elija luego. Estoy convencida de que la mujer más pro-vida se siente mejor, teniendo esta opción. Y en Polonia la tiene. Por esto pienso que las discusiones sobre el aborto no son justas, porque se desarrollan en foros de personas que sin mayor consecuencia se pueden pelear por estos valores abstractos.

Estoy pensando, cómo serían las discusiones (sobre el aborto) si no existiera el aborto clandestino, lo cual es muy sencillo de cambiar. Si, y estamos cerca de ello, todos los hospitales se negaran a practicar abortos. Además, se debería prohibir a todas las mujeres en la edad reproductiva salir del país. Entonces nosotras, las mujeres que tenemos la libre elección, también las mujeres pro-vida, nos encontraríamos en una situación igual a la que se encuentran muchísimas mujeres polacas. Las que no tienen pasaportes, ni los dos mil, ni ningún apoyo cuando van a buscar un aborto a la sanidad pública. Entonces a lo mejor cantaríamos una canción diferente, y el tema nos dejaría de aburrir.

\subsubsection{Graff, Agnieszka. 2001. Świat bez kobiet. Płeć w polskim życiu publicznym. [El mundo sin mujeres. El género en la vida pública polaca]. Varsovia: W. A. B.}

Agnieszka Graff (n. 1970), licenciada de Amherst Collage, Oxford y la Escuela de Ciencias Sociales de la Academia Polaca de Ciencias, en 1999 defendió una tesis doctoral en literatura inglesa. Es profesora en el Centro de Estudios Americanos y en el postgrado en Estudios de Género en la Universidad de Varsovia. Autora de ensayos feministas, traductora de La habitación propia de Virginia Woolf. Świat bez kobiet es 
considerado uno de los textos fundamentales del feminismo polaco. Su último libro de 2008, Rykoszetem. Rzecz o płci, seksualności i narodzie [Rebote. Sobre el género, la sexualidad y la nación], trata la sexualidad en relación con la construcción de la nación en Polonia (datos de la portada del libro Świat bez kobiet..)

La introducción al capítulo Znikajqca kobieta - czyli polskie rozmowy o prawie do aborcji [La mujer desaparece - las conversaciones polacas sobre el derecho al aborto], 111-151.

Traducción mía.

Desde la introducción de la ley sobre "La planificación familiar, la protección del feto humano y las condiciones de la interrupción del embarazo" han pasado más de ocho años, y el tema del aborto se ha convertido en una especie de "huevo podrido", evitado por los medios de comunicación de masas por si acaso. Provocada por mi pregunta, porque hoy nadie habla públicamente del aborto y de las consecuencias de su prohibición, Kinga Dunin escribió un ensayo titulado Dos mil por una intervención, reteniendo que el tema hoy en día aburre a aquellas mujeres que tienen la libre elección, es decir, disponen de los dos mil [zlotys para un aborto: A. I.] o de alguien que se los puede prestar. En otras palabras, la ley no tiene efecto sobre las personas con dinero. Pueden permitirse tomar las decisiones morales de manera autónoma dirigirse a una consulta privada [para abortar: A. I.] o tener un hijo no planeado, sabiendo que hayan tenido otra opción. 
Entre estas mujeres están también las católicas, porque la división que se ha creado gracias a esta ley no es una división ideológica, sino económica. Hay que añadir aquí, que solamente el 26 por ciento de las mujeres polacas está en contra del aborto, y la mayoría en este grupo son las mujeres mayores de sesenta y seis años o menores de veinte, a las que este asunto tendría que importar menos. Las polacas en la edad reproductiva no se dividen entre pro-vida y pro-elección, se dividen en ricas y pobres. Tienes la pasta - escribe Kinga Dunin- eres un sujeto, no la tienes - te conviertes en un objeto.

Aquí podría bien terminar el capítulo sobre el aborto. Estoy de acuerdo en que el dinero es importante, pero ¿es decisivo? Sin embargo, la gente que vive en Polonia bien, sigue siendo de algún modo sensible para la miseria, el paro, los indigentes ¿acaso les aburre solamente un cierto tipo de dramas humanos? Pienso, que lo que ha ocurrido tiene una raíz diferente. A las personas, que en la cuestión de aborto no comparten la visión de la Iglesia Católica - y las encuestas demuestran que seguimos siendo la mayoría en este país - se nos ha quitado el lenguaje con que expresar lo que piensan y sienten. El debate público no es una disputa académica; aquí es importante no solamente la fuerza de la argumentación, sino también el volumen de la voz. Lo que realmente importa, es que en Polonia se ha legitimizado un modo de pensar, hablar y valorar el aborto que tiene sentido solamente a un nivel religioso. Durante los últimos años han desaparecido prácticamente del lenguaje público palabras como "feto" y "embarazo". Su lugar lo han ocupado palabras como "niños no nacidos" y "protección de la vida no nacida". Al aborto se le llama "asesinato", y a la mujer embarazada 
simplemente "madre". Con este leguaje no se puede hablar de una libre elección, de la planificación familiar o del derecho a la maternidad consciente, porque la palabra "mujer" ha dejado prácticamente de funcionar en el debate público sobre el aborto. Esta "desaparición de la mujer" no sucede solamente en los textos escritos claramente desde la posición pro-vida. Muchos artículos, que son aparentemente objetivos, hablan del embarazo como si fuera un proceso autónomo, separado de la mujer. En los títulos de la prensa aparece "el aborto" y su "prohibición", "la búsqueda de la intervención", "el caos ginecológico", "la disputa sobre la barriga", "el derecho natural", "el Dios", "la salud", "la vida", "el niño" y (cada vez menos frecuente) "el feto". Pero no aparece la palabra "la mujer". No lo hay tampoco en los textos de estos artículos. Así los medios de comunicación de masas ignoran el hecho fundamental que la ley anti-aborto perjudica a las mujeres, porque son ellas que se quedan embarazadas, tienen (o no) hijos y los crían.

\subsubsection{Szczuka, Kazimiera. 2004. Milczenie owieczek. Rzecz o aborcji [E] silencio de los corderos. Sobre el aborto]. Warszawa: W. A. B.}

Kazimiera Szczuka (n. 1966) es historiadora y crítica literaria. Trabaja en el Instituto de Estudios Literarios de la Academia Polaca de Ciencias y en el postgrado de Estudios de Género en la Universidad de Varsovia. Publica en la revista feminista Zadra. Además de Milczenie owieczek..., es autora de libro La cenicienta, el Frankenstein y otros (2001). Es también presentadora en la televisión privada polaca TVN.

Fragmentos de la introducción (7-9).

Traducción mía. 
En el debate sobre el aborto estoy a favor de las mujeres. Si nosotras somos una parte en el conflicto, ¿cuál es la otra? La respuesta más simple es, sin duda, que lo es el patriarcado. Si, de algún modo es un cuento sobre el patriarcado como un sistema, en el que las mujeres tienen que obedecer las leyes que, se nota tanto, fueron escritas por hombres, como lo escribió Tadeusz Boy-Żeleński en 1929. Pero el sistema no es el protagonista en el sentido en el que se suelen escribir libros sobre el feudalismo, el comunismo o el colonialismo. Las protagonistas de este libro son las mujeres.

Desde la perspectiva de los oponentes actuales de la interrupción del embarazo, una parte en el conflicto son los "niños no nacidos". A ellos defienden "los defensores de la vida" de mis protagonistas. Es una decisión valiente - idefender el feto de la mujer que lo lleva y obligarle a dar a luz a un niño no deseado! Pero este libro no pretende defender a las mujeres contra los niños no deseados. Defiendo a las mujeres y sus hijos contra el sistema patriarcal, que en muchos casos es igual al Estado. Este, por un lado nos obliga a dar a luz en nombre de teorías exaltadas del derecho a la vida, pero por otro lado, como escribía Boy, no le importa si la persona que lleva el feto tiene para comer:

$Y$ una cosa particular, el mismo feto, por el que se preocupan tanto los legisladores mientras está en el vientre materno, una hora después de nacer se queda sin ninguna protección legal y puede morirse de frío mientras la madre - cuya "sagrada" maternidad la excluye a veces de la sociedad - no tiene el techo bajo donde dormir. 
En Polonia hay una prohibición legal del aborto. La práctica de negar los abortos legales a las mujeres en los hospitales públicos. En el mismo tiempo, el Estado no subvenciona la anticoncepción ni se hace responsable de la educación sexual. Al contrario, permite su ridiculización o lucha contra ella efectuada por los medios de comunicación de masas católicos, que se han convertido en los medios de comunicación públicos, como trasladado de la televisión [católica: A. I.] Plus al canal 2 de la televisión pública programa "Merece la pena hablar" [un talk show con clara vocación católica: A. I.]

Una prueba drástica de descuidos en el campo de la educación sexual es el aumento de los embarazos de las adolescentes (en 2001 los partos de las adolescentes constituyeron los siete por ciento de todos los partos). La Federación Polaca por las Mujeres y la Planificación Familiar organizó el 28 de mayo de 2003 una rueda de prensa titulada “...Para que las niñas no tengan niños", en la que su presidenta, Wanda Nowicka, dijo: En Polonia el problema de las adolescentes embarazadas y las madres menores de edad no es un objeto de la política del Estado. La falta de cualquier acción preventiva por parte de las instituciones del Estado es un pecado de negligencia.

Por otro lado, doctora Danuta Duch comentó, que la juventud está completamente sola con los problemas de su sexualidad. La falta de acceso al conocimiento científico acreca de la educación sexual y la ley anti-aborto tan restrictiva provoca la maternidad premadura, poniendo en riesgo la salud física y metal de las jóvenes madres. 